

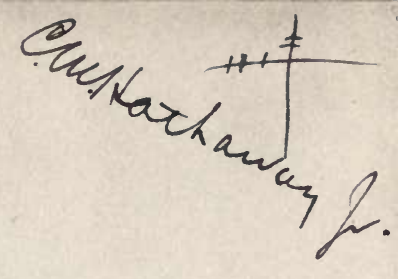



$\$ 1.20$

Chas M Hath anay9

the 7 Baldurin 99 




\section{BY THE SAME AUTHOR.}

Evolution of To-Day.-A Summary of the Theory of Evolution as held by modern scientists, and an account of the progress made through the investigations and discussions of a quarter of a century. Octavo . . . \$1 75 CoNTENTS: Introduction - What is Evolution ?-Are Species Mutable ?-Classification of the Organic WorldLife During the Geological Ages-Embryology-Geographical Distribution-Darwin's Explanation of Evolution-More Recent Attempts to Explain Evolution-The Evolution of Man.

"There have been so many volumes upon evolution that an ordinary reader may be inclined to overlook this of Professor Conn. We warn him, however, that in so doing he is sure to miss a rare contribution. It is just the thing to set a layman right and is thoroughly judicial. It sets down the general trend of thinkers as to evolution and Darwinism, finding limits to both and marking their usefulness when properly employed."-Hartford Past.

"Dr. Conn evidently favors the theory, but he does not write as a partisan or to carry a point, but simply to show what has been the result of the fruitful labors of the last twenty-five years. As a devout theist, he considers evolution simply a method of creation, and does not believe that this derogates from the glory of the Divine Architect." $-N$. Y. Observer.

G. P. PUTNAM'S SONS, NEW, YORK AND LONDON. 


\title{
Evolution of TO-DAY
}

\author{
A SUMMARY
}

OF THE THEORY OF EVOLUTION AS HELD BY SCIENTISTS

AT THE PRESENT TIME, AND AN ACCOUNT OF THE

PROGRESS MADE BY THE DISCUSSIONS

AND INVESTIGATIONS OF

A QUARTER OF A CENTURY

BY

H. W. CONN, Ph.D.

PROFESSOR OF BIOLOGY AT WESLEYAN UNIVRRSITY

NEW YORK \& LONDON

G. P. PUTNAM'S SONS

The Sinicherbotker press

1896 
COPYRIGHT' BY

G. P. PUTNAM'S SONS

I886

Press of

G. P. Putnam's Sons

New York 


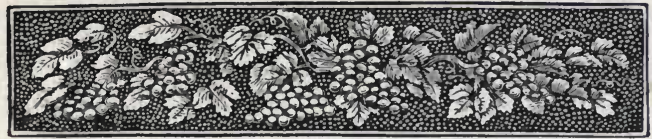

\section{PREFACE.}

MUCH misunderstanding exists, even in the minds of educated people, concerning the relation of the thinking world to the theory of evolution. Comparatively few, except those who have made special study of the subject, are aware even of the sort of arguments which have led scientists to accept evolution. The question is, however, too important for any educated person to be satisfied with ignorance. The excuse for the present book is to fill a vacancy in our literature: to give for those who are interested in the vital questions of the age a brief account of this theory as it stands to-day in the minds of scientists. Much advance has been made since the time of Darwin's first writings. Some of his claims have been substantiated and some disproved. His own theory has been examined, tested, and partially abandoned, and others have been advanced in its place. This book is intended to indicate as nearly as possible the foundation which the theory has built for itself. I shall therefore attempt to summarize the various lines of arguments advanced and discussed upon all sides; to enumerate the important difficulties which have arisen, together with the 
evolutionists' answers ; and briefly to consider the most important of the theories of evolution which science has produced; to give, in short, a summary of the evolutionary thoughts of the past quarter of a century.

These pages are intended for those who, having an interest in the question, have neither the time nor the requisite knowledge of biology to read the numerous special discussions upon the various phases of the subject. The works of Darwin and Spencer are too ponderous for any except special students. Frequently, indeed, their abundance of detail somewhat obscures the general line of argument. For this reason, readers who are not scientists frequently fail to perceive the force of the arguments, even after they have carefully read the books of these authors. I shall therefore try to free the arguments as much as possible from detail, only mentioning special cases for the purpose of illustration. It will be understood that the generalized statements made are supported by numerous facts, even though in many cases only the bare statement is given.

The subject will be treated as a scientific question, with only a word here and there regarding its relation to other lines of thought. Evolution, if true, is simply a law, and as such should be treated as any other scientific law. It is true that the relation of this question to theology, philosophy, and metaphysics is of the highest importance; but no more so than that of other laws. Science must first decide upon the existence of the law and its work- 
ing in nature. If it be found to express a fact, other lines of thought must determine its significance. No law is self-sufficient, and evolution no more explains itself than does the law of gravitation.

The arguments advanced in these pages are, with few exceptions, such as may be found elsewhere in the various discussions upon the subject. I do not, however, consider it desirable to give authorities, since the arguments have by this time become the common property of the world. These arguments I shall try to state as fairly as possible; and when a direct statement is made, it may be understood as one which is almost, if not universally, acknowledged. It is of course impossible wholly to eliminate the factor of personal opinion; but in most cases the conclusions drawn are those which have been arrived at by students in general, and are not the opinions of individuals.

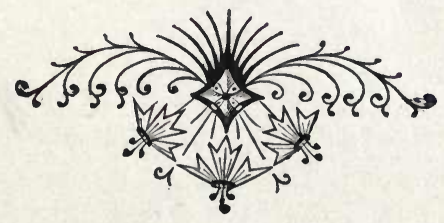





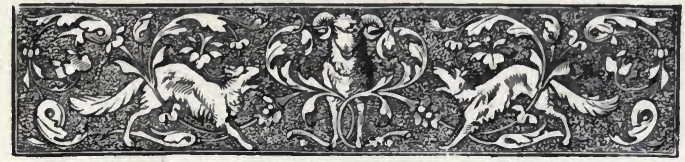

\section{TABLE OF CONTENTS.}

\section{INTRODUCTION-What IS EvOLUTION ? . .}

Original meaning of the term in scientific literature-Evolution and Darwinism-Evolution and theology-Prevalence of the evolutionary theory to-day.

I.

Are Species Mutable? . . . . .

Immutability of species-Variation-Causes of variationLimits of variation-Are species stable ? -Sterility of hybrids and fertility of mongrels-Indirect evidence from the relations of animals ; From fossils, from reversions-Summary.

II.

Classification of the Organic World . .

Existence and significance of a classification-The explanation of Cuvier-The explanation of evolution-The relation of species expressed by a branching structure-Reasons for this conclusion-Value of the tree-like classification-Application of the theory to the explanation of homology-Homology in general-Serial homology-Rudimentary organs -Aborted organs-Nascent organs-Summary.

III.

Life During the Geological Ages . • $\quad 89$ Significance of the evidence-Imperfection of the recordFirst appearance of life in the Silurian age-Difficulty in regard to time-Absence of numerous generalized forms in 
the Silurian-Diversity of Silurian life-Recent discoveries of connecting links-Geological position of these links-Development of the brain of mammals-Paleobotony-Summary

IV.

\section{EMBRYOLOGY}

Importance of embryology-Embryology a repetition of past history-(I) Truth of this assumption, as shown by comparison of embryology with paleontology ; with a hypothetical history drawn from classification-Contradictions arising and their explanation-Result of previous considerationsEmbryology as an assistance in classifying animals. (2) Significance of the parallel. (3) Application of the principle -Difficulties to be overcome in drawing a history from embryology-Abundance of hypothetical stages necessaryEmbryological history of animals in general-Early divergence of types from a common point-Summary.

V.

Geographical Distribution

Complexity of the factors-Animals not distributed according to climate-Laws of distribution which should follow if the descent theory is true-Relation of the present to the past-Zoological regions-Present distribution of species, genera, families, and orders-Do barriers limit the areas of distribution ? - Oceanic islands - Bermudas - Galapagos islands-St. Helena-Summary.

VI.

\section{Darwin's Explanation of Evolution . . 203}

Summary of the evidence-Darwinism-Incompleteness of Darwinism-Difficulties from the slowness of the modification; from the minuteness of changes-Transitional stages wanting-Specific characters not always useful-Ornamental structures-Tendency toward elimination by crossing-Development of organs by small steps-Similarity in independently acquired organs-Mimicry-Sterile insects-Summary. 
VII.

More Recent Atrempts to Explain Evolution

PAGR

244

Necessity of additions to the theory of natural selectionTheory of migration of Wagner-Internal factors in evolution-Tendencies toward progression, Nägeli-Extraordinary births, Mivart-Neo-Lamarckianism, the American school - Heredity-Brooks' theory of heredity and the cause of simultaneous variation-Summary.

\section{VIII.}

\section{The Evolution of Man}

Reason for a separate consideration of this subject-Man's physical nature-Geological evidence is lacking-Man as an intelligent animal-Method by which the evolutionist accounts for man's great intellect-Evidence from fossils impossible-Instinct and intelligence-Emotions-Knowledge of tools-Language-Consciousness-Power of improvement-Power of abstract ideas-Various intuitions-Moral nature-Religion, reverence, belief in immortality-Conscience-Darwin's explanation of conscience-Chief point where this explanation fails-Summary-Man according to all theories is radically distinct from other animals-General summary and conclusion.

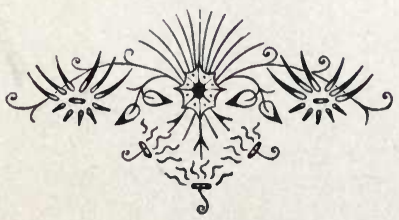





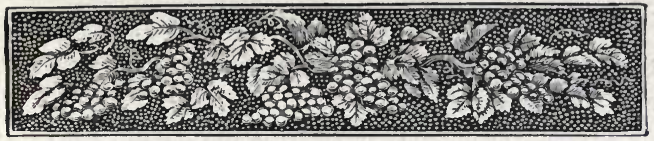

\section{EVOLUTION OF TO-DAY.}

\section{INTRODUCTION.}

IT is now a full quarter of a century since the publication of Darwin's "Origin of Species" opened to the world a new line of thought. Not only in science did this book offer an untrodden field for investigation, but its influence has extended to all other departments of learning. The general idea of evolution which this book brought into prominent notice has invaded the domain of philosophy, mental science, philology, and even our conceptions of religion and revelation have been modified by it. Hardly a line of study can be taken up without meeting at the outset this question of origin. Whatever may be the conclusion as to the truth of the ideas embodied in this work of Darwin, no one will fail to recognize that they have had an enormous influence upon the thought of the age. We read everywhere of evolution, evolution of the universe, of life, of intellect, of morals, of language; and even artificial products are viewed under a like law, and the evolution of the steamboat or of the steam-engine is not an unfamiliar phrase. All this 
is, largely at least, the outcome of the theories first advanced and discussed by Darwin.

It is impossible that twenty-five years of mental activity could have passed without adding much to the evidence both in favor of and against the views of Darwin. Evolution, using the term in a general sense, has been applied to every possible notion; its meaning has been expanded and contracted; every realm of science has been searched both for proof and disproof of the idea; facts have been collected from all sources both relevant and irrelevant, until the amount of matter which has been written bearing upon some of the numerous phases of the question is so great as to make it hopeless for any one to attempt to fathom it all. The amount of evidence which various investigators have brought forward is so great, and the facts are so varied, that no one with the slightest bias of opinion has any difficulty in finding arguments for almost any view. This is well shown by the numerous secondary theories which have been advanced in connection with the general one, some of which are contradictory, but all well supported by facts. Even on the general theory of evolution itself, so varied are the data collected, that neither friends nor foes have the slightest difficulty in selecting from the large stores of facts many which support their views. Quite frequently indeed, the same set of facts is made to serve on both sides, as an argument for and against evolution. If one desires to do so it is easy to make out a case on either side. By confining the attention to favorable arguments alone, evolution can be 
made to appear demonstrated; and by considering the difficulties, alone, an opposite result may be obtained. Unfortunately most of our publications take one of these two courses, and are, therefore, in a measure unsatisfactory. It requires more extensive reading and more careful balancing of evidence than most readers are inclined to give, to perceive the real force of the arguments.

\section{What is Evolution?}

It is necessary at the outset to inquire into the meaning of the term evolution. So varied has been the discussion, and so numerous the senses in which the word is used, that to say that one accepts evolution conveys no adequate idea, for it may mean much or it may mean almost nothing. When first used, the word had a very different significance from that which now is attached to it. It was believed by certain naturalists of the last century that there then existed in the egg an individual precisely like the adult, except that it was too small to be visible. The development of the egg was simply the growth of this minute individual, a growth precisely similar to that taking place in animals after birth. This theory was called evolution. Very soon, however, it was disproved, for a few observations served to show that no such simple growth took place. But the word evolution was still retained to apply to development in general, and thus for a long time it simply referred to the development of the individual from the egg. But slowly the word came to be applied to a different series of 
phenomena, while it is still occasionally used in its earlier significance. It has come almost universally to refer not to the development of the individual from the egg, but to the development of the whole existing order of nature from the past. In this sense, too, it has a wide range. On the one hand, it may mean a simple advance of one generation over another in any particular. Man's rise in intelligence during the last two thousand years is said to be evolution; or the gradual growth in the efficacy of weapons of war may be called an evolution. But on the other hand, the term has been stretched in its meaning until it covers the origin of all things, and with certain philosophers it is supposed to be a universal law which explains the present universe. Foremost among these stand Spencer and Haeckel, who believe that, starting with the existence of a homogeneous nebular mass, the result by the simplest natural laws would be a system such as we now find. Spencer tells us that by the unequal action of force upon this nebula, its homogeneity is soon broken up, and the nebula thus becomes resolved into a number of unequal masses. By the continued action of the same persistent force, the masses concentrate, and the planets appear with their satellites. Later, by the same process, atoms of carbon unite with atoms of hydrogen, nitrogen, and oxygen, and the result is protoplasm; and thus life arises spontaneously. Life now goes on developing, the old giving rise to new and constantly higher and more complex forms, until the result is the present vegetable and animal world, which has thus 
arisen by ordinary generation. Finally, by the continued development of the nervous system, the intellect makes its appearance, rises higher and higher, until it reaches the grade which we find in man. Evolution is here, then, a comprehensive theory, covering the slow growth of the whole universe by the simple action and interaction of force, according to natural law. But even in this most comprehensive sense the theory does not attempt to explain the origin of the universe. To start with, it assumes the existence of force and of a homogeneous mass of matter.

Between the two extremes may be found almost every grade, for evolution, when defined, means simply that the past has given rise to the present by the simple process of development according to natural law. But, although the word may thus mean almost any thing, and does have different significance with different thinkers, it has, nevertheless, in scientific literature, a tolerably definite meaning. Among scientists the term seldom covers the amount of ground which is included in Spencer's theory, nor does it ever stop at the other meaningless extreme. As ordinarily used in most scientific books to-day, evolution, organic evolution, and the theory of descent are practically synonymous terms, and each of these is used to indicate the theory that all species of animals and plants existing to-day have been derived from others living in the past, by direct descent, and that they will themselves give rise in the future to other still different species. It further implies that if the histories of all animals 
living to-day could be traced backward, they would all be found to converge, until finally they met at a common point of union, which would represent a common ancestor living in the remote past. In short, evolution, as the term is commonly understood to-day, is chiefly a denial of the former belief that species were independently created, and the replacement of this belief with its opposite. It assumes that no species is an independent creation, but that all are derived from past forms now mostly extinct. This is evolution as Darwin understood it; this is the common understanding of the term today in scientific literature; and this is the question which has been so thoronghly investigated in the last twenty-five years.

As thus defined, it is easy to see that the theory is not complete, since nothing is said as to the origin of life. The essential idea which underlies the whole theory is that species have had a natural rather than a supernatural origin; and it is evident that unless we give a natural explanation of the origin of life, the idea is lacking at its very foundation. Nor is this all; for the same logical necessity will compel us to explain, in a similar way, the origin of the world and the solar system, and thus to reach a theory something like that of Spencer. But even this theory does not reach any bottom, for it assumes the existence of the nebula, and Spencer found it necessary to put behind and beneath his system an "unknowable," which he considered the same as the God of theology. It is therefore impossible to make evolution a complete theory. 
Since, then, this is a logical impossibility, it is best to admit the fact and confine our conception of evolution to the realm where there is evidence for it. Now, at the beginning of life there is a break in the series. There is not yet the slightest evidence that living matter could arise from non-living matter. All of the most recent experiments have certified this conclusion. Scientists, perceiving it a logical necessity of these views to believe that life could have arisen from inorganic matter, have had naturally a great desire to prove this possibility. The fact that spontaneous generation is universally given up is therefore a testimony to the cogency of the conclusion and the honesty of the investigators. But on the other hand, it is evident enough that while the experiments of Tyndall and others prove that life cannot arises $\$$ pontaneously in the conditions under which they have performed their experiments-i.e., in closed flasks containing boiled solutions, they by no means prove that spontaneous generation could not have taken place under other different circumstances. We can know nothing as to what may have taken place under different conditions. It is equally possible for one side to claim that the experiments teach that life cannot arise spontaneously, and for the other side to claim that while it does not do so now, it might have been possible under very different circumstances in times past. In short, the question is not open to investigation. It is impossible to prove that spontaneous generation could never have occurred; and it is extremely improbable that the opposite view will 
ever be demonstrated. All that can be done is to discuss the question from theoretical grounds. There is then a break at the beginning of life, since spontaneous generation can be neither proved nor disproved. This fact makes it far preferable for the present at least to confine the term evolution, in our ordinary discussion, as Darwin did, to the development of life, without including any theory as to its origin; realizing all the while that as thus stated the theory is not complete. If we do confine the term to these limits we have a theory which is open to investigation, and which may some time be approximately demonstrated. But if we attempt to include all that Spencer understands by the term, there is little hope that we can advance beyond hypothesis. Scientists, therefore, as a rule, restrict the term to the development of living organisms. It is the object of the following pages to discuss the question in this sense, as a scientific theory, therefore, without reference to the deeper metaphysical problems underlying the more comprehensive significance of evolution as applied to the origin of the universe. Whenever the term evolution is used in the following pages, it is in the sense above indicated, and is synonymous with the terms organic evolution and the theory of descent.

Are there any other breaks in the chain of continuity which may make it wise to limit still further the meaning of evolution? It is claimed by many that such a break is found in man; not so far as his body is concerned, but because he represents a new order, in intellect and morality. This question is 
reserved for a separate chapter. But more than this, it has been held by certain naturalists that species have arisen from several distinct points, and not from one. They would say that there have been a number of points of origin, one for each of the subkingdoms. But this position is hardly a tenable one and is now generally abandoned. It is, of course, perfectly possible that such might have been the history of animals, even upon the theory of evolution, but there is not the slightest evidence that such was the case. On the contrary, as we shall see later, the evidence is such as to apply to all species alike, and if its force is admitted at all, it must be admitted as linking the organic world into a single unit, and not into several. The sub-kingdoms are united together at the bottom, and if evolution is admitted at all, it must apply to the whole organic world. While, then, it is desirable to confine the subject to limits where it can be investigated and attested by facts, it is equally desirable to avoid the other extreme and fail to see that evolution must cover all organic species or none.

\section{Evolution is not Darwinism.}

We have now reached a conclusion as to what is ordinarily meant by evolution, and such was Darwin's understanding of the term. But it must not be confounded with Darwinism. Evolution is simply a theory as to the method by which species have been introduced into the world, entirely independent of any idea as to the causes which have brought about their introduction. Darwinism is evolution; but it 
is more than this; it is at the same time an attempt at an explanation of the causes of evolution. It not only claims that species have been slowly evolved from each other, but it also gives an account of the manner in which they have arisen, and the laws which govern their gradual modification. It is, therefore, possible to accept evolution and to reject Darwinism completely; to believe that species have been evolved from each other, but to deny that Darwin has discovered the causes of this evolution.

And so with various other theories of evolution, of which science has proposed several. All agree as to the evolution of species from each other, but no two explain the fact in the same manner. For we must recognize two quite different questions in considering the subject. The first is as to the fact of evolution. We must discover, if possible what has been the history of organisms; whether each species is to be considered as an abrupt innovation, utterly independent of all others- $i$. e., a special creation, or whether species have been derived from each other by the ordinary methods of reproduction aud slow change. If it is discovered that the evidence is sufficient to prove evolution to be a fact, or to render it probable, a second and more difficult question remains. We must discover what are the laws which regulate this evolution, and must determine how species have been derived from each other, whether slowly or abruptly, whether by internal or external forces, and other problems of like nature. In reality these two questions have been considered simultaneously, all theories of evolution attempting 
to answer both questions; or more frequently they assume evolution and attempt simply to find an explanation of the fact.

In the following pages these two questions will be considered separately as far as possible, though they are so intimately connected as to make a complete separation impossible. In the first five chapters we shall discuss the question whether evolution be a fact. Here we shall consider the various arguments which have been adduced to prove that species have been derived from each other, and the various difficulties and objections which have arisen against the unhesitating acceptance of this view. In the sixth and seventh chapters we will examine the several theories of evolution held by different scientists, which attempt to explain the fundamental fact, and to give the causes which have produced the development of new species.

Darwinism proper is, then, not evolution, but its explanation. Darwin's contribution to science was his law of natural selection, a principle which he believed to be the chief cause of the development of new species. Darwin did not originate the theory of evolution, although it is rightly associated with his name. If the writings of Descartes, Leibnitz, and Goethe be carefully studied, the beginnings of the modern ideas involved in the term can be traced. Very indefinite they were, it is true, and so they remained until about the beginning of the present century. At this time a French naturalist, Lamarck, formulated a logical and consistent theory of evolution, a theory which agreed in almost all respects 
with the one that is still held at the present day by many American naturalists. He not only believed in the origin of species from each other, but he gave an explanation of his theory. And the explanation which he gave is accepted to-day by many naturalists as being nearer to the truth than that of Darwin. But Lamarck was ahead of his age, and the world was not ready for his views. He had, moreover, the great authority of Cuvier against him, and the weight of Cuvier's name soon caused Lamarck and his evolution to sink into oblivion, to reappear occasionally at fitful periods as the next half century passed. In 1859 the publication of Darwin's “Origin of Species" brought the old view once more into prominence under a new light. For twenty years Darwin had been patiently investigating the theory before he published a word, and when he did appeal to the world he not only could give very strong arguments for accepting the general theory of evolution, but he offered at the same time an extremely simple and comprehensive explanation. A consideration of this explanation we must defer; but so strong were Darwin's arguments, and so skilfully were they handled, that the scientific world began immediately to discuss the question. Not a little of Darwin's influence was due to the great candor of his discussion and the readiness with which he acknowledged the difficulties which he could not meet. From that time evolution has been constantly before the world. Not only has much evidence been collected in the endeavor to prove or disprove evolution, but the explanation offered by 
Darwin has been subjected to thorough examination. It has been carefully applied to all sorts of facts; its weak points and strong points have been discovered; and new theories have been suggested in its place. The prominence of this question in modern times is therefore due to the influence of Darwin, and his name will always be associated with it, even though he was not the originator of the theory of evolution, and though his own explanation of the theory should be largely abandoned.

\section{Evolution and Theology.}

From the very first, evolution has been obliged to contend with prejudices arising partly from ignorance of the theory and partly from the natural tendency to cherish old ideas. The current conflict of science and religion has at times been vigorous over this question. Scientists, by this theory, offered to remove a whole series of miraculous events from nature. Species, which were before looked upon as the direct handiwork of God, were now regarded as the results of natural law. Evolution was supposed to be in contradiction to revelation, which had always been supposed to teach the special creation of species. Atheistic scientists claimed to have aimed a heavy blow at theism by this theory, and the theists quite naturally attempted to destroy the weapon before the blow reached them. The weapon has not been destroyed, but it has been found to be harmless, for theism stands unmoved by evolutionary theories.

The arguments which have been most potent in 
causing a rejection of evolution have frequently been of no scientific importance. Instead of trying to find out whether evolution is true, many begin at the other end. They select certain unpleasant results which they say will follow if the theory be true, and then proceeding to show that these results cannot be accepted, assume to have disproved the theory. One voluminous book, published within a year, assumes to start with, that if evolution were true Christianity would be overthrown, and with this as a foundation proceeds to demolish the theory. But such reasoning is worse than worthless; it is a positive injury both to science and religion, because it gives a false idea of both. Christianity does not want such defence, nor does science care in the least for such attacks. The truth of the theory of evolution must be decided by the evidence which can be adduced, and not by the results which we may think would follow.

Hugh Miller used to say that it was the misfortune of theology to be fifty years behind science. As soon as science advances any theory, theology thinks to discover it to be contrary to revelation, and immediately attempts to prove this contradiction. After much time is spent in such discussion the discovery is made that science has in the meantime demonstrated the theory in question. Theology is then obliged to retrace its steps ; and usually discovers very soon that its earlier interpretations were erroneous. This has been the history of almost all scientific theories, and thus according to Hugh Miller theology is fifty years behind science. 
Fortunate enough perhaps it is, for this fact prevents a too precipitous advance, and compels science to give good reasons for every step it takes.

In regard to evolution, however, it has not required fifty years to show that a belief in religion is not materially affected by its acceptance. Already our leading thinkers among theologians, as well as elsewhere, have recognized that the question is a scientific one purely, and must be decided upon scientific grounds; whether it is decided in the affirmative or the negative it does not trouble the belief in theism. Some people appear to think that to explain any phenomena by law, is to take it out of the hands of the Creator; and hence, if all things could be reduced to law, there would be no longer any need for a Creator. But this is plainly far from the truth. Even if evolution be admitted to its fullest extent, it does not explain creation; it only proves continuity. Darwinism itself explains the origin of nothing. It simply claims that the universal survival of the fittest varieties would slowly give rise to new species. And even the other theories which attempt to account for these varieties do not touch any bottom, although they go deeper into the matter. It is an old saying, that evolution cannot exceed involution; a saying which is sometimes held up to ridicule. But in its true sense it expresses an undoubted truth. Evolution, using the term now as Spencer uses it, does not create, it only modifies. Were it not true that under all nature there existed harmonious laws; were it not true that matter possessed certain properties; 
were it not true that these laws and properties were such that certain results could come from the introduction of matter and force, no evolution would be possible. In this sense, then, evolution cannot exceed involution. Evolution does not, in any form, attempt to deal with the question of the origin of matter, law, and force, but simply to show that, assuming the universe to have been such-and-such at the start, its subsequent history has been one of continuous growth. Once given matter and force and the laws regulating their interaction, and evolution claims that it is unnecessary to assume the addition of any thing more to explain the existing order of nature. To pretend that such a view is opposed to the better conception of theology is absurd. Evolution, if accepted, does remove many miracles from nature. But this is not to be regretted. To think of God as working by law is a conception vastly superior to the thought of his working by miracle. Even the most extreme evolutionist finds it necessary to assume the existence of something behind matter and force as its foundation, and a belief in evolution is only the conception of this power acting constantly and in an orderly manner. Some people would seem to think that evolution either denies the existence of God, or assumes that $\mathrm{His}$ only direct contact with the world was at the creation, and perhaps again at the appearance of life; and, except at these two periods, he has left his creatures to themselves. But while it is true that some evolutionists deny the existence of a God, it is also true that the latter view is seldom conceived 
of. There is such a belief as theistic evolution; and this belief would look at all nature as the continued manifestation of God. The power of the universe is just as truly manifested in the birth of an individual as in the creation of a world. Naturalists have not succeeded in explaining life, but have, in evolution, discovered a new law regulating life. Instead of being sufficient in itself, evolution finds it necessary to assume the constant action of power underneath nature. Instead of excluding God from nature, theistic evolution finds him as its eternal explanation.

It is not our purpose here to discuss the relation of evolution and revelation. The question has been much studied, and the rapidly growing opinion among theologians is that, considering evolution as a method of creation, it is not at all out of harmony with the teachings of revelation. There are certainly some views of evolution which would be fatal to any religious belief, but this is not because of any principle necessarily implied in the theory. Neither natural theology nor revelation finds any difficulty in accepting the theory. Gradually the conviction has been growing on all sides that this subject is purely scientific and not theological; that it must be decided by scientific investigators upon scientific evidence. The applications of evolution to other realms besides the organic world are interesting and valuable, but they will not aid toward settling the question at issue. Almost everywhere we find a readiness to leave the question for scientists to settle; at least to permit 
them to settle the method of the origin of species, although mental philosophy, metaphysics, theology, etc., may still dispute with science as to the interpretation and significance of the laws discovered. Evolution is held by Dana, a Congregationalist; Lecont, a Presbyterian; McCosh, the President of a Presbyterian college; Asa Gray, an Episcopalian; Mivart, a Roman Catholic; Winchell, a Methodist; Wallace, a Christian spiritualist; by the Bishop of London, and by hosts of others, ministers and laymen, whose names are enough to indicate that it is no longer considered a heresy to accept evolution; and that the best thinkers recognize the fact that evolution produces no discord when compared with revelation. So far, then, as concerns the relation of evolution to our ideas of Christianity, we may examine the evidence for and against the theory with no prejudice, and with perfect equanimity as to the results.

\section{Prevalence of the Evolutionary Theory.}

It may be well to say at the outset that evolution, as we have defined the term, is almost universally accepted by scientists. A very few-they can be counted on the fingers of one hand-are still inclined to withhold their acceptance. These are chiefly the older scientists, who had their views formulated before Darwin wrote, and their number is growing less. But with these few exceptions, scientists are so firmly convinced of the truth of evolution, that it is always assumed as a fact, and no more time is spent in discussing it. We find 
investigations constantly carried on which add data to the question tacitly assumed. We find many discussions as to which of the various theories of evolution is the nearest the truth; but it is very seldom we find in scientific literature any discussion as to the truth of the theory. Indeed, the study of biology to-day assumes evolution as its foundation. Whether a right or wrong method of study, it has proved to be a necessity, and will at all events serve to indicate how firmly the theory has become rooted in modern science. Unless there is a marked change in the tendency of thought, it is a safe prediction that a few years more will see it a universal conclusion of science. The question is, however, still open to investigation, and, as we shall see, there are still many difficulties which have not been cleared away. There are still obstacles to be overcome before the theory can be regarded as positively settled.

Among students of mental science, the term evolution seldom has the same meaning that has been indicated above. Their whole line of thought is different, and they cannot, therefore, consider the question as a purely scientific subject. In their minds, evolution has more meaning than it has among natural scientists. It is frequently made to include certain metaphysical conceptions of the meaning of the individual life; the significance of reproduction in general, as well as of the origin of matter and force; all questions of the greatest significance, and, perhaps, rightly included in a philosophical definition of evolution. But these ideas 
do not form part of the theory which scientists hold and claim to have approximately demonstrated. For this reason, then, we find various verdicts upon the question from students of mental science; though here, too, there is a growing tendency toward a belief in some sort of evolution.

Among theologians, while there are still some who oppose evolution on the ground that it is contrary to revelation, the number of those who concede it to be a purely scientific theory is a growing one. The willingness to accept the conclusions of science upon this question of fact is becoming more and more prevalent.

While, then, there is some unanimity as to the fact of an evolution, the unanimity goes no farther. When the attempt is made to explain the theory, or to discover the laws regulating it, or to discover its limits, if such exist, or when the theory is applied to mental or moral science, all agreement disappears. Each thinker has his own view. Darwin explained evolution by natural selection, while others deny to this explanation more than a secondary position. Some would say that there has been a continual slow progress; others, that there have been alternating periods of rest and rapid progress; some would say that new species may arise in the course of a single generation, or, at most, a few generations; while others make the production of a new species a matter of many centuries; some find the regulating factors in the organism; others in the conditions surrounding it. Some confine the law to the lower animals, and say that it does not apply to man; 
some would include man's physical, but not his mental, nature; while others believe that man has been wholly derived from the lower animals. To these views we shall again refer; but it is first necessary to examine the evidence for evolution, exclusive of any of these special theories.

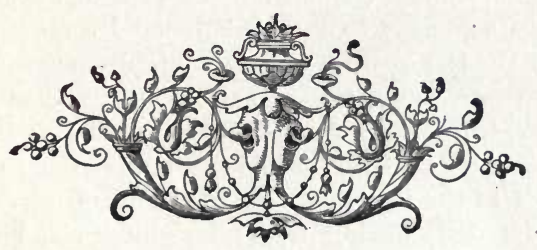




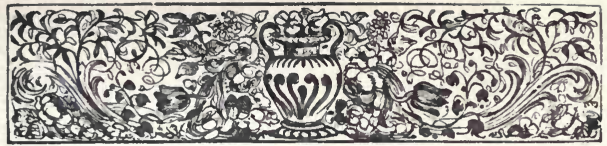

CHAPTER I.

ARE SPECIES MUTABLE?

THE subject around which the question of evolution is centred is the immutability of species. Are species so stable that they always produce offspring like themselves, or can they change so as to give rise either slowly or rapidly to new ones? If evolution is a fact, the latter must, of course, be true. Most naturalists claim that the evidence accumulated is sufficient to establish beyond a reasonable doubt the fact that species are mutable. They look upon those living to-day as descended from past species, from which they differ; and as continually changing, so that they will, in turn, give rise to new species in the future. Indeed, the term species is considered as having no real significance, but as simply a convenient method of classing similar organisms together. If this be admitted, the whole problem of organic evolution is in reality conceded; for when once it is recognized that species are derived from each other by descent, the method of this derivation, and the number of originally created forms, are simply matters of detail. But this position is not everywhere conceded, for it is still claimed by a few that the evidence is not sufficient to war- 
rant the conclusion of the mutability of species. While, then, most naturalists regard the mutability of spècies as no longer questionable, it is a conclusion which has not been definitely proved.

It will be admitted at the outset, on all sides, that no unquestionable instance has been observed of one species being derived from another. This is not surprising, even if the mutability of species be granted. It has been only twenty-five years since naturalists have perceived the importance of the question, and this is far too short a time for changes of importance to occur. But there is even a greater difficulty than this. Whenever it is shown that one form has given rise to another, it is, of course, a very simple matter to say that they are simply two forms of the same species. It is, therefore, impossible at present to place the matter beyond question. Two very distinct animals are studied, which are everywhere acknowledged to be distinct species. After careful study and experiment, it is found that one may be converted into the other, and from this time these two species are regarded simply as different forms of one and the same species; and thus the whole force of the proof is lost by this circular argument.

\section{Variation.}

That species are absolutely immutable no one will pretend to claim. It is repeatedly proved by facts of every-day observation that species are subject to a certain amount of variation and change. Every one is aware of the effect of food, climate, hardship 
and ease upon animals. No child is precisely like its parents. The man of the nineteenth century is very different from the man of 2000 B. C. The European is very unlike the African. Variations do occur, then, and may (by being transmitted from generation to generation) give rise to races. Among animals and plants it is everywhere recognized that there are species and varieties, and all of the varieties of a species are understood as having descended from the same ancestor. Indeed, the commonly recognized distinction between species and varieties has been, until evolution modified it, that varieties are descended from the same parent, while species are not thus genetically related. Nor will any one attempt to deny that the variations which may thus arise may be very great, equalling, or sometimes even exceeding, the amount of difference between species. Compare the English dray-horse with the racer, the short-horned with the long-horned cattle, the domestic hog with the wild boar-remembering all the time that we have here simple varieties. The various breeds of domestic pigeons differ among themselves so much that, if found in a state of nature, they would be ranked as different species, as different genera, or in some cases as different families, so great is the difference between them. The fan-tail has more tail feathers than any other known bird, and this is a tolerably constant feature among birds. The swollen crop of the pouter pigeon is absolutely unique, and yet all breeds of pigeons are simple variations, and no one is inclined to deny that they are derived from the same ancient common ancestor. 
In such cases as these the common origin of the varieties is frequently a matter of observation. But the same sort of varieties occurs in a wild state, although here it is seldom possible directly to observe their common origin. It is probable also that they are not so numerous or so great as in the case of domestic animals. Domestic animals are under such abnormal conditions, they are so free from the struggle for existence, so frequently manipulated by the breeder, as to make them very much more liable to variation than are wild species. Our breeders can, by careful selection, produce changes much more rapidly than would take place naturally. All of this is of course absent in animals under nature, and the variation will consequently be rather less numerous. That animals in a state of nature do vary is, however, well known. Individual differences are every. where found, for no two animals are alike. Nor are these variations confined to isolated individuals. They are inherited and transmitted. Changes in the environment produce very great effect upon organisms, changes which gradually increase by inheritance. Changes in food affect the color of animals, changes in temperature, climate, moisture, or dryness, winds, - all have been found to produce marked effects upon organisms. Șome rats escaping from a ship upon the island of Formosa became wild, and in a very few generations had become so much modified as to be no longer recognizable as European species. Allen has shown that variations in latitude produce in American birds changes in color, length of bill, claws, and tails, while variations in longitude 
only produce changes in color. Hardly a species of animals exists which does not have two or more well-marked varieties, sometimes referable to differences in conditions, but more frequently not, since they may exist side by side. Now since these varieties are all descended from a common stock, their existence is proof that a great amount of change is constantly taking place in the structure of our species.

A word as to the amount of the individual variations. The changes which occur in single individuals are of all grades, great and small. Sometimes they are so minute that only a practised eye can see them, while on the other hand they may be so great as to be almost incredible. The pug dog, the shortfaced tumbler pigeons, the hook-billed ducks appeared suddenly in nearly the same state in which we now find them. We thus see that the modification of species through variation may be a slow continual process of accumulation of minute variations; or it may be an interrupted process occurring by a series of greater or lesser jumps. It is true that it is seldom possible in the case of wild animals to determine by direct observation that these individual variations are transmitted from generation to generation. But the existence of varieties in nature which do breed true is a sufficient proof that such is the case. Moreover in some instances it has been di. rectly observed. Perhaps the best instance of the kind is a series of experiments of a Russian naturalist, Schmankewitsch. These experiments were upon a species of crustacea (Artemia Milhausenii) which 
lives naturally in water of a slight degree of saltness. By gradually raising the percentage of salt this experimenter succeeded in transforming this species into an entirely different one ( $A$. Salina), and by reversing the process he transformed the latter species into the former. Nor was this all. Still further freshening the water by gradual changes, he succeeded in transforming this same species into still another, which was so very different from the first that it had previously been ranked as a distinct genus (Branchippus). These changes took place slowly, several generations being required for the complete transformation, showing that the individual variations were transmitted from one generation to another, increasing in importance with each generation. All of these species had been known before, and had always been considered as distinct species and genera. Here was actual proof of their genetic connection with each other. It is important to notice that this naturalist was led to carry on his experiments by seeing them performed by nature on a grand scale by the gradual freshening of a saltwater lake. This instance is, therefore, enough to prove that not only do variations occur under nature, but that they may by being transmitted become sufficiently great to give rise to varieties which all naturalists rank as species.

\section{Causes of Variation.}

For every one of these variations, whether it be minute or great in amount, there must be an adequate cause. But in regard to the nature of these 
causes there is much difference of opinion. The causes of the variations must evidently be something connected with the organism and internal, or something outside of it. We can suppose that all variation is due to the action of external conditions. Most animals have two parents and cannot, of course, be like both. But aside from this fact, the reason that a child differs from either of its parents may be due to the fact, that it is never under the same conditions as its parents. All variation would thus be dependent on the action of the environment. But it is also possible to suppose that the causes of variation are in the laws of the organism, and only indirectly related to the environment. If this were true, the child might be like neither parent, nor even midway between them, though the circumstances were all alike.

And right at this point lies the difference between most of the modern theories of evolution. All theories are based fundamentally upon variations which, we have seen, are so abundant. It is evident, therefore, that the particular theory which any one may hold as to evolution, will depend upon his conception of the causes of and the laws governing these variations. Assuming, for a moment, that new species have arisen by the accumulation of such variations, the question is resolved into another one, what causes the variations? The answers to this question have been numerous. Darwin, while supposing that all of the variations had a sufficient cause, could discover no sufficient cause, and thought that they were only indirectly related to 
external conditions. $\mathrm{He}$ assumed, therefore, as a basis for his theory, that all organisms have an inherent tendency to vary. In accordance with this tendency, every individual departs more or less from the form of its parents. Such departures he believed were indefinite and irregular, simply being the result of a tendency to change. Darwin came to this view because he was seldom able to trace any definite connection between the environments of an organism and its conditions. Another school, which is called the Neo-Lamarckian school, does find a definite connection between the organism and its environment. The representatives of this school point to instances increasing every day, where it has been shown that definite changes in condition induce definite changes in animals. They show that many animals, under the same conditions, vary in the same or in parallel directions. They point to numerous instances where changes in locality produce definite changes in structure-such as the case above mentioned of American birds. They conclude, therefore, that we are to look at the environment exclusively for the cause of variation; and they say that if we find any series of variations accumulated generation after generation, it is because the same external conditions continue to produce them. Some naturalists believe in an internal law, which is supposed to have charge over variations, and to regulate them independently of external conditions. In accordance with this supposed law, any amount of variation may appear suddenly, without any external factor for bringing it into existence. 
This law differs from Darwin's " inherent tendency " to vary, in that it is supposed to produce definite changes rather than chance variations. And there are not wanting facts which give support to this view. In the case of domestic races, it is easy to show that the variations are not indefinite, being to a certain extent confined to special directions; and it is also plain that this definiteness is not wholly explained by external conditions. The pigeons, for instance, vary in some directions, but not in others. They show no tendency to develop the bill of the humming bird or the plumage of the bird of paradise ; nor is there the slightest reason for thinking that they would do so if placed in the same conditions. Moreover, the pigeon varies with the greatest of readiness, while some other animals-such as the goose-scarcely vary at all. Many instances of this kind might be selected, to show that variations are not indefinite, not entirely dependent on the environment, but are regulated, to some extent, either by natural laws or by the nature of the organism. Still other views of the nature of variations are held. Indeed, the facts of variation are so extremely numerous; they have been collected under such very different circumstances, and by so many hundreds of people; they are so very varied in their seeming import; and, above all, so great is our ignorance of the conditions of animals, even when we seem to be well acquainted with them, that it would hardly be possible to invent any law of variation which could not be attested by some facts. 
Two conclusions can at least be unhesitatingly drawn: I. Variations are partly dependent upon external conditions. 2. They are not wholly so dependent.

\section{Limits of Variation.}

A very great amount of variation is thus proved and everywhere admitted. The question for discussion is not as to its existence but as to its limitation. Is it unlimited? Can any variation go on increasing generation after generation, until new species arise by a continual accumulation of variations? Evidently if these variations are not limited, but can continue indefinitely, becoming greater with succeeding generations, the final result would be such great differences between animals as to form new species. And this is the position that is held by most evolutionists, though not by all. New species are believed to have arisen by the accumulation of variations, each slight in amount, but when added together becoming sufficient to constitute the differences between species. Variations are thus considered as unlimited. It must, of course, be true that there are certain limits set upon variation by physical conditions. Our race-horses, for instance, have been continually increasing their speed since racing has become common. No limit to this variation has as yet been reached. But evidently there must be a limit to this increase in speed toward which horses can tend but beyond which they cannot go. So in other features; it is usually possible to see a limit to variation set by physical conditions. 
But the evolutionist says that these are the only limits. He tells us, moreover, that in most cases these physical limits are so distant that there is abundant opportunity for many new species to arise before they are reached.

But those who believe in special creation, and at least one prominent naturalist who accepts evolution, claim that there are other limits. These limits are internal and form the boundary line between species. Animals may, it is said, vary in any direction within these limits, but can never exceed them. A pigeon may vary very much, but it never ceases to be a pigeon. Simple variation can never produce a new species, but only varieties of the old species. And this brings us to the real subject of this chapter-the immutability of species.

\section{Are Species Stable?}

The question we are to consider is this: Can variations, by continual accumulations, become so great as to form new species; or are there boundary lines between species beyond which variation cannot extend?

What is a species? Can this term be so accurately defined as to make it possible to decide whether the variations occurring are always within the limits of the species, or whether they may not exceed them?

The answer to this question is, unfortunately, No. Naturalists are unable to tell us what a species is and what a variety. The greatest confusion exists in the various systems of classification. No two systematists agree as to their classification. Forms 
ranked by one as true species are ranked by another as simple varieties. If two animals are quite like each other they will usually be called varieties; if quite unlike they will be called species. But no one has been able to tell us how a line can be drawn by which we can decide whether two forms are unlike enough to be called species. This confusion makes it utterly impossible to come to any conclusion as to the mutability of species. Species are.generally considered to be so distinct as not to be connected by intermediate forms, while varieties are thus connected. If, therefore, the evolutionist shows that any two well-defined species are thus connected, they immediately lose their rank as species and become simple varieties. Thus the whole force of the proof is lost. When, as above described, the Russian naturalist showed that Artemia could be con. verted into Branchippus, it would seem that something had been proved. These forms had always been considered distinct species, and doubtless would have been so regarded were it not for this demonstrated connection between them. But now it is evident that they can be regarded as the fresh-and salt-water varieties of the same species. Indeed, they must be so regarded or the immutability of species is proved. Thus the argument is inevitably in a circle. The naturalist, by long study, succeeds in uniting, by intervening varieties, two forms which are considered as distinct species, only to have the satisfaction of seeing that he has shown them to be varieties of one species. And thus, until a very large number of species have been united, this phantom chase will continue. 
The only really logical distinction ever given to separate species and varieties is that of the sterility of species when crossed, and the fertility of varieties under the same conditions. It is said that species cannot interbreed with each other, while all varieties are perfectly fertile when crossed. This gives a new understanding of species and varieties. The difference between the two is not in any amount of difference in bodily structure, but in affiliation. All the varieties of a species are believed to have descended from the same parent, and can consequently breed with each other. Different species, however, have not thus been connected, and cannot interbreed. Sterility is thus regarded as a bar set by the Creator to prevent the confusion which would result from crossing. It is upon this distinction that those who believe in the stability of species found most of their argument. If this be admitted as the definition of a species, the question can at least be discussed, although open still to the phantom chase above mentioned. Here is a limit beyond which it is claimed variations cannot go. It is pointed out that so far as our observations have gone, no amount of variation has ever produced a new species, if this be admitted as a distinction. In no case has variation produced among domestic varieties any degree of sterility. All of our breeds of pigeons, as widely different as they are, can breed freely with each other; all of the numerous and diverse breeds of dogs are perfectly fertile inter se; and so with domestic races in general. Indeed Darwin himself admits that he knows of no well- 
authenticated case of domestic races being sterile when crossed, a fact which he considers extraordinary, considering the great difference between domestic breeds of dogs, fowls, pigs, etc., and the very slight differences between natural species which are sterile inter se. So far, then, as experiments on domestic animals are concerned, the evidence seems to indicate that no amount of ordinary accumulation of variations is able to produce forms so different as to be infertile when crossed. If, then, this be accepted as a criterion for specific distinction, there is no case on record where there has been even an approximation toward the production of a new species.

Possibly the human race may be a partial case in hand. The races of men are to-day pretty universally admitted to be simple varieties of a single species. The different races are well known to be fertile when crossed, a fact attested by half-breeds of all sorts. But it frequently appears that halfbreeds form a somewhat weak race, having lost the vigor of either parent. Particularly is this true when half-breeds intermarry. It is stated by Broca that in some cases the fertility is not kept up for many generations, unless the pure blood of one of the parents is introduced. This is true he says of the cross between the Australian and European races. It is frequently stated that mulattoes are not very fertile, and soon become sterile unless the pure blood of one of the races is once more introduced. But all of these statements are denied. Others who have studied the matter claim that all 
half-breeds are fertile for an indefinite period, and sometimes even more so than the pure breeds. This subject has in the past become so much involved in theological discussions as to make it somewhat difficult to know what is the true state of the case. It is not possible, therefore, to say definitely whether or not man can be cited as a case where varieties have a certain amount of sterility. The evidence for such a conclusion is at all events very slight.

Finding, then, no cases where domestic varieties are sterile when crossed, naturalists have attempted to meet the difficulty in another way. They have questioned this definition of species by showing that true species are not always sterile when crossed. In accordance with the idea that sterility is a bar which has been laid down to separate species, it is difficult to see how there could be any grades of sterility. We should expect either that all species would be sterile when crossed, or they would all be equally fertile. But investigations have certainly shown that sterility is no such rigid bar as this. It is true that species are usually sterile when crossed, but the amount of fertility is a variable quantity. Many species do not produce any young when crossed; while many others do produce young, which are themselves incapable of reproduction. And in still other cases even this amount of sterility is not found.

Owing to the difficulty of experimenting upon animals, observations upon this question have been more largely confined to plants than is desirable. 
Among plants, at all events, there are many instances of hybrids between species being perfectly fertile, and continuing so for an indefinite period. Experiments during the last twenty-five years have increased the number of such fertile crosses many fold. Direct experiments upon plants are very easily carried on, for the pollen can readily be transfered from one plant to another. By these experiments, so great an amount of crossing has been found possible, that one writer comes to the conclusion that fertility of hybrid plants is the rule and sterility the exception. So far as plants are concerned, there is not the slightest ground for considering sterility as a distinctive bar, separating species.

Animals are not so easy to study, and the difficulties in the way of experimenting have prevented any extended observations. Of course, only those animals under confinement can be studied, and confinement always produces great changes in the reproductive function. Some animals will not breed at all when in a state of captivity or domestication, while others appear to breed more freely than in their natural condition. It is difficult to get two species to unite so as to make it possible to discover whether or not they are fertile. But nevertheless quite a number of cases of cross-breeding are known. Two species of apes, belonging to different genera, have crossed and produced young; the rabbit and the hare very commonly cross; the tiger has bred with the lion; the leopard with the jaguar; the polar bear with the brown bear; various species of the horse family have repeatedly crossed. A hybrid 
snake, between two genera, was born in the Zoölogical Gardens of London. Hybrid ducks are common and hybrid fishes are easily produced. In most of these cases the hybrids thus produced are themselves sterile. But this is not true of all. The cross between the rabbit and the hare, two good species, is perfectly fertile. The cross between the dog and the jackal, or the dog and the wolf or fox, remains fertile, for a number of generations at least. The common goose and the Chinese goose when crossed produce perfectly fertile offspring; and hybrids between the mallard and muscovy ducks show no sterility. Infertility of hybrids is by no means a universal law, among domestic species at all events. But a similar hybridity has been observed among animals in a state of nature. A cat has been described by Cuvier, which is a cross between the domestic cat and Felis Bangalensis. A hybrid duck is known to exist in nature, and no less than eight hybrid fresh-water fishes are known in Germany. The polecat and the ferret produce hybrids. A male white cockatoo and a female rose-colored cockatoo, which never bred in confinement, were set at liberty in the woods, and bred together for two years. It is, of course, impossible to say whether hybrids are themselves fertile or not, for no observations are possible.

A careful examination of the facts of cross-breeding, collected by our ablest experimenters, reveals thus several significant facts. It is true that in a great majority of cases a certain amount of sterility results from the crossing of distinct species. But 
this sterility is a variable quantity. Some species will not unite at all, or if they do will produce no young. Others will produce young occasionally, but these young are sterile. Some produce young, which in their turn occasionally reproduce. And so on; cases can be selected with constantly increasing fertility, until in some extreme instances the fertility of hybrids seems slightly greater than that of the legitimate young. The power of hybrids to reproduce varies from zero to absolute fertility. Again, it is the rule that varieties are fertile when crossed, but, according to the best experimenters, there are also exceptions to this rule.

The ability of two species to interbreed does not depend upon the amount of structural difference between them, for it is found that some species which are very closely related will not cross, while others much more unlike will cross with the greatest facility. It is frequently found that reciprocal crosses produce very different results; for the male of one species may cross with the female of another and readily produce young, while the female of the first species can cross with the male of the second only with difficulty. The cross between the ass and the horse is a case in point. The mule is obtained readily as the cross between the male ass and the female horse; but the attempt to get a cross in the other direction is rarely successful. It sometimes happens that all of the species of a genus will cross with the others except one, and this one, in structure no more different than the rest, will not hybridize with any of the others. Differences of this kind 
are also found in individuals, the ease with which crosses can be made varying very much in different individuals of the same species. Occasionally species which are very difficult to cross produce, when they do cross, offspring which are very fertile; and species which cross with great ease produce absolutely sterile hybrids. And it is important to notice that the best experimenters not unfrequently disagree in regard to the very same species; some claiming that given species are fertile when crossed, and others claiming that they are sterile.

Now all of these facts do show one thing, viz.: that sterility of species, when crossed, is no definite law. Sterility is a variable matter. It is not dependent upon specific limits, nor upon the closeness of the relations of the species crossed, but upon some other factors not easily discovered. It is plain from all these cases that sterility is not a bar which rigidly separates species from each other. Naturalists have proved that this distinction between species and varieties is not absolutely correct. Whatever be our belief as to the origin of species, we cannot believe that each was created with the bar of sterility to separate it from others.

Why, then, are species usually sterile when crossed? If this is not a created bar, how did it arise? We have seen that ordinary variations have not yet been shown to give rise to sterility. From various considerations most scientists are to-day inclined to accept the view that it is due largely if not entirely to differences in the sexual organs independently of differences in the rest of the body. Two 
species, very much alike in other respects, may have their sexual organs very dissimilar, and sterility would be the result, while two other species, or varieties, while very unlike in most features, might have their sexual organs so similar as to produce perfect fertility. If this is true, we reach a new distinction of species and varieties. The differences between varieties may affect any part of the body except the sexual organs. Differences between species include, as a rule, also the sexual organs.

It is now possible to see some reason why our domestic races continue fertile. These races have been produced by selection on the part of the breeders, who do not pay any attention to the sexual organs in their selection. The general differences may therefore become very great without producing sterility. Moreover, there is very good reason for believing that domestication has the effect of making many animals more readily susceptible to cross-breeding. Our various breeds of dogs, for instance, are almost certainly descended from several wild stocks which must once have been distinct species. But to-day, all dogs, with the exception of certain South American indigenous species, breed freely with each other. Now either these wild stocks originally could interbreed, or, what is more probable, they have acquired the power by domestication. If it is thus true that domestication sometimes produces greater fertility in this way, another suggestion is found in the fact for the fertility of domestic races.

In spite of all these facts and suggestions, this 
matter of cross-breeding raises a very serious difficulty for those evolutionists who believe that species arise by the accumulation of variations. The difficulty lies not, however, in the fact that species are usually sterile when crossed. This is easily understood, as soon as sterility is found to be variable, by supposing that species have become so much unlike that cross-breeding is no longer possible. The difficulty lies in the fact that no amount of variation in our domestic races has produced any sterility. It is not possible here to plead a lack of time, since a glance at domestic races shows that there has been time enough to produce enormous changes, much greater than those which separate wild species. Science, indeed, knows very little of the causes of sterility. Elephants, when kept in a state of only partial captivity in their native country, are unable to breed. And yet two of them in the hands of American showmen did produce young, under conditions differing as widely as possible from those of their native country. When science can explain this, it will probably be able to tell why some varieties are sterile when crossed, while most are fertile, and why some species can breed freely together, though the rule is almost absolute sterility. At present, however, this explanation is lacking, and it is useless to deny that Darwinianists are embarrassed by the continued fertility of our domestic races.

Most of the evidence which concerns the origin of species from varieties must be obtained from domestic animals, since these alone can be carefully observed. Our domestic varieties are regarded by 
most evolutionists as incipient species. It has been frequently urged as an argument against this view, that when allowed to run wild these varieties return to their original condition, all of these acquired peculiarities disappearing. This is thought to show that domestic varieties, and, therefore, presumably all varieties, are simply oscillations from a central form, to which return is made as soon as opportunity admits. This is, of course, an argument for specific stability. But, really, there is no ground for the argument. It is simply an assumption that these varieties return to their former ancestral condition. In most cases, naturalists do not know what the aboriginal stock was, and it is, therefore, impossible rightly to make any such assumption as that on which this claim is founded. It is true that our domestic races do change very much when they become wild. But this is not surprising. That our carefully selected varieties should disappear under a return to the feral condition, is a matter of course. They have been produced under peculiar circumstances, and by very careful breeding. It would, of course, follow, that as soon as these circumstances are withdrawn the peculiar varieties would disappear. So long as the conditions remain constant, the varieties do not have any tendency to revert to any former type, and this is all that the theory of evolution requires.

It is true enough that naturalists have been unable to find a single unquestionable instance of the production of a new species. It has been, therefore, assumed by some who admit the theory 
of evolution in general, that nature is not forming any new species to-day, but only varieties. This is, however, nothing but an assumption. Among domestic varieties it is true that the methods of selection have not succeeded in inducing sterility among the varieties. In some instances, on the contrary, they have probably rendered mutually fertile, forms originally sterile. But the variations have been very great, and have been sufficient to constitute distinct species and genera in every respect except this one of sterility. In the great realm of nature it is impossible to say whether or not new species are being constantly produced. New species are certainly being constantly found. Since the fauna and flora are not thoroughly known in any country, new species may be constantly appearing without the possibility of their being discovered. Even in England, the country whose fauna is best known, new species are occasionally being found. It is only twenty-five years since the matter has been considered so important, and this is too short a time to make negative conclusions of any value. Naturalists are now collecting and carefully studying the species of various localities, and are slowly gathering data for an answer to this question. When, in another century, naturalists can compare the world which they know, with the record left by naturalists today, it may be possible to answer this question. But to-day the problem cannot hope for immediate solution. To state that no new species are now forming, is not only to beg the whole question at issue, but is to make a statement for which the 
only evidence is the fact that domestic races are fertile when crossed. Considering all that is known as to the fertility of hybrids, this is certainly too slim a basis to authorize the assumption of the whole question.

\section{Indirect Evidence.}

Not having time enough at their disposal and not being able to define the term species, naturalists are still unable to decide by direct evidence whether or not species are immutable. If the evidence that species have been derived from each other ceased here, few would be inclined to accept evolution. But there is a large amount of indirect evidence bearing upon the question. If species have arisen by the process above described, certain relations would necessarily follow. It is the exact accord of all the evidence collected with these necessary relations, which has caused such a wide acceptance of organic evolution. Such evidence is indirect, but it is none the less forcible. In the following four chapters this evidence will be chiefly discussed, but a word of preliminary introduction is here desirable.

When we come to examine the relations of true species, we find many points which suggest genetic relation. As already mentioned, no naturalists have been able to distinguish in nature between species and varieties. All grades can be found between two similar varieties and two very distinct species. Indeed among the sponges careful students have been unable to find any thing which they can call species; for the whole group is connected together 
by minute gradations. These connecting links are not so prominent elsewhere, but they can be found in all groups of animals. It is not to be understood from this, however, that there is no difference between species and varieties; the former show much greater differences than the latter, and are usually more stable. But there is no marked line between them. If we examine the relations of species to each other and compare them with the relations of varieties, a strict parallel can be drawn. The large number of domestic pigeons, with their numerous races, can be divided into groups and sub-groups corresponding exactly to the divisions which are found in nature of genera and species. It is only necessary to imagine the mutual fertility to disappear, and these groups would resemble in every respect the natural grouping of genera and species. In other words, the working of nature in accumulating variations produces results which, if carried far enough, would give relations exactly such as are found existing between species.

Turning to fossil deposits there is in some cases evidence amounting to practical proof that species can arise in this way. The best illustration of this is found in the Steinheim Lake deposit. At Steinheim, in Würtemberg, there is a large deposit of shells which has been subject to special study. The deposit represents the bed of an old lake, and it appears that in Tertiary times there migrated into this lake a species of fresh water mollusk, called Planorbis. This animal found an unoccupied field in this lake, and multiplied rapidly. As fast as the 
animals died, their shells sank to the bottom of the lake and there accumulated for ages. The shells are now found in this old lake-bottom in great quantities, and being found as they are in layers, the whole history of the animals can be studied by examining successive layers. And most beautifully has such study shown the origin of species. Beginning with a few sample varieties, there is a rapid divergence until very diverse forms are reached, so diverse, indeed, that they must unhesitatingly be set down as different species. At least this would be the fact, were it not that all these diverse forms are connected by an infinite number of intermediate forms. It is of course possible to claim here, as elsewhere, that we are simply dealing with a single highly variable species. But the extreme forms are so very different from each other that this claim is a very weak one. If species be defined as forms not connected with each other by intermediate gradations, of course nothing is to be said. But if we use any other definition for species that it is possible to apply, the Steinheim Lake appears as the site of the origin of a number of species from a common ancestor.

One very interesting argument for the common origin of the species of any genus, is found in a class of variations called reversions. Animals and plants frequently show quite suddenly features which, upon close examination, are found to be the characteristics of their ancestors-characteristics long since lost but suddenly reappearing. The circumstances which bring about these reversions are quite varied. 
The most common is the crossing of two quite different individuals. If, for instance, two very different breeds of pigeons be crossed, there is a great tendency to produce young quite unlike either parent, but resembling the rock pigeon, which is known to be the ancestor of our races of domestic pigeons. This tendency to reversion can always be found more or less marked in domestic races. It is certainly a marvellous thing that characteristics which have been lost for many generations should have thus the power to reappear. Science has no explanation to offer for the fact. Such reversions are never supposed to give rise to new varieties. They are, on the other hand, claimed to prevent the formation of new varieties. It is said by those who do not accept the unstability of species, that these reversions keep the species true, by continually bringing the individuals back to the central type when they depart too widely from it. Reversion has, however, never been known to produce such a result. It does not take place in ordinary circumstances, but only when the great changes occur.

But these reversions are frequently of great assistance to the naturalist in enabling him to trace the history of varieties. When it is found that all of our domestic pigeons revert in this manner to the rock pigeon, it is almost sure proof that this rock pigeon was their common ancestor, even if this fact stood alone. Now the important point to be noticed is, that reversions of a precisely similar character occur among the species of a genus. For instance, when 
the horse and the ass are crossed, the offspring possesses features which are found in neither parent. The mule, in ninety cases out of a hundred, shows a number of bars on the legs, and several stripes on the shoulders. In rare instances it is found that the horse and ass of pure breed possess the same features, scattered cases having been observed in almost every variety of horse and ass. But hybrids almost always show them. Not only the hybrid between the horse and the ass, but all hybrids of the various members of the horse family, show the same features. The similarity of this case with that of the pigeons is exact, and plainly indicates that here is a true case of reversion. Now in the pigeons it is known that the reversions refer to a common ancestor of the breeds crossed. It is certainly a legitimate inference that the reversions occurring in the horse family also refer to a common ancestor. When, therefore, we find various species of the horse family, the horse, the ass, the zebra, the quagga, the hemionus, all showing this tendency to reversion, we can hardly avoid the conclusion that they have had a common ancestor. Our naturalists have even thought it possible to tell pretty accurately the specific features of this ancestor of the horse family, drawing their conclusions from these reversions, together with other evidence. The common ancestor of the horse family, they tell us, was an animal somewhat smaller than the ass, of a dun color, and with stripes much like those of the zebra. If this evidence is accepted, it is plain that the common origin of some species is no longer a matter of question. It is of course possible to 
deny that these features are really reversions to a common ancestor.

\section{Summary.}

If animals and plants produced young precisely like themselves there would be no possibility for a belief in evolution, for of course no new species could arise by genetic descent. But a study of animals under domestication, where they can be carefully watched, as well as under nature, has proved that animals do not produce young precisely like them. selves. Two laws are found to govern animals in their reproduction. The first is heredity; and in accordance with this, species tend to repeat them selves in their young. The second is variation; and in accordance with this law animals produce young which are in many features unlike their parents. These variations in the young are very numerous. They are sometimes very small and sometimes very great. They are transmitted from generation to generation, and have a tendency to become greater and greater. Each variation has of course its adequate cause, either in the organism or in its external conditions. Occasionally it is possible to discover their causes, but in most cases it is impossible. Plainly, if the same conditions continue to act upon organisms for many generations, the variations they produce will continue to increase. And this is found to be true. By the accumulation of these variations there are finally formed groups within the species. Each group differs in certain respects from the others, though they all show so much likeness that they are still grouped together as a single species. 
The sub-groups are called varieties, and are everywhere regarded as genetically related to each other.

The question then arises as to whether there is a limit to this accumulation of variations. It is claimed by evolutionists that there is no limit except that set by physical conditions. They continue to increase, causing the varieties to become more and more unlike, until they finally become so different that cross-breeding becomes no longer possible in all cases. Thus individual variations become varieties; and varieties become species. But it has not yet been found possible to prove this claim by direct evidence. For it is asserted on the other hand that these variations are not accumulated indefinitely, but are confined within certain bounds. The limits thus assumed are supposed to constitute boundary lines between species. In attempting to define these specific limits, it has been found impossible to discern them in any amount of structural difference. The differences between true varieties may surpass those between species. Such a limit has been drawn at the point of sterility, the position being taken that no amount of ordinary variation can cause the varieties thus arising to become mutually sterile. The evolutionists have been unable to disprove this claim by direct evidence, for they can cite no instances where varieties have become unfertile. But they deny the correctness of this definition, showing that sterility is not a rigid bar separating species, since in some cases true species are fertile when crossed; they have further given reason for believing that sterility is caused by differences in the sexual organs. 
When challenged to produee a new species by variation they acknowledge their inability to do so, and demand more time. Direct evidence is therefore not sufficient either to prove or disprove the mutability of species. Meantime the scientist claims that he can bring forward enough indirect evidence to substantiate the theory of evolution; since all of the facts of the organic world appear to him to be in conformity with the belief that species have been evolved. To this indirect evidence we will devote the next four chapters.

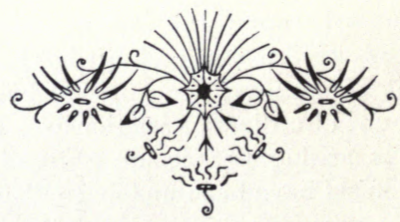




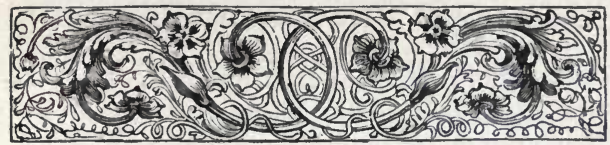

CHAPTER II.

THE CLASSIFICATION OF THE ORGANIC WORLD.

The Existence and Significance of a Classification.

A CERTAIN writer who disbelieved in the theory of evolution once asked Prof. Huxley where he could find the strongest arguments in its favor, which he acknowledged he desired for the sake of publicly refuting them. Prof. Huxley advised him to take a course of study in comparative anatomy. The man was naturally somewhat angry at this unexpected piece of advice and of course did not follow it. But Prof. Huxley knew whereof he was speaking, and his advice was full of wisdom which no one can appreciate who has not gained experience by following it, and making a careful study of the animal kingdom. The strongest arguments which are found in favor of the theory of descent, and frequently too, many of the most significant difficulties, come from the innumerable little points which familiarity with animals brings under one's observation; too many to introduce into any discussion for the sake of argument, too minute, most of them, to seem worth publication, but all together forming a complete whole whose weight is very great. 
It is almost hopeless to attempt to give to any one not acquainted with the subject, any thing like a complete understanding of even the general bearings of the question. It is useless to try to give instances, because they are significant only from their abundance. To show how many features man has in common with the lower animals; to show how the abnormalities of his body are readily explained by reference to other vertebrates; to mention the fact that the human embryo possesses gill slits at the side of the neck like those of the fish, and has a similar distribution of blood-vessels: to show that the highly developed mouth parts of the crab are simply modifications of a primitive type of appendage existing in all crustacea; that there is every stage from a simple hydroid bearing sexual organs to a free swimming jelly fish; and to bring forward an unlimited number of other similar facts, means nothing to the general reader, or indeed to any one except those already familiar with the facts from personal knowledge. Or if they do mean any thing, they are looked upon as simple instances of the acknowledged fact that there is in nature a possibility of classification, and that animals show homologies with each other. It is needless to attempt to show how universal is this principle of homology in animate nature, for its existence will be everywhere acknowledged. The real question to be raised, as far as this subject concerns evolution, is, not as to what organs are homologous in different animals, nor as to what may be the true classification, but what does homology mean, and why should 
there be a true classification in distinction from a false one. Likeness is always more difficult to explain than unlikeness, although we frequently think the contrary, and that animals should show likeness according to which they may be classified is a fact requiring explanation. Granting that a classification exists, and all of the above-mentioned classes of facts follow as necessary consequences; still, why should a classification and homologies exist? This is the significant question upon which the argument rests.

Any thing can be classified. Chairs may be classified into rocking-chairs and stationary chairs; or into walnut chairs and pine chairs; or into caneseated chairs and wooden-seated chairs. Any of these divisions would be classification, and any one would be as true as the others. But a long study of the organic world has shown that its classification is quite different from such artificial divisions. Naturalists have everywhere agreed that there is in the organic world a natural classification, a true classification in distinction from hundreds of false ones which can be made. No such natural classification exists among artificial products nor among minerals, but only in the organic world. Such a classification existing in nature demands explanation.

\section{Two Explanations of Classification.}

Practically only two explanations have been offered toward the solution of this problem. The first is the theory of types held by Cuvier and afterward by Agassiz, and is briefly as follows. The Creator 
had in his mind certain types in accordance with which he created species. All animals and plants created must be moulced according to one of the types, although great variation could take place within the type, and never exceeding its limits. The type was, therefore, a purely ideal form existing only in the mind of the Creator. Of these types Cuvier recognized four. But besides the great types, it is necessary, in order to make the theory complete, to assume that each class of animals was made according to a sub-type, each order according to a sub-sub type, and so on for families and genera. Individuals could vary within the type of the species, species within the type of the genus, genera within the type of the family. The whole animal and vegetable kingdoms are thus moulded in accordance with many types and sub-types, each of which must have existed in the mind of the Creator when he created species.

Modern scientists are, however, not satisfied with this explanation, for reasons which will presently appear, and have offered evolution as the explanation sought. This theory claims that the likenesses between animals are due to descent from common ancestors; that the well-known principle of heredity, in accordance with which the child is like the parent, is a sufficient explanation of classification and homology. The classification of organisms is thus simply arranging them according to their genetic relationship: those animals showing the greatest likeness having the most recent common ancestor; those more unlike being more distantly related; 
while the great types of Cuvier have had no common ancestor later than the very beginning of animal life on the globe.

It is very interesting to compare the arguments brought forward by the last great exponent of the theory of types, and those which evolutionists to-day use in support of their own views. Agassiz' "Essay on Classification," appearing just before the "Origin of Species," was a masterly attempt to prove the theory of types. In this essay are brought forward thirty different lines of argument, each of which was carefully considered, and was believed to be strong evidence for the views held by the author. Now an examination of these arguments gives a rather surprising result. Of the thirty lines of argument, no less than twenty-six have been directly turned upon their author, and are now used as arguments in favor of evolution, some of them, indeed, forming the strongest pieces of evidence which the evolutionist has to offer to-day, e.g., the parallel between embryology and paleontology. Of the other four points, one still remains as a difficulty for evolution, viz.: the simultaneous appearance of the different types in the earliest geological ages; one of the others has been disproved, while the remaining two do not at present seem to have any particular significance for either side of the question. This result, which must have been very un'expected to Agassiz, simply indicates what a different theory evolution has been since Darwin from what it was before, and that the theory which Agassiz was combating was very different from the evolution of later years. Both 
Agassiz and Darwin recognized that there is a unity in the organic world, and to prove this unity essentially the same arguments were used by both. In the interpretation of this unity only did they differ. While Agassiz places the unity in the mind of the Creator, Darwin finds an equally intelligible and a much more natural explanation in the theory of genetic descent. Agassiz' essay was thus as strong an argument for evolution as it was for his own theory, although, of course, he did not recognize this fact.

Either of these theories is an explanation of classification, and either of them if admitted will account for many or most of the facts. It is, moreover, by no means impossible that both may be in a measure right; that types of the animal kingdom did exist in the mind of the Creator, and that his method of expressing or materializing these types was by genetic descent, or evolution. While then the two views are not incompatible, we must recognize that the first is not open to investigation, since it lies beyond the realm of human knowledge. The evolutionist, moreover, claims that whatever be our belief as to creation, the facts of the organic world are such as to indicate that the introduction of species, families, etc., into this world, has been by genetic descent, and that the history of the organic world has been evolution. The reasons for this claim we must now examine. The Relation of the Various Great and Small Types
is Expressed by a Branching Tree-like Structure.

It has been in the first place urged by those who argue for evolution, that upon the theory of types 
the animal kingdom ought to be arranged in parallel lines. "Strict classification of forms supposed constant excludes any natural relationship." If the types were definite norms, their lowest representatives should be just as different from animals of other types as are the highest. Each animal would be moulded strictly in accordance with its type, and since the types are distinct, the different sub-kingdoms could not approach each other, but would remain as separate parallel lines from their first appearance. And, moreover, since to make the theory complete it is necessary to assume sub-types, the same would be true of smaller divisions, and there could be no conveyance of lines of relationship toward each other, but they would remain always parallel. If, e. $g$., the mammal and the fish are distinct creations according to different sub-types, they ought to be as distinct when created as they are today. But it was claimed by Darwin, and the claim has been growing in favor since then, until it has received universal acceptance, that such is not the relation of the divisions of the animal kingdom. There are no parallel lines, but all converge toward each other as we go downward and backward. The relation of the different groups of the animal and vegetable kingdoms is to be looked upon in the form of a branching tree, each sub-kingdom representing a great branch; each class,order, family, and genus smaller and smaller branches, while the species are simply the terminal twigs and leaves. The trunk of the tree, where all of the great branches unite, has been carried farther and farther back until 
it has all but disappeared in the dim past, although such a trunk can be found by studying embryology. If this claim of the tree-like arrangement of the animal kingdom be substantiated, it is proved that the old idea of types is not in accordance with the facts, while the theory of genetic descent is in exact accordance. We must, then, now examine the evidence which morphologists have brought forward to substantiate their claim.

It has been shown in the first place that if types be admitted at all, more than four must be recog. nized. Modern science has conclusively proved that Cuvier's Radiata must be divided into cœlenterata and echinoderms; that the Articulata consists of two very different groups, artheropoda and vermes; and that one extra group, the protozoa, is undoubtedly to be added. The sub-kingdom, vertebrata, is still retained, though to it has been added one class of animals formerly called mollusks; while there exist some animals which do not belong to any of these types (brachiopoda, polyzoa, and chaetognaths). And, finally, it is becoming daily more and more evident that the modern sub-kingdom, vermes (part of Cuvier's Articulata), is a group which is made to contain almost any animal which shows no marked relationship to others, and consequently is a heterogeneous collection of animals with almost no likeness to each other. And so in regard to the other sub-kingdoms. If we attempt to define the limits of any of the so-called types, the result is only confusion and contradiction; and after we have settled upon a certain number of them as represent- 
ing the nearest approximation to the truth, it becomes evident that the divisions thus recognized have an unequal value. Indeed, one of the best of modern scientific books does not attempt to arrange the animal kingdom into sub-kingdoms, realizing the futility of all such endeavors, but simply takes up in different chapters animals which seem to the author to deserve separate rank. No less than twenty-six different types are thus considered, although their value is not by any means the same, the author recognizing that his division is only provisional. The old idea of types has thusbeen supplanted by the more modern view, that types are not rigid norms, or that if they do exist we know nothing about them, not even their number, for the animal kingdom can be divided with almost equal justice into five, seven, eleven, or even more different groups.

It appears then that no rigid lines can be drawn separating from each other the so-called types. Various attempts to draw such lines have been made. It was urged for a long time that no homologies exist between members of the different types; that the parts of a vertebrate can be homologous with those of any other vertebrate, but never with a mollusk or a radiate. If this were true it would certainly define the types. This subject, therefore, has been the scene of a long battle, which is not entirely settled even to-day. It is now recognized, however, that it is possible to discover certain homologies between members of the so-called types, though naturally not so exact as between animals more closely related. The whole series of homologies is 
a graded one. Between man and his nearest allies, the apes, the homology is very close, the structure of the body being very similar, except in small details. Between man and more distant forms, such as the dog, it is much less exact. Between man and the reptile it is still less striking. Between man and the bony fish it is very much less exact. If man be compared with the lowest vertebrate the homologies. to be found are confined to two or three organsthe alimentary canal and the nervous system; and even in these organs the differences exceed the likenesses. And now if we go one step farther and attempt to compare man in a similar manner with some invertebrates, while the homology is still less. exact, it can be distinctly traced. The nervous system is in some invertebrates at least partly homologous with that of man; and the alimentary canal remains the same. Vertebrates and invertebrates possess a circulatory system fundamentally alike, and the excretory system in almost all animals. shows a remarkable resemblance. Finally, if we extend our comparison to the embryonic stages we can find very abundant evidence that homologies. do exist between all animals. The young mollusk, the young worm, the young polyzoan, in a stage called the trochosphere show a likeness amounting almost to identity; and if we take a still younger stage, we find all types possessing a structure practically the same. If now we take these identical embryonic stages as a guide, there is no longer any difficulty in drawing homologies between the adults of all animals. While this is everywhere recog- 
nized, it must be acknowledged that different morphologists have not reached the same conclusions as to these homologies in all cases.

But it is undoubtedly a fact that to a certain extent homologies can be traced between animals as widely separated as the so-called types. It is further a significant fact that these homologies are most noticeable when the lower members of the different types are compared with each other; in other words, the types approach each other at the bottom. The lowest vertebrates approach much more closely to the invertebrates than do the higher members of this group; so close indeed that in some cases low vertebrates have been classed with one or another of the invertebrate classes. All of this would of course naturally follow from the descent theory; for the lower members are nearer to the supposed common ancestor. And this theory would lead us to expect that there might be some animals intermediate between the great types, which represent their common starting-point. Very careful search after such forms has been made, and certain small circumscribed groups have been found, consisting perhaps of only a single species, which show so many general likenesses that they do not seem to belong anywhere, but have been changed about from place to place, now with one class of animals and now with another, until it has been assumed by the advocates of the evolution hypothesis that they form connecting links between the great types. This point has been strongly emphasized by some naturalists, and would be highly important if true; 
but it has proved upon close examination to be in most cases a delusion. Most of these animals have been found to be simple but somewhat modified representatives of one of the large classes, and.not connecting links between them. For instance: the Ascidians have been classed in many places, and finally when the discoveries of a Russian naturalist showed their vertebrate affinities, they were immediately hailed as connecting links between the vertebrates and some group of invertebrates, probably the mollusks. But a more careful study in the last few years has shown that the Ascidians are true vertebrates, degenerate forms it is true, but still unquestionably vertebrates, and not in any sense connecting links as was at first hoped. Another animal, the far-famed Amphioxus, held its rank as such a connecting link for a longer period; but this too is now seen to be a very simple and degenerate vertebrate. And so in general the connecting links between the sub-kingdoms and of ten too between the smaller groups, prove upon examination to be modified members of one or the other of the groups which they are supposed to unite.

And indeed connecting links are very little looked for now ; for it is recognized that we cannot expect to find them living to-day. The animals which exist to-day are not in direct line with each other, but are the separate terminations of lines converging toward each other in the past. The common ancestors representing the points of union of these lines were animals which have lived in the distant past, and as a rule they will have disappeared. Perhaps 
in the case of closely related species, connecting links may be found, for they are of so recent origin that the common form from which they have descended may not in all cases have become extinct. But when a wide difference exists, such as that between the different sub-kingdoms, the common point of union is so far back in the past that the existence of connecting links to-day would be a marvellous thing. Such forms must have lived at the very be- ginning of or even before the Silurian age, and if they were found to-day it would indicate a survival through periods longer than any form has been known to exist. They would thus be obstacles rather than arguments for the descent theory. And to take another somewhat different case : the demand for the "missing link" between man and the ape, at one time so strenuously urged, has been nearly abandoned, for it is recognized that the very fact that man has arisen, necessitates the disappearance of his primitive ancestor.

But evidently these links must have existed at some time, if not to-day, yet in the past. We ought to expect, therefore, that the various types, although not connected by living forms, are connected by fossil forms. This question is treated more at length in another chapter, and it is here only necessary to say that even by fossils the subkingdoms are not connected. No fossils have been discovered which unite the sub-kingdoms with each other, the earliest animals known belonging to one or another of the types; a fact which forms one of the chief difficulties which evolution has to meet. 
But although this is true, fossils do enable the naturalist to classify all divisions within the subkingdoms, in a tree-like arrangement, by presenting numerous links. To consider briefly an example. The vertebrates to-day consist of many widely separated orders unconnected by intermediate forms. But fossil vertebrates are very numerous, and in a great many cases fall into gaps between existing orders. The Ungulates, the Proboscidea, the Hyracoidea, and the Sirenia, can all be traced backwards by converging lines, until they meet at a point represented by a mammal of the lower tertiary. The Cetacea, Carnivora, and Rodents in like manner approach each other. The birds and reptiles approach ancient Cretaceous forms, which represent their common point of origin, although the record is less perfect here than in the case of mammals. Beyond the Cretaceous the record is so incomplete as to make the history less positive: but the evidence, as far as collected, points to the union of all the classes of vertebrates in some ancient fish-like form which lived in the Silurian age. In no case is the record of these lines complete; even in the most perfect instances there are many gaps. But fossils do show many of the intermediate links for which we are searching, and beyond a shadow of doubt the paleontological record indicates that the classification of the animals within any given subkingdom is such as is represented by the tree-like arrangement of expressing relations.

In order to complete the evidence that this represents the true classification of the whole animal 
kingdom, it is necessary to show that the sub-kingdoms-the types of Cuvier-are themselves connected at the bottom. This, we have seen, cannot be done by living animals nor by fossils, but a third source of evidence makes it possible. The subject of embryology is also reserved for a later chapter. The last few years' study in this subject has shown that there is no lack of evidence that the great types can be united in some common ancestor of ancient times. Embryology enables us to connect the different sub-kingdoms with each other at a common starting-point, and to trace this common form still further back toward the simplest animal. And thus our tree of classification has a trunk. If we take any two animals and trace their embryology backwards, we find them becoming more and more alike, until they finally merge in a common form in the early part of their history.

And, finally, it must be noticed that not only do the sub-kingdoms approach each other and unite at a common point, but the two kingdoms of organic life, animals and plants, in a like manner, converge. So evident is this, that it has led to the establishment of a third kingdom of organisms, neither plants nor animals, but representing the union of the two. This kingdom, called the Protista, contains a number of microscopic forms. Although the advisability of forming such a kingdom is very questionable, the very fact that it has been done by some naturalists is sufficient indication that the animal and vegetable kingdoms do approach each other at the bottom. 


\section{The Value of this Tree-like Classification.}

When now this sort of classification, as taught by anatomy, paleontology, and embryology, with its implied theory of genetic descent, comes to be applied to interpreting the existing animal kingdom, it is found that a wonderful light is thrown upon the whole subject. This conception has, of course, gradually grown out of the older one, and has only step by step taken its place. The nominal relation. ship of animals remains, therefore, much the same as it has always been, although many are now classed together which were previously thought to be separate, and many are now widely separated which were previously thought to be closely related, and many animals whose relationship was formerly a complete mystery, are now easily understood. For the term relation has now a meaning, and it is seen that an animal may be a vertebrate, and still show some relationship to other types. To use the words of a modern writer: "All the enigmas of structure become resolved; representative and aberrant, progressive and degraded, synthetic and isolated, persistent and prophetic types no longer baffle comprehension." It becomes evident that there is a real meaning to the term natural classification, a fact long since recognized, but not understood. We can understand now why it is that organs of the least importance to the animal are usually of the greatest weight in classification; for organs of no functional importance can only be explained by inheritance from some ancestor in which they were useful; and since they are of no present value, they 
will not be modified to suit the surroundings, but will (until they finally disappear) retain something of their primitive structure. The common possession of these organs is, therefore, an evidence of common descent, and since they are slightly modified, they will be the most important features for determining relations. It is seen, on the other hand, why it is that adaptive likeness, such as that between the fish and the whale, is of no use in classification. It becomes evident why indeed it is that the rudimentary teeth in the jaws of the embryo whale are of more importance, as indicating relationship, than the whole of the remarkable resemblance to the fish. Nearly all of the somewhat intricate principles of classification, arrived at originally from purely empirical grounds, can now be elucidated by a clear understanding of this principle and explanation of classification. In short, it becomes clearly evident that the true classification of the organic world is not in isolated parallel lines, as was previously believed, but after the form of a branching tree. This sort of classification may therefore be looked upon as definitely settled by the combined aid of paleontology, embryology, and the comparative study of adult anatomy, although it was originally the result of the conception of evolution.

Although this conclusion may be regarded as settled, it of course by no means proves the descent theory. What it does prove is that the facts are in harmony with the descent theory and are not in harmony with the older idea of types. It is perfectly possible that the idea of types and of special creation 
can be modified so as to be in accordance with all of the facts mentioned. The force of the evolution argument here is not in the impossibility of making some other theory to fit the facts, but in the fact that (I) all other theories are supernatural explanations rather than natural, and (i) that they are unnecessary, for the simple theory of descent is entirely sufficient to explain the classification of the organic world.

Application of the Theory to the Explanation of Homology-Homology in General-Serial Homology.

Let us now turn to some of the minor applications of the argument and see how the theory explains some special features. First let us notice the explanation of homology in general. Homologous organs are those whose structures are alike, though their functions may be entirely different; for instance, the short useless tail of the hog and the highly developed prehensile tail of the monkey are homologous; or the arm of a man and the wing of a bird. Analogous organs are those whose functions are alike, though their structures may be very different; as the bird's wing and the butterfly's wing. Analogous likenesses are plainly of secondary importance, existing because the organs in question have similar functions. Homologous likeness is of much more significance, since it exists in spite of differences in function and clearly indicates some fundamental likeness between animals. The whole subject of comparative anatomy or morphology is the study of homologies of structure. When 
two animals somewhat closely related are compared, let us say the dog compared with man, it is found that they are built upon exactly the same plan, and can be compared with each other bone for bone and muscle for muscle. The more thorough be the comparison the greater appears the likeness, for the very abnormalities strengthen it. Muscles occasionally found in one are universally present in the other; and so with special protuberances of bones, with nerves, and with almost every other feature; everything shows that there is a complete homology between the bodies of different vertebrates, and it is the duty of the anatomist to discover these homologies.

What is the exact answer which the theory of evolution will give to the question of the real explanation of this homology? A man's arm and a bird's wing are organs with totally different functions and very different in shape; yet in spite of this difference they are fundamentally alike in their muscles and bones. The theory of evolution will say that this likeness is due to the fact that both man and bird have descended from a common ancestor, living long ago, which possessed an appendage, neither an arm nor a leg, but containing the fundamental structure of both, i.e., the features which they possess in common. The descendants of this ancestor in the course of many generations became modified in two directions and their appendages were correspondingly modified. On the one hand the descendants became flying animals and the anterior limb was developed into a wing, retain- 
ing, of course, its fundamental features, but changing its shape to suit the change in function. On the other hand, the descendants remaining terrestrial, the limb became a grasping organ, likewise retaining its fundamental structure. Thus the theory of descent with modification explains both the similarities and the differences between homologous organs, the former being due to inheritance and the latter to variation. And as far as instances of this kind are concerned the explanation is certainly sufficient.

But there is another very different class of homologies which cannot be thus explained. What can be said of the homology which exists between the arm and leg of a man, between the wing and leg of a bird, between the members of the long series of legs of the lobster-in short, between all sorts of serial organs? Here is an homology as exact as that in the case considered above. Every bone in the arm has its homologue in the leg; every appendage of the lobster is strictly comparable, joint by joint, with all the others. Indeed, the exactness of this serial homology is frequently more complete than that of the general homologies above referred to, and it is very evident that this type of homology requires an explanation just as truly as did the first. But the explanation given to the first case will not apply here. Let us see what would be the result. Using the above explanation, we should say that the arm and leg owe their likeness to the fact that they have both descended from a common ancestor, which possessed the funda- 
mental features of both. Now this means absolutely nothing, for it necessitates the assumption that there once existed a vertebrate with only one pair of appendages; and no one has the hardihood to make such a claim. In such serial appendages we have, therefore, an homology which is not open to the explanation given to homologies in general, and the fact that the explanation will not apply here makes it at least a legitimate question whether it is sufficient in the other cases. At all events, unless some other way of accounting for serial homologies can be discovered, it can hardly be claimed that the reason for homologies is understood. The whole argument for descent, derived from comparative anatomy, is, in a measure, weakened unless these cases be met.

Spencer has attempted to answer this question in accordance with the theory of evolution. $\mathrm{He}$ would distinguish two sorts of serial homologies which have had different origins. The first is that which is found in Crustacea and other animals, where the whole body consists of a series of equivalent segments, each having essentially the same parts. This sort of segmentation has arisen, according to Spencer, by multiple division. Many low animals possess the power of dividing into two parts, each of which is like the other. Every organ shares in this division. If now, as frequently is the case, these two segments, instead of completely separating from each other, remain connected after the division is nearly complete, we should have a compound animal of two segments, in which every part 
is duplicated. Supposing this division to continue, we should soon get a chain of individuals which grows longer and longer, and if the segments remained connected, the result would be a segmented animal, each segment of which is homologous with all the others, for the simple reason of descent. The serial homology of the appendages of such animals is, therefore, explained in a manner quite similar to that of the first class. Whether this theory is correct, is not definitely agreed upon by naturalists. It is true that such a division does take place in many low animals. But it is also true that there is no tendency shown to form thus single segmented animals, but rather chains of independent individuals; and further, the embryological evidence derived from Crustacea is opposed to the view.

But whether this theory of Spencer be true or not, does not materially affect the argument we are considering, for it will not, does not, apply to the homology of the four appendages of vertebrates. If ever the vertebrates were derived from the division of a primitive unsegmented animal, as above suggested, it was very long ago, in fact before the animals possessed bones at all. Even supposing that the appendages did originally owe their likeness to such descent, the homologies between the bones which have since appeared must be a later acquired feature. The appendages must have grown alike. Moreover, embryology has shown that the earliest vertebrate appendages were very unlike the leg or arm of man, and this is another proof of the secondary character of their present homology. Indeed, 
Spencer does not attempt to apply his previous explanation here. He thinks that the segmentation of vertebrates, $i$. $e$, the division of the spinal column into vertebræ, arose as the result of strains. Originally the vertebrate was unsegmented, but in bending its body from side to side in locomotion through the water, its spinal column became divided by the action of the simple mechanical force. But with this understanding of the segmentation, the explanation of the homology between the leg and arm is lost. Spencer simply says that this homology is due to like conditions acting on the two appendages. But plainly we are no better off than we were to start with, when we remember that similar conditions do not always produce the same results, and that almost everywhere can be found instances where the same structure is preserved in spite of different conditions. It is palpable that, when Spencer tries to account for serial homology in vertebrates by likeness of conditions, he has simply abandoned the question altogether.

But, moreover, we have absolute proof that this sort of homology is due to some internal cause rather than external conditions. Many abnormalities of structure show this: instances where extra digits occur on both hands and feet, or the absence of the same digit on both hands and feet; instances of both hand and foot being similarly affected by peculiar diseases; the development on the feet of birds of wing feathers like those of the anterior appendage. Enough cases of this kind are known to make it plain that there is some sort of internal 
connection between serially homologous organs. Since, then, the likeness of these appendages cannot be due to inheritance as commonly understood, and since such cases as those just given indicate some intimate internal connection between them, it is evident that the theory of descent will not account for serial homology. It is necessary to admit, unless some further explanation can be found, that homology does not prove descent.

One other way out of the difficulty has been suggested, still in accordance with the theory of descent, though applied in a very different line. This suggestion, first advanced by Darwin, asks if it is not possible to turn to the developing ovum for assistance, and suppose that the internal bond of likeness may be due to the fact that the parts in question are derived from similar parts of the ovum. The first change which takes place in the developing ovum, is its division into a number of segments or cells. After this division has continued for some time, until the cells are quite numerous, certain cells are set apart to become developed into certain parts of the adult. Now we can assume that one of these cells is destined to form the four appendages. This cell goes on dividing, and the resulting cells are moulded into the form of the legs and arms. It is easy to see, therefore, that the leg and arm would show a tendency to develop in similar directions, since they have descended from the same cell of the embryo. Serial homology of all sorts thus receives an explanation compatible with that given to the more general cases. Every 
instance of homology is due to descent from a common ancestor, but when the organs compared are upon different individuals the common ancestor was a remote independent animal, and when the organs compared are upon the same individual the common ancestor is a simple embryonic cell with no appendages but with power to produce them. The likeness between the man's arm and the bird's wing is due to descent from an ancient intermediate ancestor, that possessed an appendage with the fundamental structure of both wing and arm. Man's leg and arm owe their likeness to descent from a certain cell, arising from the ovum, which has given origin to both.

This idea has been too little discussed to justify any conclusion as to its adequacy to meet the question, for indeed it has been hardly more than suggested by one or two writers. There is some embryological evidence in its favor, though as yet not very extensive. It is certainly an internal connection which many facts demand, and will enable us to understand why the two arms and two legs are liable to similar diseases, or why abnormalities occurring in one would not be unlikely to occur in all the others. Because any influence acting on the embryonic cell would affect all appendages alike, it would readily account for serial abnormalities of such organs, of which numerous instances occur. Whether it is sufficient to explain the exact homolologies so noticeable in serial organs is not quite so clear. But admitting this as a partial explanation, we introduce a new factor into our theory of descent, 
which is called embryonic or ontogenetic descent. And this is a factor of which almost nothing is known, and whose limits are as yet undrawn. One naturalist, as will appear later, is inclined to make this the all-important factor in heredity. But we know too little of the real value of this hypothesis to justify us as yet in admitting that it is sufficient to clear up the vexed problem of serial homology. Evidently this new factor will not explain homologies between different animals, any more than the ordinary theory of descent will account for serial homology, although both are explained by descent. If we can accept this theory the descent hypothesis becomes logical as far as homologies are concerned. If not, we must wait for another; at best, we must admit that the subject is still a perplexing one.

\section{Rudimentary Organs.}

An important feature in connection with the classification of animals and plants, is the series of organs known as rudimentary organs. They have always been an object of interest, for, utterly functionless, their presence seems entirely unaccounted for unless they are assumed to be rudiments of organs previously of value. Every one is acquainted with examples. The coccyx of the human skeleton represents the tail of other mammals; the so-called splint bones of the horse's feet are the remains of the lost fingers and toes; the rudimentary legs of the boaconstrictor, which do not protrude through the skin; the rudimentary teeth in the whale, which never pierce the jaw so as to become in the slightest 
degree functional; the gill-slits in the embryo chick; the aborted pistils found in staminate flowers; all these and numerous other instances will occur as illustrations of rudimentary organs. All of these structures are, without the slightest question, homologous with similar structures well developed and functional in other animals and plants. They are of no use to their possessors; they may be widely distributed, and yet very variable, being found almost exactly alike in distinctly related species, while of two closely related species, one may possess them and the other have almost no trace of them. Frequently they are of the greatest value in classification. They must be comprehended in any explanation of the organic world, and no theory of classification can be for a moment entertained, which does not have its explanation of these organs.

The theory of types meets the question in a manner which at first sight seems to be intelligible. Animals are built according to certain plans, and it is necessary, in order that the plan be complete, to have all its parts represented. For symmetry of plan, therefore, all of the usual parts must be present, but since, in many cases owing to different habits, some of them may be useless, they are quite naturally permitted by the designer to be rudimentary. But aside from the fact that the whole idea of types is unsatisfactory, it is evident that in this case it is inconsistent with itself. If all closely related animals were thus supplied with the requisite rudimentary organs, this explanation might do, but where one animal possesses them and another almost like it in 
other respects possesses them not, the idea of types becomes plainly inadequate. It may be said that the boa-constrictor possesses the rudimentary legs that the vertebrate type may be complete, but why are they wanting in other snakes? No intelligible reason can be given why the type should be adhered to in one case and not in another. Here again we find the theory of types lacking.

The theory of descent has a better explanation, though it is not in all respects satisfactory as yet. In this theory it is necessary to distinguish two classes of rudimentary organs, aborted organs, and nascent organs.

Aborted Organs.

Aborted or atrophied organs are, according to evolution, actual remnants of organs, which were functional at one time in the history of the ancestors of the animals now possessing them as rudiments; but which, on account of some change in the habits of the animal, became no longer useful, and consequently by disuse gradually became smaller until they are finally simple rudiments. The ancestors of the boa-constrictor were animals which in common with all other reptiles possessed legs; but this animal, from some change in its environment, acquired creeping habits, and its legs were no longer used. Through disuse they began to atrophy, and finally nothing remains of them except the rudiments now found. In most snakes they have completely disappeared, but here, for some reason, perhaps they were used for a longer period than in 
other cases, they have not totally disappeared, but remain as rudiments. The splint bones of the horse's foot, as abundantly proved by fossils, are remnants of toes, formerly well developed and func. tional in the horse family, but which have become useless and consequently reduced. Of the five toes which were formerly present, two have completely disappeared, two remain as rudimentary splint bones, while the fifth is well developed and functional. And similarly through the simple influence of disuse nearly all cases of atrophied organs are simply and naturally accounted for.

But this explanation, though unquestionably superior to the other, is not yet quite satisfactory, and meets difficulties in at least two points. First, it will not explain all rudimentary organs. Each sex possesses rudiments of organs found in the other. The mammæ on the breasts of the male mammal are truly rudimentary organs, and their presence can hardly be explained by inheritance. This difficulty is quite similar to the one considered above in regard to serial homology. We can hardly suppose that the male mammal ever possessed mammæ, which through disuse have become aborted, although even this position is held by some naturalists, who instance the fact that it is the male in many species who cares for the young. But this hypothesis will not be received as an answer by many; and we must admit that such rudimentary organs are unexplained, unless we say that one sex has a tending to inherit the characteristics of the other sex. A second difficulty, somewhat more serious, is to 
understand how these organs could have become so much aborted by simple disuse; or even more, to see how they could have disappeared completely. Darwin has recognized the difficulty. "After an organ has ceased being used, and has become in consequence much reduced, how can it be still further reduced in size until the merest vestige is left; and how can it be finally quite obliterated? It is scarcely possible that disuse can go on producing any further effect after the organ has once been rendered functionless. Some additional explanation is here requisite, which I cannot give." From this passage it is evident that the theory of descent, at least as understood by Darwin, has still something to explain at this point.

It must be noticed, however, that the difficulties here mentioned are not necessarily difficulties for evolution, but only for certain theories of evolution. Pure Darwinism meets serious obstacles at these points. The trouble is simply in our understanding of the manner in which organs could have become rudimentary; and although we may not yet comprehend this, the presence of rudimentary aborted organs is just as significant an argument for descent as it would be did these difficulties of method not exist.

\section{Nascent Organs.}

The second class of rudimentary organs are those which Agassiz has been pleased to call prophetic organs, and which evolution would call nascent organs. They are organs which, very simple in low 
animals, seem there to foreshadow the coming of homologous organs, highly developed in higher animals. As good an example as can be chosen of a nascent organ, is the air-bladder of fishes. It is of very little use to the fish, or, at all events, is only valuable for a hydrostatic apparatus; but it occurs in such relations as to show that it is the undoubted homologue of the lungs of land animals. Occurring in low animals, while lungs only belong to those more highly developed, it cannot be regarded as the aborted remnant of a previously functional lung, for the ancestors of fishes never possessed lungs. Agassiz considered them to be prophecies of the coming lungs; an idea in perfect accordance with his general theory of types existing in the Creator's mind, but of no meaning otherwise.

But the theory of descent has also its explanation of these cases, which is as intelligible, and has the advantage of being natural rather than supernatural. These organs are considered not as remnants but as beginnings. They are new organs, capable of further development, and not organs on their way toward disappearance. The theory claims, moreover, that they are not functionless, like those resulting from disuse, but are of some value to their possessor, although the value may be a slight one. Every organ, according to the descent theory, must make its appearance as a very simple structure, which gradually develops, generation after generation, and in the course of time may become very greatly developed. A very simple organ in a low animal may therefore evidently be some such rudi- 
mentary beginning. To use once more the above illustration: the descent theory would say that the air-bladder of fishes is not a useless organ, being of importance as a hydrostatic apparatus, and its presence in the fish is explained, not as a prophecy of coming lungs, but as being of direct use to the animal. The theory would go on to say, that this airbladder in certain fishes in the past became more complicated, and that in some cases there was developed within its walls a considerable supply of blood-vessels, so that by taking air into this airbladder the fish could carry on a certain amount of its respiration. And this is not hypothesis simply, for some fishes (Dipnoi) do make use of swallowed air in this way. Now these fishes, the theory goes on to say, being able to respire slightly by means of this highly developed air-bladder, would be able to survive if left upon the beach for a short time by the retreating tide. Perhaps they would acquire the habit of escaping from their enemies by retreating into shallow water when the fall of the tide would leave them for some time exposed to the air. Such favored individuals would survive and multiply, and the habit of breathing air would become more marked. Finally, the air-bladder would become so well developed by use, that its possessor could live for a long time out of water, breathing air by its means, or could still live in the water like a fish : a condition found in the amphibia. A true land animal would thus arise breathing by means of lungs. Meantime other fishes whose air-bladders did not present these favorable variations, or who did not 
make use of them, would still retain this organ as a hydrostatic apparatus. And thus we find the airbladder to-day the homologue of the lung, but not a remnant of a formerly functional lung, nor a prophecy of a future lung, but a rudimentary beginning, which is or has been capable of further development. It is not, of course, claimed that such has been the exact history of the development of the lung, for of exact history we are profoundly ignorant. The example has been taken as an illustration of the sort of explanation which the evolution theory has to offer for nascent rudimentary organs. It was the presence of this highly variable air-bladder which enabled the early land animal to leave the water, for a short time at first, but afterwards for longer periods. The rudimentary lung, or vascular air-bladder, did not appear in order that animals might become air-breathers, but animals became air-breathers to escape their enemies, as soon as their air-bladders, varying by chance or otherwise, enabled them to do so. This air-bladder was the cause of air-breathing, but not, according to the descent theory, created for this distinct purpose. They were the predecessors, but not the prophecies, of lungs.

It is by no means always possible to determine of a given structure whether it be an atrophied remnant or a nascent organ; and indeed sometimes it may partake partially of both characters. It would be expected that an atrophied organ would be very similar in form to its developed homologue, but much smaller, and with various parts lost or fused 
together; while on the other hand a nascent organ would probably be very different in many respects. Again, an atrophied organ would always be functionless, while a nascent organ would have some function, though frequently a different one from that possessed by its developed homologue. Thus it is easy to decide that the rudimentary leg of the snake is an atrophied organ, while the fin of a fish is probably to be considered as a nascent structure. But although it may not always be possible to distinguish into which category to place a given organ, it must be recognized that the theory of descent as well as the theory of types comprehends and explains both.

\section{Summary.}

A careful study of living things has been slowly but persistently forcing naturalists to the conclusion that the organic world forms a unit. Species are found to graduate into each other, and so, too, do genera show connecting links. If we take into cogrizance the discoveries of paleontology, we find that the larger groups of families and orders exhibit the same tendency toward convergence. And when, finally, we consider the evidence of embryology, the great sub-kingdoms, and even the kingdoms of animals and plants, come together. The whole organic world is thus found to be related in groups subordinate to groups, a relation which is diagrammatically represented by a highly branching tree, each twig of which is related either closely or distantly to every other. And that such a conception of the re- 
lations of the organic world represents the true one, is admitted by all who have taken the trouble to study into the matter.

Recognizing that a classification exists, it is necessary, if possible, to give some reason why it should exist; recognizing a unity, it is desirable to find the bond of union. In answer, only two important theories have been advanced-the theory of types, which finds the bond of union in the creating mind, and the theory of evolution, which finds it in the principle of descent. The first, in spite of the masterly attempt of Agassiz to establish it, has been constantly losing ground since the appearance of the second. The impossibility of deciding even as to the number of types, to say nothing of the impossibility of defining them; the infinite number of sub-types, and types within types, required to explain smaller groups; the impossibility of finding a position for many animals under any of the great types; the gradual approach of the groups toward each other in their simpler and earlier forms, and if embryology be taken as evidence, the union of the sub-kingdoms, and kingdoms with each other, at a common starting-point; and finally (and this has in reality had more weight than the rest), the fact that this explanation is a transcendental and not a natural one;-all of these considerations have led to the gradual abandonment of the theory of types.

But the disproof of the first theory does not, of course, prove the second. Each must stand on its own merits, and not upon the disproof of the other. We do find, however, that the evolution theory is 
in accordance with the evidence. Upon examination, it is found to fit the facts marvellously well, and to do away with many perplexing problems. With careful study this theory has been found to offer a simple explanation to many classes of facts which had hitherto been troublesome puzzles. The theory has, it is true, raised certain difficulties of its own, for it has found itself unable to explain every thing. The problem of serial homology, and the difficulty of understanding the degradation of organs to a rudimentary condition, and their final disappearance, are the chief ones, but even these are difficulties for Darwin's explanation of evolution, and not for the descent theory itself. Admitting, however, their full force, they are not sufficient to offset the great advantages offered by the descent explanation. No one thoroughly acquainted with the organic world hesitates to say that the theory of descent must be admitted as a factor, though perhaps not the only .factor. As a conclusion from the study of classification, it seems that we must either accept evolution as the explanation of the bond of union in the organic world, or wait for some other better theory, of which the descent idea will doubtless form a part.

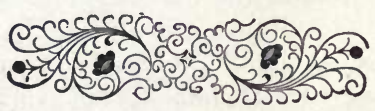




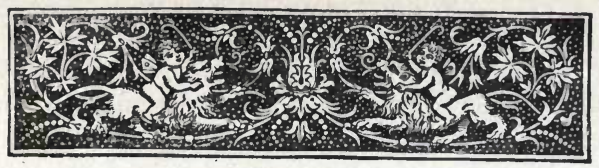

\section{CHAPTER III.}

\section{LIFE DURING THE GEOLOGICAL AGES.}

THE fossils of the stratified rocks are believed to give a history more or less complete of the life of the world during past ages. Here it is, therefore, that we should expect the most complete evidence toward settling the question of the origin of species. If existing organisms have been slowly evolved from others, and if paleontology gives us a history of the past, we might here expect something like proof. The necessity of appealing to paleontology has been seen by all scientists, and one of Darwin's most difficult tasks was in endeavoring to reconcile the known facts of this science with his views of evolution. For it is safe to state that paleontology has offered to Darwin and his followers greater difficulties than any other branch of science. Here, where it would seem the strongest evidence might be expected, have been found the most serious obstacles, and the evidence has been the weakest. At least this was true at the time of the appearance of the "Origin of Species," and Darwin with his usual candor acknowledged the great difficulties thus arising. Since that time there have been great additions to our collections and knowlege of fossils, and 
a great amount of positive evidence has been accumulated. But the subject is still in an unsatisfactory condition, and in spite of all advance the chief difficulties occurring to Darwin and others thirty years ago have not been removed, but stand out as boldly as ever. The evidence collected has, it is true, added very much positive evidence in support of the general theory, and in many cases we now have practical proof of the gradual origin of species from each other. But even yet there is not the slightest difficulty for any one so inclined to point out many places where paleontology disagrees with the deductions of evolution, for the past history of the world as taught by its fossils still offers many difficulties to the descent theory.

\section{Imperfection of the Record.}

It has been clearly recognized by all scientists, that it is absolutely impossible to reconcile paleontology with evolution, unless it be assumed, to start with, that the history of animals which we get from fossils is extremely imperfect. According to evolution, our present species are descended from others, quite different from them, living in the past. Not long ago, the various species of our now existing genera were simply varieties of an ancestral species. Still earlier, the genera of our present families were in turn only varieties of a still older ancestral species. The present orders and classes also ought gradually to converge toward some very ancient generalized ancestor. All of this history has been a continual slow growth, according to the ordinary con- 
ception of evolution. There have, therefore, existed between the animals of to-day and their ancient ancestors a long series of intermediate links. In each case these connecting individuals will differ from their parents no more than the child differs from its parents to-day. But the number has been so great that the slight differences accumulated through the ages have finally amounted to wide distinctions. If fossil history gives us any thing like a complete record of the past, all of these stages, or at least many of them, ought to be found. By means of fossil links, therefore, all generic and specific differences should disappear in a graduated series of connective links.

But no one ever pretended to claim that any such a series could be found. Paleontology at the time of the appearance of Darwir's book showed very few such connecting links; while to-day many more are known, they are really as nothing compared with the countless numbers which must have exexisted. We know enough of fossils to-day to cause us to abandon hope of ever making out such a complete history as the theory calls for. Perceiving the great lack of these intermediate stages, some naturalists have been led to modify the first conception of evolution. Many hold the position to-day, that development in the past has not always been slow and gradual, but by alternate periods of rapid development and comparative rest. This saltatory evolution, as it is called, does not demand such a long series of intermediate links. It assumes that under certain unknown circumstances species are very rapidly modified, and that a few generations 
only are required to produce much change. If this were true we would only expect to find evidence of the periods of rest, the periods of change being too brief to give much chance for preservation. While, then, fossils do not show the numerous stages of a slow evolution, it is possible that the fossil record may be in harmony with this saltatory evolution.

But even with this modified and more favorable form of evolution in mind, the record of paleontology cannot be regarded otherwise than as remarkably imperfect. Its imperfection is indeed a necessity for evolution. Nor can there be the slightest doubt as to the teaching of recent years on this matter. All evidence from every source emphasizes the fact that the paleontological record is very imperfect; that the few animals which we have preserved are almost as nothing compared with the countless myriads which have disappeared and left no trace. Indeed recent years would indicate that this imperfection is even greater than assumed by Darwin. The discovery, in quite a number of cases, of a single imperfect specimen of an animal in a bed of rocks whose accumulation must have taken thousands of years, is a slight indication of what we may look for in this direction. The causes of this imperfection are very varied. The chief are as follows: (I) Only those animals which possess some sort of hard skeleton can be preserved as fossils, soft animals leaving almost no impression in the sedimentary rocks. This is demonstrated by the fact that about nine tenths of the orders which are entirely unrepresented in the 
rocks have no skeleton. This is the more important, because in very many cases the animals which we must look for as ancestral types, could have possessed no skeleton. For instance, the original vertebrate ancestor could not have had a skeleton, and we can therefore have no hopes of finding any record of its existence among fossils. (2) Fossils can only be deposited during the accumulation of sediment, and, therefore, during periods of slow subsidence at the localities in question. All periods of elevation, or of rapid subsidence, will be almost or entirely unrepresented in the geological record. How great these gaps may be, we have no means of determining, but they are doubtless enormous. (3) Fresh-water and land animals can only be preserved by being carried to the sea, or some inland lake which is filling up; or by being deposited in the river beds. Evidence of this is found in the great scarcity of fresh-water fossils, and particularly in the remarkable scarcity of insects in all rocks-a group which must have existed in numbers, but whose light bodies prevent them from sinking to the bottom of the water. (4) Many of the rocks, particularly those of the earlier ages, have been subjected to such great metamorphic changes, that whatever fossils they might once have contained have been entirely or partially destroyed. These four factors, with other minor ones, have appeared sufficient to geologists to justify the belief in almost any amount of imperfection in the geological record.

This imperfection is certainly growing less with the continual study of new localities, for many gaps 
are being thus filled. One striking evidence of this is in the gradual disappearance of the lines of demarkation between the different geological ages. Geologists no longer recognize the history of the world as divided into distinct ages, but look upon it as continual progression. The lines of demarkation between the formerly accepted ages are due to the almost universal gaps in the record at certain periods-gaps which are slowly being filled by new discoveries.

Having reached this conception of the imperfection of the record, the evolutionist seems to have assumed an unassailable position. For whatever connecting links chance to be found, they are immediately claimed as positive arguments, while the difficulties arising from absence of links are readily answered by appeal to the imperfection of the record. It is not easy, therefore, to discuss the subject except by beginning with the begging of the question.

\section{The First Appearance of Life.}

The chief difficulties offered by this branch of science to the theory of evolution, cluster around the life of the Silurian age, the earliest age in which fossils appear. The still earlier archean rocks do contain the well-known Eozoan Canadense, which is supposed by some to be a fossil. But it is very questionable whether this deposit is any thing more than a mineral. It is found in the oldest rocks, which contain no other traces whatsoever of any other organic remains. Dawson, its discoverer, 
believes it to be a low foraminiferon; but later researches make this very doubtful. The direct examination of the deposit itself scarcely lends support to the belief in its organic nature. It is found in the lower Laurentian rocks, which are covered with thousands of feet of rocks less metamorphosed than those containing the Eozoan, and yet themselves containing no fossils. It now appears, also, that this so-called fossil is sometimes found in veins in the rocks, and this position is utterly impossible for a true fossil. These facts, therefore, render it improbable that the Eozoan is any thing more than a mineral deposit; and lead to the conclusion that the first traces we have of life begin with the Silurian age. But whether it be a true animal or not, does not materially affect the difficulties surrounding the sudden appearance of a highly differentiated fauna in the very beginning of the Silurian age. The first record we have of life is very surprising. Instead of a few low forms of life, instead of a few synthetic genera, the Silurian age was supplied with a highly developed fauna of comparatively highly organized animals. All of the great types were represented: Coelenterata, Polyzoa, Brachiopods, Echinoderms, Mollusks, Worms, Arthropoda; and the late discoveries of Claypole have traced the vertebrates not indeed to the bottom of the Silurian, but to the bottom of the upper Silurian rocks, a number of remains proving that fishes were then in existence. Within a few months two scorpions have been added to the Silurian fauna, adding another class to the already 
extensive list. It is true that not all of these animals are found at the very bottom of the Silu. rian, but even in the oldest rocks the fauna is sufficiently diverse: and before the age is over, all of the important classes of animals have made their appearance without previous warning. This sudden appearance of life is certainly unexpected. The possible organic nature of the Eozoan in the older rocks is no help toward solving the difficulty. Should this prove to be a fossil, it only shows that it was possible for fossils to be preserved during the pre-Silurian times. Evolution must, of course, suppose that it was during this period that the first forms of life were developing into the condition which we find with the beginning of the Silurian. The question is even more forcibly asked, if the Eozoan be a fossil, why we find no trace of this early fauna?

The only possible explanation of this sudden appearance of life in the Silurian, is an appeal to the incompleteness of the record. Vast periods of time must have elapsed before the Silurian times, during which the world was peopled with living things, every trace of which must be supposed to have been lost. There can be no doubt that there was an enormous period of time between the solidifying of the world and the beginning of the Silurian. But whether the world was inhabited at this time it is impossible to prove. That a long period elapsed between the latest pre-Silurian rocks of any one locality and the earliest Silurian, is also unquestioned. But how long this lost period might have 
been, is simply a matter of conjecture. The two periods together must have been long enough to account for the development of the Silurian fauna out of the simplest form of animal, or the evolution theory falls to the ground. Whether this appeal to these enormous lost intervals is considered sufficient to explain the sudden appearance of life in the Silurian age, will depend largely upon one's previous views as to the significance of the whole question of evolution. If we wish to accept evolution, we can readily believe this explanation to be satisfactory; if we do not wish to do so, we can find here an almost insurmountable difficulty.

This same difficulty of time has been attacked from another standpoint, by an attempt to reduce to years some of the intervals. Darwin has set as the lowest limit which he considers necessary for the development of the now existing species, three hundred millions of years. Mivart, ostensibly taking the facts given him by Darwin, considers that twenty-five hundred millions of years is nearer the limit. This estimate is, however, worthless, as the very data upon which it is founded are simple guesses. On the other hand, Sir Wm. Thomson has concluded from cosmic phenomena, that the solidification of the earth took place probably not more than one hundred millions of years ago. Dr. Croll considers this conclusion almost indisputable. The age of the inhabitable world is thus much less than the necessities of Darwinism demand.

These estimates can only be reconciled by shortening the time required for the development of 
species. The estimates of the age of the world, made from geological researches of late years, are smaller than those of twenty years ago, and fall readily within the estimate of $\mathrm{Sir} \mathrm{Wm}$. Thomson. The only difficulty lies in Darwin's three hundred millions of years. Now this estimate of Darwin is nothing more than a guess. We know almost nothing concerning the rate of modification of species to-day, not to speak of our absolute ignorance of what it may have been in the past. Sir Wm. Thomson insists that the physical changes were more rapid in early times than they are now, and this would necessitate a proportionate rapidity in the changes of the organic world. Moreover, modern embryology, as we shall see in the next chapter, seems to indicate that the history of animals has not been so long and circuitous as was once supposed. Instead of passing through a long series of great changes, all of the large groups of animals, even the vertebrates, have had a direct simple history from the simplest multicellular animal. This early ancestral animal branched off directly into several directions, and thus the time necessary for the development of a diverse fauna like that of the Silurian age is less than could formerly be supposed. Again, the time since the Silurian age has been sufficient to develop the group of vertebrates from its simplest form to its present condition, and an equal amount of time, and probably a much shorter period, before the Silurian age, would be amply sufficient to account for the primordial fauna. The duration of this period in years is of 
little importance to our subject, the amount of geological change being the important factor; for rapid geological changes will cause rapid organic developments. If, then, it is true, as embryology teaches, that the first variations from the original ancestral type produced directly the various subkingdoms of animals, and if, further, the changes were more rapid at this early period, it becomes probable that the time required for the establishment of the types of the Silurian period, was not so long as would be required for what would seem to be an equal amount of change in animals as they exist to-day.

The Absence of Generalized Forms from the Silurian.

This old Silurian fauna is puzzling in another respect. It is undoubtedly a highly specialized fauna. It has been and is still forcibly urged that, according to evolution, the farther back we go, the greater and greater should be the generic likeness of fossils, and the less and less their specialization. For if our classes, orders, and genera existed at any time as simple species, the fossils ought all to be more or less generalized forms; $i$. e., forms possessing the fundamental characters of all the classes that arise from them. The oldest fossils ought to be almost entirely of this character. The number of species should become less and less, and it might be expected that in the earlier ages we should find almost nothing corresponding to species, since no specialization would have taken place. But it is further pointed out that this is not the teaching of paleon- 
tology. At the beginning of our record of life, the world was not filled with a few generalized types, but with an already well-differentiated fauna of genera and species. For instance : the Echinoderms, instead of consisting of a few generalized types, were already divided into the perfectly distinct orders, Crinoids, Blastids, Cystids, Asteroids, Ophiuroids, and Echnoids. All had their special genera and species, and almost none of them such as can be imagined to have given rise to the groups of later times.

This claim is, however, partially a misunderstanding, for it seems to imply that we should expect to find animals which were purely generalized, with no specific characters. The most comprehensive types which ever existed must have had, along with their general characteristics, their own special features, which adapted them to surroundings. While they would be synthetic in that they shared the characters of many different forms, each one would also be distinctly specialized. No animal could exist without having definite shape, size, color, etc., and these characters would be specific. It is, then, not at all surprising that we find even in the Silurian a specialized fauna and flora, for it could not have been otherwise. And, moreover, it is perfectly intelligible that some of the simple groups, even at that early date, could have become highly specialized, as highly, in fact, as they became afterwards. The force of the difficulty here, as far as it is a difficulty, lies not in the presence of specific distinctions, but in the absence of generalized characteristics. 
It must not be understood, however, that no synthetic types have been found at this early period, for many are well known; but it is a fact that their number is very few compared with the highly specialized types which possessed no synthetic features. Upon the theory of evolution, great numbers of these synthetic types must have then existed, and it can be well asked why we get no more traces of them. It is a significant question to ask where are any traces of the simple generalized vertebrate which must have lived in the Silurian age, possessing the characteristics of all classes of vertebrates. But at the same time we can readily understand how other groups of simple animals should have met with such favorable conditions as to give rise to rapid divergence and specific distinction. The high specialization present in some of the Silurian fauna, the great numbers of highly developed forms of Brachiopods, Echinoderms, Crustacea, etc.; the great profusion of reptiles in the Jurassic, the abundance of plants in the Dakota group, require no special explanation. But the absence of cotemporaneous forms, with generalized characteristics, is for evolution unfortunate.

Two reasons for this can be given. Firstly, there are certain definite reasons for believing that at these very points the imperfection of the record would be great. As a rule, the generalized forms which we would expect, would be those which from absence of hard parts could not be preserved. The primitive vertebrate, for instance, could have possessed no skeleton,-at least nothing more than a 
gelatinous rod for a back-bone,-and this could not have been preserved as a fossil. If this animal possessed scales, the scales might have been preserved; and we do find certain fish-scales at this period. But simple scales of course give us no idea as to what sort of an animal possessed them. For all that we know this animal may have been exactly the synthetic type we are looking for. And so in many cases, the early ancestral forms of various groups must have been animals with very few hard parts, and there would be, therefore, no chance of their preservation.

A second reason for the abundance of specialized forms compared with the synthetic types is, that they doubtless existed in greater numbers. Nor is this begging the question, as it at first sight seems to do. A synthetic type can only remain synthetic by existing in small numbers. All experience teaches us that as soon as any animal begins to multiply rapidly it becomes rapidly specialized. It is only specialized forms which can exist in great numbers. As a result, we should expect to find, at all ages, that those forms which become specialized to adapt themselves to peculiar conditions, would multiply the most rapidly and exist in the greatest numbers. Here, then, is a reason for the comparative scarcity of forms with generalized characteristics, at all geological ages, - a reason which would be as significant in early times as at present. A synthetic type can remain synthetic only as long as it exists in small numbers. 


\section{The Diversity of Silurian Life.}

Still another difficulty has arisen in connection with Silurian fauna, closely related to the one just mentioned. Our paleontologists have within the last thirty years had most wonderful success in tracing existing types back to the oldest rocks; a result which the theory of descent, with modification, would not lead us to expect. It must be admitted that upon this theory we should expect to find the Silurian fauna radically different from that existing now. Taking into account the enormous time that has elapsed since then, it would seem that the whole organic world would have become altered. The amount of modification possible in this time is shown by the fact that the entire group of vertebrates has developed into its present condition since the Silurian. It will probably be admitted by every one that, did we not have any actual knowledge of the Silurian, a hypothetical fauna would be assumed differing entirely from that of to-day. It might be admitted that there were even then specialized groups; but it would be supposed that they had long since passed away. Perhaps a few lingering forms might be thought to have survived, but in general the old species, genera, orders, and classes would have become replaced by others. In short, just such a fauna would be assumed as is now thought to belong to the pre-Silurian times.

It is true that the fauna of to-day is different from that of the Silurian age, but the difference lies chiefly in the species and genera. We find that in the Silurian fauna are represented all of the sub-king- 
doms which now exist. If now we leave out of account those forms which, having no hard parts, could not have been preserved, such as worms, etc., we find a large majority of the groups have been preserved. About five sixths of the orders, nearly an equal proportion of sub-orders, a great many families, some genera, and it has been claimed that some of our present species, are known to have been in existence during the Silurian age. It is truly remarkable to find such a very large portion of existing groups represented in the earliest fauna of which we have any knowledge. When we remember the great imperfection of our knowledge of these early animals, the difficulty here arising becomes somewhat formidable. Still more forcible does this difficulty become as we realize that the diversity of this early life is increasing as the record is more carefully studied. The tendency of the late years of paleontology seems to indicate that if our record were more perfect, it would be found that nearly all our existing forms, down to groups as small as families, were represented in the Silurian age. The vertebrates have, however, nearly all developed since that time. And when we compare the great advance of this sub-kingdom with the small advance of all others, the contrast is very striking. Such a result is certainly one which evolution would not lead us to expect.

It must be noticed, however, that this concession to the Silurian fauna is too great, since this age lasted a very long time, and many of these modern families did not appear till toward its close. By the 
time the Silurian age came to an end, nearly all of our existing families of animals were probably present; but at the beginning they were by no means so abundant. But the fauna of the very earliest primordial rocks was sufficiently diversified to be surprising; and even with this understanding of the great length of the Silurian age, the difficulty is still very great.

In explanation, one of two assumptions is necessary: either that the time preceding the Silurian age was much greater than the time since thenand this is highly improbable; or that slight modifications at the bottom of a diverging series produce greater results than equal modifications higher up. Starting with a very simple ancestral form at the bottom of the tree, it is evident that slight variations will immediately produce widely different forms, giving rise at once to the great branches of the animal kingdom; but after somewhat highly specialized forms have arisen, slight variations will have less effect; just as slight variations in the direction of the growing buds in a very young tree may produce eventually great branches, while similar variations at the ends of these branches, after they are grown, produce only twigs. After groups become highly specialized, the tendency is to produce leaves rather than branches in zoölogical classification. If this tendency express a fact, we can perhaps get a hint toward the elucidation of the above difficulties. Preceding the Silurian age, enough time must have elapsed since the world was inhabited to produce the large branches of the animal 
kingdom, and many of the smaller ones. The invertebrates in general, owing to their comparatively simple organization, had already reached a condition where slight variations produce only twigs, and the development has since then been much slower. The vertebrates, however, developed more slowly, and did not reach a similar condition until much later. The evidence indicates, in short, that the power of divergence of any type is not unlimited. Each has a certain place to fill in nature, and having once approximately filled it, the future development is of such a sort as to produce twigs rather than branches; and further, the evidence shows that by the close of the Silurian, many of the invertebrate divisions had reached such a condition, while the vertebrates have passed through nearly all of their development since that time. To this latter group, therefore, must we look for the bulk of our evidence for evolution.

In this connection it has frequently been urged that the existence of any animal unmodified since the early Silurian times, is a grave difficulty for evolution. The existence of Lingula (a small bivalve shell) with almost no change since the earliest fossiliferous rocks, has been regarded as a serious obstacle for Darwin. But this idea comes from a misunderstanding. Time does not necessarily imply change, even upon the theory of evolution. Those organisms become modified which are not in harmony with their conditions, and consequently it requires change of condition to produce change of organic structure. Now Lingula is a very simple animal, 
with few enemies and a remarkable tenacity of life. It finds its most congenial home on sand-flats, and these conditions must always have existed. It is not difficult, therefore, to understand that, perfectly adapted to these conditions, with few enemies and with great tenacity of life enabling it to endure considerable changes, it has continued to exist till the present day with very slight modification. It is suggestive to notice that another animal which exhibits a similar tenacity of life is the kingcrab, also an animal of very great antiquity. And when with these considerations we remember that all of the Silurian animals which have been preserved were marine animals, and hence living under conditions which have remained practically the same, we see another suggestion as to the reason why this ancient fauna has continued to exist with so little change.

\section{Recent Discoveries of Connecting Links.}

Thus far our attention has been confined exclusively to the difficulties offered to an unhesitating acceptance of evolution, and it must be admitted that they are very great. Most of them were realized by Darwin, and he attempted to cope with them. And these difficulties have not grown less since the appearance of the "Origin of Species," but have in some respects grown greater. To explain, the Silurian fauna, is the greatest problem which the evolutionist has to solve; and except as it has emphasized the imperfection of the record, modern paleontology has not helped toward the 
solution, but has rather increased the difficulty by increasing the extent of that ancient fauna, and making it more like that existing to-day. Various suggestions have been offered in explanation as detailed above, which show that the problem is not beyond solution, though they are hardly sufficient to answer the objections. In spite of all, the Silurian fauna is a surprise, and remains an unsolved problem.

Turning now from these difficulties to positive evidence, we next ask whether the recent discoverers have been successful in finding any of the infinite number of connecting links which the theory assumes must have existed. And here we find that paleontologists have been successful almost beyond what could have been expected. Naturally it is the vertebrates which have furnished most of the evidence. They form a group which has been developed since the Silurian age, and are, moreover, well adapted for preservation as fossils. Their bones are found in abundance in the later formations, and consequently are not metamorphosed. They are better known and more studied than any other group, and it is not surprising, therefore, that most of our advance in paleontology has been in regard to the vertebrates. The work of Cope, Marsh, and Huxley has been so careful and painstaking, and has been attended with so much success, that the actual history of many of our vertebrates has been accurately traced from fossil specimens.

It is interesting to compare the state of our knowledge to-day as to these intermediate types, with that which the first edition of the "Origin of 
Species" could bring to its aid. A few synthetic types were at that time known; but they were so little understood as to have no particular meaning. Darwin, realizing as he did that one of the weakest points in his theory was the impossibility of finding the many links which it demanded, was only able in the first edition of his book to claim that Owen had shown that Ruminants and Pachyderms were connected by fossils. To-day it would take pages to enumerate the different fossils found to connect, in a more or less direct manner, the living with extinct animals and with each other.

It may, perhaps, be well to mention a few of these instances. The best-known history is that of the horse family. The earliest representative was the eohippus of the Eocene rocks, which had on its fore feet the representations of five toes, and was a small animal about the size of a fox. From this startingpoint the history has been carefully followed. The animal becomes larger; it loses one toe, then a second ; and coming on later, two of the three remaining toes become smaller, and finally all that is left of them are the so-called splint bones. Accompanying these changes are others, so that almost every step in the history of this family from its fivetoed ancestor, is known. And not only this, but the even-toed Ungulates have been similarly traced back to a five-toed ancestor. Indeed, by means of the numerous fossils found of late years, almost all of the orders of mammals have been traced backwards by converging lines. And Cope has discovered a very early animal which presents such 
generalized characteristics that he considers it as representing the common ancestor of all true mammalia, and has named the group the Condylarthra. The number of connecting links uniting this animal with the modern orders is very great. Still earlier is found a series of fossils uniting birds and reptiles. These classes, in their anatomy, show a close relationship, and they have been united in a surprising manner by fossils. The world-renowned Archeopteryx and the remarkable Odontornithes, the toothed birds of the American Cretaceous, are reptilelike birds; while the Composgnathus seems to be a bird-like reptile. Indeed, so successful have been the researches upon fossil vertebrates, that Cope, who has studied the subject with great care, thinks that they have "disclosed the ancestry of the mammals, the birds, the reptiles, and the true fishes," and he unhesitatingly gives a phylogenetic history of the whole vertebrate sub-kingdom. Whether this history, as given by Cope, be right or wrong, does not, however, concern us; the very fact that it is possible to make such a history from the study of fossils, shows what a great advance has been made in the direction of finding links, since the matter has been subject to careful investigation under the inspiration of the "Origin of Species."

It is hardly possible to exaggerate the importance of this result. From the very first the absence of these connecting species has been recognized as a most serious obstacle for evolution. But, as year by year goes by, fresh discoveries have been continually bringing to light instance after instance 
of these types of union, until the difficulty has not only disappeared, but has been turned into a very cogent positive argument.

One very important feature in regard to these connecting links is the geological position in which they are found. A connecting link ought to appear before the two forms which it connects, or sometimes between them. The former position is the more natural one, and a synthetic form in this position is understood to be the common ancestor of the later groups which it connects. Most of our fossils are of this character, being anatomically intercalated between existing groups, and always occurring at earlier periods. The second position might sometimes occur, and would be explained by supposing the fossil in question represented a transitional stage between the earlier and the later groups which it connects. The occurrence of a connecting link later than the animals connected by it, would be, according to the descent theory, surprising, and only explained by supposing that it originally appeared earlier, but left no trace of itself, while some individual survivor, in after-ages, did happen to be preserved as a fossil. And this explanation would evidently only apply to sporadic cases. Now, the universal rule is, that true connecting links occupy one of the first two positions, and never the last. The successive fossils which connect the horse family with the ancient five-toed ancestor occur in successively lower and lower rocks; while the forms connecting this family with the eventoed Ungulates occur still lower down. Indeed, I 
can find no instance where a true fossil connectinglink appears later than the groups connected by it. In short, the geological location of fossils is exactly that which the theory of descent would lead us to expect.

For reasons already considered, the number of synthetic forms found among invertebrate fossils is not so great as that of the vertebrates. But still they are not absent, though they are few and scattering. It is not possible in any case among invertebrates to build a connected history such as we have seen can be done, with some vertebrate families. The scattered connecting forms only enable us to get a hint here and there as to the probable development. The Crustacea form an interesting group. The existing crabs can be traced back through various simple form to the Oolitic rocks, where they seem to merge into the less highly developed group Anomoura, a group in many respects intermediate between them and the Macroura (lobsters and shrimps). Still further back the Anomoura disappear, and the group of Macroura take their place in the Carboniferous. And still earlier these are united to the Phyllopods by Silurian forms (Ceratrocaris). In another line the ancient Euryperids are united to the family to which the king-crab belongs, by a fossil called Hemiaspis, while the king-crabs are united to the ancient Trilobdes by another fossil (Prestwichia). Alexander Agassiz has very carefully studied the whole series of fossil forms of seaurchins. From the fact that the classes of this group were already differentiated in the Silurian age, it 
was, of course, impossible to discover connecting links between them; but he had no difficulty in discovering a continuity between the Silurian Echinoderms and the existing forms, and thus to show that the present forms are descendants from the ancient fossil families. He was not able to trace the history of the successive genera, but easily made out a general slow modification.

But there is no need of multiplying examples. The full force of the argument can only appear by a long and careful consideration of special cases, and this lies beyond the scope of this work. Undoubtedly the tendency of recent advances in paleontology is to fill in the gaps between large numbers of our present widely separated groups. Particularly is this true of vertebrates, and inasmuch as it is this group alone that has left behind it any thing like a satisfactory history, it must be to this group that most of our future discoveries will be confined.

Undoubtedly many of the so-called connecting links which have been described are not what is claimed for them. Imbued with the evolutionary belief, our paleontologists are everywhere in hunt for these links, and will be quite apt to find such links in animals where analogical likeness is all that exists. The various histories drawn from paleontological evidence may be in error at many points. But making all allowance for these errors, there can be no questioning the statement that the last twenty years have added so much to our knowledge of the connected history of vertebrates in the past, as to 
justify the statement that the fossil history since the Silurian age is in strict accordance with what we should expect to find according to the theory of evolution. Scientists to-day who have carefully studied the subject, claim that paleontology practically demonstrates the derivative origin of species. It shows as far as it is possible to be shown that our fauna is derived from that of the geological ages; our classes being descendants of the older generalized forms, our families from later types, and our species from the very recent branches of the later divisions.

\section{The Development of the Brain in Mammals.}

One very interesting result has appeared from the work of Marsh upon tertiary mammals in regard to the growth of the brain. To give his own summary: (I) All tertiary mammals had small brains. There was a gradual increase in the size of the brain during this period. (3) The increase was mainly confined to the cerebral hemispheres or higher portions of the brain. (4) In some groups the convolutions of the brain have gradually become complicated. (5) In some the cerebellum and olfactory lobes have diminished in size. These are very significant results when we consider the enormous size of many of the older animals and the comparative small size of the modern ones. It appears that till the time of the appearance of mammals the struggle for existence had been confined to physical superiority ; but that, with the beginning of the Tertiary, a new era ensued, resulting in the 
growth of the brain, and from that time the contest has been one of intelligence.

\section{Paleobotany.}

The fossil history of plants has not been so much studied as that of animals, and much less is known about it; or at all events it has given less important results. Plants are not so easily preserved as animals with hard parts, and while from a few specimens it is known that an abundant flora existed even in the Silurian era, the record is very meagre. In general, paleobotany offers somewhat the same sort of testimony as that which we have examined above. The plants of the Silurian, however, present no such difficulties as do the animals, chiefly perhaps because so little is known about them. They constitute a quite well developed flora of Algæ, Sigillaroids, Lycopods, ferns, and Equisitacea, all plants of undoubted low scale of organization. Conifers make their appearance next, in the Devonian, and Dawson claims to have found here an angiosperm. This claim is more than doubtful, however, and the Devonian is on the whole characterized by Cryptogams and Gymnosperms. This flora passed directly over into the profuse vegetation of the Carboniferous age, with little change, nearly all of the genera of the one period being found in the other, though few of the species are common to the two. At this time also Monocotyledons made their appearance. With the beginning of the Mezozoic the Cycads are expanded, while the peculiar carboniferous forms are disappearing. In the upper Cretaceous rocks finally ap- 
pear the Dicotyledons, and the modern forest-trees can be traced back to this time.

It will be seen that this history represents a continual advance : first, Cryptogams, then Gymnosperms, Monocotyledons, and Dicotyledons, in consecutive order. But no such minute histories have been traced here as we have seen in the animal kingdom. The most remarkable feature of paleobotany, and the only one which offers any serious difficulty, is the appearance of dicotyledonous angiosperms in the upper Cretaceous. In Western North America is found a vast bed of rocks known as the Dakota formation, whose age is by some high authorities considered as lower Cretaceous, and by others as upper Tertiary. Whichever it may be it is a fact that here suddenly appear the highest plants. Previous to this time no Dicotyledons are known to have existed, but here abruptly appear in a perfect condition a flora almost exactly agreeing with the flora of to-day. There were oaks, poplars, magnolias, maples, beeches, elms, firs, hollies, and hosts of other modern plants, agreeing, as far as can be judged from leaves, even to the species, with those now existing. Indeed the forest of this period must have borne an almost exact resemblance to the forests of to-day. The sudden appearance of such a remarkably diversified flora, and the fact that it has since that time remained almost unchanged, are two great difficulties for evolution to meet. The first can only be met by appealing to the imperfection of the record. To the second difficulty it may be suggested, that the group of plants, once de- 
veloped, so well fitted its place in nature that further change would be unnecessary, unless some change in conditions should arise. This is, however, only a suggestion, not an explanation.

\section{Summary.}

"It must be conceded that, on the whole, the testimony of the rocks is in favor of the doctrine of evolution," is the decision of the most advanced geologists to-day. Undoubtedly there are many difficulties in the way, and very serious some of them are, which yet remain unanswered. The sudden appearance of such a highly differentiated fauna at the very base of the Silurian, and the character of this fauna, consisting, as it did, of all of the sub-kingdoms, are facts which are unfortunate for the evolution theory; for, if they do nothing else, they make it utterly impossible to show that the great types are related to each other by converging lines. The absence of life in rocks older than the Silurian, shrouds in absolute darkness the origin of the various sub-kingdoms and classes, for at the very first glimpse we have of life they were as widely apart as they are now. The result of careful research, which tends to show that a very large majority of our orders, sub-orders and families can be traced back to these early times, makes it still more difficult to recognize converging lines, and confines the search chiefly to the one group of vertebrates which has developed since that time. The occasional survival of some forms almost unmodified through the enormous geological ages; the great 
preponderance of specialized forms at all times over generalized types, which the descent theory assumes have existed; the sudden appearance of various highly-developed groups of animals and plants in later times, such as the Teleost fishes and the $\mathrm{Di}$ cotyledonous plants abruptly in the Cretaceous with absolutely no previous indications of their existence; the discrepancies as to the necessary amount of time required for the development of the animal kingdom, as estimated by Darwin, and the probable age of the world as estimated by Sir William Thomson and others;-all of these difficulties, though partially answered and certainly not unsurmountable, still demand the attention of our scientists.

On the other hand, the researches since Darwin have proved that our paleontological record is very imperfect, particularly at its beginning, where most of the difficulties occur, and with this conclusion many of them disappear. "As the area over which accurate observations have been carried on extends, and as fossiliferous rocks found in one locality fill up the gaps left in another, the abrupt demarkations between the fauna and flora of different epochs disappear," and in numerous cases fossils have been found to bridge over the gaps existing between widely different groups. The patient study of vertebrate fossils, which have left the most complete record, has given a very exact history of their development, a history becoming more and more complete with the discovery of every new fossil. The accumulation of the numerous links connecting animals, and the satisfactory explanation which evolu- 
tion gives to every newly discovered fact, the exactness with which the new fossils fall into their places, both as regards their structure and the time at which they lived, have all together led paleontologists, as a rule, to conclude that the positive evidence is sufficient to outweigh the numerous difficulties, and indicate that the history of animals has been an evolutionary one of some form.

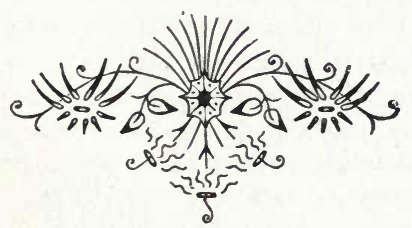




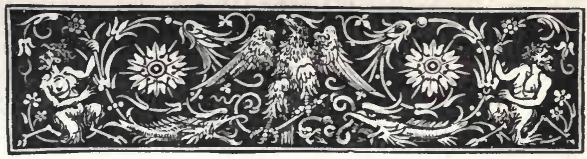

CHAPTER IV.

EMBRYOLOGY.

The Importance of Embryology.

THE evidence which organic evolution derives from classification and geological succession is as conclusive as could be expected from such data. The genetic connection of animals is, however, only a matter of inference, if this evidence only be considered; a very strong inference it is to be sure, but one which does not necessarily follow from the facts. It is always possible to say, and frequently has been claimed, that although animals are classified as if genetically.related, and although the fossils appear in order exact'y in harmony with the same idea, yet there is no proof that the species thus appearing did develop from each other. It is possible to admit all of the facts which we have hitherto considered, and still to claim that it has only been shown that if evolution were true, classification and paleontology would be as we find them, but that no direct argument has been offered to prove that the species living to-day have passed through these various early stages. Direct proof of genetic descent of the nature demanded by this claim is impossible, but the inferences from the classes of facts considered is the 
present chapter and the next are somewhat different in their nature from those already considered, and bear more directly on the question of genetic descent.

When the "Origin of Species" was written, its author did not realize the great aid his views were to receive from the study of embryology, and the subject was passed over by him in a manner which to the scientists of to-day seems entirely unsatisfactory for such an important subject. But this source of evidence did not exist at the time the "Origin of Species" was written, for embryology as a science is of later date. A few embryological facts had at that time been collected, and the generalizations of Von Baer and Rathke had laid the foundation of what has since become a science. It was impossible to appreciate the significance of the facts until evolution was sought as an interpretation. As soon as this theory began to be seriously discussed, it became evident that along the line of embryology might be expected the most cogent arguments upon the question.

Nor has this expectation proved delusive, for the evidence here afforded has been perhaps the most important factor in leading modern scientists to accept evolution. Although embryology was only slightly considered by Darwin, either in the earlier or later additions of his book, the subject soon obtained able exponents. Spencer and Haeckel, with an immediate perception of the significance of the subject, treated it ensemble, and deduced from the then imperfectly known facts some brilliant gener- 
alizations, which have been the guiding principles of embryologists ever since. Spencer contented himself with pointing out the general principles connected with embryology in its relation to evolution; and so well taken were his deductions that most of them will stand to-day as he wrote them twenty years' ago. Haeckel did not stop here, but having recognized the underlying principles, attempted to apply them to special cases; and because his data were then scanty he was led into many erroneous conclusions. $\mathrm{He}$ attempted at that time to do more than embryologists, with all their advance in knowledge, consider themselves able to do to-day.

\section{Embryology a Repetition of Past History.}

The fundamental principle which underlies all modern research in this direction, is simply the assumption that the development of the individual repeats briefly the development of the race; that if we could trace perfectly the development of any animal from the egg, we should thus get an epitomized history of the development of the race to which the animal in question belongs, through the countless ages of the past. The great significance of this assumption is at once evident. If true, it gives the student, with his microscope and section instrument, the opportunity of studying in the laboratory the past history of animals, of discovering thus the exact blood-relationship of animals to each other, and thus explaining most of the anomalies of classification. In short, if embryology is 
a summary of past history, it is a key to the problem of the origin of the animal kingdom as it exists to-day.

For the pursuance of this study three tasks are necessary: (1) We must discover whether or not this assumption is true ; (2) we must find, if possible, an explanation of the fact, if its truth is demonstrated; and (3) we must apply the principle in every conceivable direction, and construct, as far as possible, the history of the animal kingdom, in order to discover if the result be in harmony with the evidence from other sources. A perfectly satisfactory answer cannot as yet be given to any of these questions; but the evidence is daily increasing, and it is not difficult to see what the final result will be.

\section{I. - As to the Truth of the Assumption that Embry- ology Repeats Past History.}

Several methods of investigation are here possible. The simplest, and the one most readily suggesting itself, is to compare the history of animals as taught by embryology with their history as taught by fossils. If it could be shown that the two agree perfectly, we should have a demonstration of the point. But this is obviously at present impossible. Such an exact comparison can only be made when we have complete, both the fossil and embryological history of all animals, and our knowledge of both of these subjects is as yet very imperfect. That there is a general parallelism between the two is everywhere acknowledged; indeed, it was recognized half a century ago to its fullest extent by Louis Agassiz. 
He plainly saw the principle, and used it as an argument in his essay on classification. The embryo everywhere begins as a simple undifferentiated organism, and builds itself up through successively higher and higher grades, until it finally reaches the complicated adult. And so in fossil history it appears, rather indefinitely and yet distinctly, that the lower forms appear in the earlier ages, and give place as the ages go by to successively higher and higher forms, until the most complicated appear last. But such a general parallelism as this has no meaning, and, unless more definite evidence can be found, our assumption is of no importance.

But if we cease to make the question quite so broad and confine it to special cases, we may perhaps get more definite conclusions. And here we labor under the disadvantage that, for reasons that we shall see later, the vertebrates which have the most complete fossil history have the most incomplete embryological history. The only systematic attempt at such a comparison as we are considering, has been made by A. Agassiz. Having at his command a great number of fossil echinoids, he has made a very careful study of them for the purpose of discovering how accurately a parallel could be drawn between their history and that of the young echinoid. The result of this comparison was to substantiate the theory in its general bearings. "We are justified," he says, "in seeking for our earliest representative of the order such echinoderms as resemble early stages of our embryos." But he concludes further that "any thing beyond a general 
parallelism is hopeless." It may be possible, he thinks, to decide as to the general line along which echinoderms have developed, but any attempt to trace the history of genera in this way. will only result in complete failure. Embryologyalone is not a safe guide, and only so far as it is possible to verify it by actual fossils, can it with justice be relied upon as giving any thing more than a general history of the past. The parallelism exists, but our power of interpreting it is not great. This conclusion as to limiting the use of embryology in teaching history, has naturally been a disappointment to the enthusiastic embryologists, who have not hesitated to say that the work of Agassiz marks a step backward. But it is certainly a wholesome check to the too precipitous advance in this direction; for the embryologist has begun to rank his science too highly, a common fault with all specialists. But whatever be the result obtained by Agassiz as to our power of following this parallelism, there was no question on his part that such a general parallelism does exist.

Beyond this work of Agassiz, there has been no thorough attempt to investigate the matter. It is so difficult to obtain a sufficient amount of fossil material to make a satisfactory parallel, that none have had the courage to attempt it. Of course, from the fact that the assumption has been so constantly in the minds of scientists, it has followed that vast numbers of disjointed facts have been noticed bearing on the point. Usually the investigator has satisfied himself with observing a few isolated facts, and saying that they form another instance of the 
well-known parallelism between embryology and paleontology. There is hardly a class in which some such parallelism cannot be distinctly shown, and many instances are very striking. It is seen among the mollusks, particularly in the class Cephalopoda ; it is seen among the Crustacea, the Decapods showing very beautifully a paleontological development agreeing with their embryology. Vertebrates, perhaps, give the best illustrations of all, as can be seen by examining the various works on fossil vertebrates, from the time of Louis Agassiz until now. When, therefore, we take all of the facts together, seeing that with our imperfect knowledge of fossils we find a general parallel everywhere expressed, we can safely say that the investigations of the last twenty years in paleontology have been slowly but persistently strengthening the belief in the truth of the hypothesis. While the evidence is scanty, it all bears in one direction.

Embryology Compared with a Hypothetical History.

Fossils are too scanty, and paleontological evidence has been hitherto too imperfect, for a demonstration of the truth of the hypothesis. It is necessary, therefore, to search for proof in some other direction. One method of doing this is to compare embryology with the hypothetical history which the study of adult forms with their relations to each other would lead us to construct. If the two agree, we may rest assured of the truth of the hypothesis; if they disagree, something must be wrong. Two species of the same genus must, ac- 
cording to the descent theory, have had precisely the same history until comparatively recent times. Genera of the same family separated from each other at an earlier period, and families of the same order at still more remote times, while the different sub-kingdoms have had no common history since the earliest ages. If, now, embryology were an exact repetition of past history, we should expect to find the development of individuals of related species agreeing except in the very latest stages. Genera would show a similarity of development not quite so long, families and orders would separate from each other still earlier, while the sub-kingdoms would show no similarity except in the earliest stages. Every two animals should begin their development alike, and the point at which they become unlike would depend upon the closeness of their genetic relation.

Around this point has centred a large part of modern embryological research. Not always, perhaps, realizing the significance of their results, naturalists have been trying to make the various facts collected harmonize with each other. For it is almost immediately recognized, was indeed recognized by Spencer and Haeckel, that the embryological history of animals is not in strict harmony with their relations to each other. Two animals quite closely related in adult anatomy, may have embryological histories differing very widely from each other from the very first stages. The embryology of the genera of a single family does not always represent a unity, although as a rule it 
does. Two annelids may be selected, agreeing quite closely in adult anatomy, but whose development shows no likeness until the latest stages are reached. Of course these annelids must have had practically the same past history, if the descent theory is true, and the fact that their embryology is so very different, seems at first sight to disprove that the one is the résumé of the other.

But upon more careful investigation it has appeared that these seeming contradictions form perhaps the strongest argument in support of the hypothesis. In the first place, it has been more and more evident with advancing knowledge that, although small groups may show irregularities, as a rule, embryology is in harmony with such hypothetical history, and is as a whole a unity. The same principles apply everywhere, and facts are daily being brought to light showing that harmony is to be the final result. So convinced have been embryologists of the truth of this fundamental principle, that the presence of the seeming contradictions has caused no hesitation. They have only regarded them as obstacles to be overcome.

\section{Method of Explaining the Contradictions.}

In most cases these contradictions have been explained in a satisfactory manner, though some still await further discoveries before they can be made clear. The general line of argument which has been used to meet the difficulties is somewhat as follows: Assuming the law to be that embryology should repeat past history, an assumption supported by the 
majority of the evidence, the question is asked whether some valid reason cannot be given why this law should in certain cases be departed from. An answer is soon found in the influence of the surroundings of the embryo, which sometimes prevent the normal course from being followed. By its own innate tendency the embryo would follow the line of ancestral history, but while going through its development it is placed under circumstances which render this impossible. In such cases the history is shortened, either from necessity or to cut short the embryonic period, which is the period of greatest helplessness. As an illustration of the principle, let us consider the ordinary earthworm (annelid). Among other peculiarities, we find that its embryo possesses for a long time no mouth or digestive canal. This fact is in itself proof that embryology may depart from past history, for the ancestors of the annelid must at all times have possessed a mouth and digestive tract, or they could not have lived. The embryo unquestionably departs from this history, and a reason for it is found in a very simple fact. The use of the mouth and digestive tract is to supply the animal with food. But our modern annelid embryo is not required to collect food, for it has a supply already at hand. The egg within which the embryo develops contains a large store of food already prepared to enter into the body of the embryo, and therefore the presence of a mouth and digestive tract is unnecessary until a much later period when the food is used. And not only this, but the food-yolk is so bulky that it fills the whole space 
where the digestive canal ought to be, and thus by its simple bulk effectually prevents the regular formation of these organs. The embryo does seem to try, even here, to follow the primitive history, for it develops a mouth in a roundabout way, and separates off cells which correspond to the digestive tract. But the mouth frequently closes up, since it is of no use, and the presence of the bulky food prevents the alimentary canal from being formed. After the food is used up the mouth again appears, the alimentary canal becomes functional, and the typical history is once more resumed. In other words, the embryo attempts to follow the line of ancestral history, but the presence of food makes this impossible, and as a result some of the history is skipped. If now it be possible to find another annelid in which no food is stored up in the egg, evidently these modifying conditions will be absent, and the embryology can follow more closely the ancestral history. In this way two annelids closely related might differ radically in their embryology, without this fact at all affecting the truth of the hypothesis that embryology tends to repeat past history.

Or take a still more striking illustration. According to modern ideas derived from anatomical and paleontological evidence, the ancestors of the birds were at one time aquatic animals, breathing by means of gills somewhat as do fishes. If, therefore, embryology repeated exactly the past history, we should expect to find gills in the embryo chick. But consider the condition in which the chick passes its embryonic life: closed within the egg-shell, un- 
able to move to any great extent, and certainly unable to breathe by means of gills, and, moreover, passing through its entire development in twentyone days. Can we expect, therefore, that even if the tendency to repeat ancestral forms is very strong, there will be time and opportunity to complete such useless structures as gills? Now the facts are, that while the gills themselves have disappeared, the embryo chick does possess undoubted remains of them in two features. There are found in the embryo openings upon the sides of the neck, which mark the position of the former gill-slits; and the blood-vessels of the embryo at first run to these slits in a manner which shows that they once supplied gills here situated. No one can doubt that here are the homologues of a former aquatic respiratory apparatus.

This case is then most readily explained. For, if the gills are of no use, their development would be of positive disadvantage. Other things being equal, it is desirable that the embryo should go through its development as rapidly as possible, since the species will thus multiply more rapidly, and also because it will give less opportunity for the destruction of the helpless embryos by their enemies. The chick develops in twenty-one days, and it is therefore practically impossible that all of the stages of its ancestral history can be exactly repeated. Much will be, of necessity, skipped, much faintly suggested, and the whole will be condensed into small compass. Stages of fundamental importance will be more likely to be retained than those of less 
moment. We can then readily see why the chick should have lost its gills but have retained the gillslits. The ancestral stage in the history of the chick which possessed gills occurred very long ago; and since that time the embryo has slowly lost the habit of developing such useless structures. If it had been only a short time since that stage, we might still expect to find them. This we do find, for instance, in a frog of Guadaloupe, which, from the absence of stagnant water, is obliged to skip the tadpole stage, or rather is obliged to pass through this stage before hatching from the egg. In this stage, though the animal is still in the egg, there are developed gills and a tail. We know that frogs are a recent introduction into the Guadaloupe, and thus see that it takes time even for the disappearance of such useless organs as gills. But in the case of the chick the time has been much longer, and every trace of gills has disappeared. We might expect that the gill-slits would disappear too; but they have not; they still remain to mark the former aquatic life of the ancient vertebrates.

If a shipbuilder wishes to build a steamboat, he moulds his material directly into the form of boat he wishes ; we would think little of his ability if he began by building a canoe, modified this into a rowing boat, this into a Roman trireme, this into a simple sailing vessel, this into a large ship, and finally into a steamboat. Such a method would be repeating the history of the steamship, but would be a poor way to build a boat. Now the development of the chick is a compromise between 
these two methods of direct and indirect construction. Instead of repeating the whole past history, it attempts in some features to build the chick in the most direct way, and drops many of the earlier stages. But it has not succeeded in freeing itself from them all, the tendency to reproduce its earlier history being strong enough to preserve many of the more important stages. A notochord is developed which represents the primitive backbone of the vertebrates. It appears in the young chick, but is subsequently completely lost, nothing remaining in the adult chick to indicate its existence. The young chick develops gill-slits which are of no. use to the embryo or the adult. They consequently soon close up and disappear, with one exception, which becomes converted into an entirely different structure, the Eustachian tube connecting the mouth with the inner ear. Blood-vessels to supply these slits also appear, but having no use now that respiration is no longer carried on here, soon change their position and come to supply other parts of the body. In these respects the embryology of the chick can be compared to the building of a steamship, where the builder does not indeed make first a Roman trireme complete, but goes so far in that direction as to make in his boat the long tiers of openings for oars. Finding, however, after he gets his steam-engine into the boat, that oar-holes are no longer of any use, he either closes them up or converts them into port-holes. Oars he never makes, since he discovers that they will not be needed, and to make them would be sheer loss of time. 
Let us not lose sight of the problem we are trying to solve, which is the reason for the contradictions found in the embryological histories of allied animals. We have seen some of the causes which have led to the modification of the embryological record, and it may well happen that two allied animals may be modified in different degrees. And we may find some cases where there is still retained what is known as the primitive history, i.e., a development which so far as we can judge repeats quite exactly the past history. Of course when it is recognized that the embryological record can be modified, there will be difficulty in deciding just what the primitive history is. If it is admitted that the record can be modified in some respects, what right can there be in saying that any given history is unmodified? Naturalists of note have claimed that where the falsification of the record is once admitted, the whole data for work is gone; the embryologist has used up his foundation in trying to build his structure. That there is a difficulty here no one will deny; but it is not an insurmountable one. Every new fact of embryology aids in the solution of the problem, and by taking all of the facts together some general rules can be deduced which aid in solving the difficulties here presented. From what has been already said, it will be evident that in embryos which have no food supplied them in the egg, we may expect a more primitive history than in those cases where such food is abundant. Free living embryos we might expect would be less modified than those passing their development in the body 
of the mother. If we find all the representatives of a large group agreeing in some common feature, we may usually conclude that it is ancestral. Organs of no use to the embryo, such as the gills of the Guadaloupe frog; organs appearing and then disappearing ; organs arising and being subsequently converted into something else, may all be unhesitatingly set down as features inherited from the past. But the most important factor in enabling us to decide in any given case, is the directness or indirectness of the development. When we find that the young is built in a straightforward manner directly from the egg, we may rest assured that the embryology does not repeat very exactly the history of the past; but when the formation of the embryo takes place, by means of a long series of roundabout stages, we may strongly presume that some or all of them are ancestral stages. An absolutely direct development is not known, for every animal passes through some out-of-the-way stages. The development of the chick is extremely direct, but even here many ancestral features are retained. On the other hand, no animal is known whose embry. ology is such as not to lead us to believe it to be abbreviated in some respects. But at the same time many do have such a roundabout history as to indicate that in most points they repeat ancestral features. When, further, it is found that those animals with a direct development almost universally have a large amount of food-yolk in the egg, and that those with an indirect development agree in having little food, and are consequently not able to 
abbreviate their development so much, the question as to which is primitive is scarcely doubtful. And when, finally, it is seen that in many cases it can be demonstrated that the direct development is simply a much abbreviated form of the indirect development in allied animals, no doubt can remain as to which is the primitive history representing more closely the past history of the group. It becomes evident that the falsification of the record does not prove an insurmountable barrier.

\section{The Result of These Considerations.}

By various suggestions, then, as to the causes for the modification of the embryology under certain circumstances scientists have succeeded in explaining many contradictions, and in showing why it is that in some cases the history of animals as drawn from embryology is not parallel with that drawn from the anatomical relations of adults. All this has been done without in the least detracting from the force and cogency of the fundamental assumption that embryology, when rightly understood, is a résumé of past history. But notice the position that is now reached. Instead of claiming that embryology is always a safe guide in interpreting past history it is acknowledged that it seldom gives a true record, being frequently so modified that a large portion of the history is lost and the rest much disguised. Instead of proving a simple subject as at first promised, embryology has grown more and more complicated, with increasing knowledge, until it has almost resolved itself into the attempt to distinguish 
the true history from the modified, and the endeavor to interpret the latter by means of the former. But in spite of all this, or, more correctly, because of all this, the belief in the truth of the hypothesis we are considering has grown stronger and stronger. While many discrepancies occur, it is a very general rule that the embryological history is parallel to that which we hypothetically draw from anatomical relations. So far is this true, that we can predict with great exactness the course of development of any animal if we know its relations. And the facts that so many cases of unmodified history are known and are being constantly discovered, which not only agree with each other, but also assist in intrepreting the cases of modified development; that amid this great discord there is after all an underlying harmony, growing more and more apparent with every new discovery; that every advance in knowledge tends to remorve some of the difficulties; and that the hypothesis in question has so successfully succeeded in overcoming the obstacles in its way;-all of these reasons lead embryologists to the conclusion that in general embryology does repeat past history. Indeed they have long since ceased to discuss the question, and now consider it wasted time to attempt to prove it. For them it is established. It is not improbable that this so confident belief may be partly due to the attitude of the embryologist in his investigations. $\mathrm{He}$ is, to begin with, fascinated with the hypothesis, and naturally tries to explain his results in its terms, frequently thus losing sight of the fact that one of the chief objects 
of his research is to verify it. But we can hardly believe that any false conclusion will be long entertained. The naturalist is in search after truth, and must at all events be considered an honest man. Many of them would have been glad to disprove this hypothesis if it had been possible. When, therefore, all embryologists, who are the only ones who can rightly interpret the evidence, are agreed that, in spite of the complications arising from the falsification of the embryological record, the three series of historical lines obtained from paleontology, classification, and embryology, are parallel, the candid mind must accept this verdict as one of the well-attested facts of science. But it is a fact which cannot from the very nature of the case be proved.

Embryology as an Assistance in Classifying Animals.

The extent to which this idea of embryology and descent has forced its way into science, is indicated by the modern method of classilying animals. Early in the century Von Baer first proved that the development of the individuals of the various groups of animals was such that, as he says, the different types have different types of development. Since his time this conclusion has been subjected to rigid examination in every direction, with the general result of confirming it, except in the earliest stages. But this confirmation has been by no means such as Von Baer expected. Instead of leading to the establishment of types, it has broken them to pieces, and has disclosed not four, but over twenty types of development. The true result is that animals closely 
related agree in their development; that species which form a circumscribed group usually have a circumscribed type of development. The embryologist can predict with almost certainty exactly what the development of any animal will be, if he knows its adult relationship. So close is this paralleled, that scientists have considered themselves justified in reversing the argument and in basing their classifications upon embryology. Almost all of the advances made in the classification of the larger groups are made through the study of embryology ; no classification is considered complete without it; and in many points, indeed, the conclusions as to relationship are based on this study alone. And this fact is conclusive evidence that continued investigations show, in spite of the numerous contradictions, a parallelism between embryology and that hypothetical history which we should build from the study of adults. Von Baer certainly discovered an important principle, although it no longer stands as he formulated it. To-day it reads something as follows: Closely related animals agree in their development, while those distantly related show no likeness except in the early stages; but since all of the members of the large groups of animals have had in the past a common history, it will follow that they will have a common embryology, if one is the repetition of the other. We thus explain the fact that the so-called types of animals have their own types of development.

We may, then, safely assert that the investigations have strengthened almost to proof the funda- 
mental law of embryology, that the development of the individual is a repetition of past history. It is supported by the comparison of embryology with paleontology, by the complete harmony amid the discord coming from its comparison with the hypothetical history which classification teaches, and by the fact that it not only enables the student to explain difficulties, but also to make predictions-the best test of any scientific theory. Considering it, therefore, as practically demonstrated, we proceed to the consideration of its meaning.

\section{2.-The Significance of the Parallel between Embry- ology and Past History.}

The real question as to whether embryology forms an argument for evolution, concerns the explanation we can give to the parallel which has been under consideration. The embryologist assumes that the parallelism proves evolution, and busies himself in studying details and constructing from the evidence as correctly as possible the genealogical history of animals. Before following him into this field, we must first take a more general view of the matter and discover the true significance of the principles on which he works.

In reality the teachings of embryology, as expounded by its students and as verified by modern research, form the strongest direct argument in favor of the theory of descent. The parallel in question is certainly one of the most marvellous discoveries ever made; a discovery which would never have been dreamed of from a priori grounds. Why 
should an embryo go over such a roundabout road in development, instead of proceeding to the adult in the most direct manner? If possible an explanation must be given; and if an explanation can be given in accordance with natural law, it is far preferable to do so than to leave the whole matter in the realm of the supernatural. Now the theory of evolution has, or rather is, an explanation of this parallel. It is not yet, perhaps, from the want of knowledge, perfectly satisfactory in every point. But it is, on the whole, so intelligible, its obscure points are so rapidly being removed, and it so admirably fits all the facts, that it seems hardly possible that it is not the true explanation. We know that animals begin their development as a single-celled ovum; and, according to the descent theory, a single-celled animal was a stage very near the starting-point of life in the past ages. We know that animals do inherit the characteristics of their ancestors; not only those of their parents, but of more remote generations. There is abundance of evidence for the fact that these inherited characteristics may be developed in the offspring at an earlier period than they appear in the parent, and thus peculiarities of the adult may slowly become those of younger stages. Now, with all of these facts in mind, it is very easy to see why it is that in developing from the single-celled ovum to the adult, the embryo should, by the accepted law of heredity, pass over the same road which was travelled by its ancestors in developing from the unicellular animal to its present condition. Heredity, then, that mysterious law which we know 
as a fact but do not understand, is an explanation of this parallel. With this principle we can understand why it is that the embryos of higher animals resemble the adult stages of lower ones, and resemble also the animals of geological times; we see why it is that embryology is always an attempt at a repetition of past history, and also why it is that, owing to surrounding conditions, the attempt is not always successful. It has been the work of the last twenty years of embryology to show that this explanation is satisfactory, and that it throws light upon the whole subject of animal life. Although, as we shall presently see, many questions still remain for solution, enough has been done to show that the result will eventually be a harmony.

This is the simplest explanation for the fact offered, but it is not a conclusion that cannot be gainsaid. Many people have fully recognized the parallel in question and yet denied evolution. Just as it is possible to claim that, while the facts of paleontology are such as would follow from the theory of evolution, they simply prove that animals of higher and higher organization have appeared in successive ages, and do not prove genetic descent; just as it is possible to claim that, while all of the facts of classification and homology receive their most simple explanation from the descent theory, yet they do not prove it: so here it is possible to contend that this remarkable fact is only a part of a preconceived harmony-a proof of the unity of the organic world. And for this unity we have seen that the theory of types offers its explanation. The 
argument from embryology is, therefore, similar in its nature to that which has been found in classification and paleontology, but it is at the same time a more forcible argument. It is much easier to understand that even on the theory of special creation of species, animals should have appeared in the order we have discovered, and should be related to each other according to a tree-like schema, than to understand why the embryo should go so much out of its way to repeat stages which have never been comprised in the history of its own ancestry.

It is hardly necessary to do more than state this argument, for its force is one that each individual must settle in his own mind. The facts are as stated, the conclusion from them each must determine for himself. The teachings of embryology, since the appearance of the "Origin of Species," have been found to be in harmony with the descent theory; its very contradictions, when rightly understood, forming the strongest confirmation of the fact. The embryologist, finding how perfectly the facts harmonize, is simply unable to avoid the conclusion that the fact of an animal being embryologically derived from an older form, is proof that historically the same descent is true. He is unable to avoid the use of the term relationship, or to avoid interpreting the word as meaning blood-relationship. And so the matter stands to-day. That the development of the individual repeats the development of the race, is a fact abundantly demonstrated. The theory of evolution offers the only natural solution of the fact, an explanation which, when thoroughly 
applied, is found to fit the facts marvellously well. "On the hypothesis of evolution this parallelism has a meaning-indicates that primordial kinship of all organisms and that progressive differentiation of them which the hypothesis alleges. But on any other theory the parallelism is meaningless, or, rather, it raises a difficulty, since it implies either an effect without a cause, or a design without a purpose."

\section{Difficulties to be Overcome.}

The task of discovering the history of animals, even when we have the key to the problem in their development, is by no means an easy one. In the first place, difficulties of observation have proved very great. Hardly two animals can be studied in the same way, and it has severely exercised the ingenuity of our scientists to discover how single individuals can be studied. But this difficulty has been gradually disappearing. A second complication is more serious. From the difficulty of observation it has resulted that few of the observations of twenty. five years ago can be relied upon. The older embryologists did not realize how very easy it is to make mistakes in their observations on such minute organisms. A little whirling embryo, only semitransparent, is a very difficult object to study, even with the best methods and conveniences. It is therefore to be expected that the first observations, made with imperfect instruments, should be very faulty. And, moreover, the simplest principles of the subject were then unknown, and, with nothing for a guide, the early observers did not even know 
what to look for, and in a subject as difficult for observation as this, it is almost necessary to know what to expect. In short, all of the errors belonging to the infancy of a subject are found in the older investigations, and it has been necessary, therefore, to make numerous corrections. They are constantly being made, and with a new understanding of what is significant and what unimportant, new interpretations are being gained. From the general uncertainty in regard to former work, it is necessary now to review almost every thing which was done earlier than twenty-five years ago, if one wishes to make sure of any important point. The modern student has found that, so far as superficial observations were concerned, the older embryologists were accurate and painstaking in what they saw, but the internal anatomy, and particularly the changes which take place in various stages, they were likely to describe incorrectly.

Further difficulty has arisen out of the fact, already dealt with at some length, that the embryological history is so frequently modified. Not only has food-yolk produced a series of modifications, but another entirely different sort of changes has arisen in free larvæ. Many animals pass part of their early development as free-living, independent organisms, as independent, indeed, as the adults. The caterpillar is nothing more than an embryonic stage of the butterfly, and is sometimes more independent than the butterfly itself. Such larvæ, living as free forms, obtain their food by their own exertions, and have many enemies to contend with. 
They are, therefore, as truly engaged in a struggle for existence as the adult. Now, since these larvæ are known to be subject to variation, there is no reason why the action of the environment should not modify them as much as it does the perfectlydeveloped insect. If this occurs, the larvæ immediately begin to depart from the typical form, and the embryological history is much modified. Abundant instances of this occur in Echinoderms, Crustacea, and insects. We see, therefore, that the embryologist has to deal with modifications arising from a stationary, dependent condition of the embryo, and others arising from its free, independent existence. Neither the direct nor indirect development can be implicitly relied upon. It would almost seem, therefore, that here was a bar to further advance. Some biologists have expressed themselves as out of sympathy with any further reasoning after the great falsification of the record is once admitted. But the difficulty is not so great as it seems. Undoubtedly, such modifications exist, and the only question is as to the ability of the student, with the evidence at his command, to recognize them. Of course, this cannot be done from single specimens, but it has been found possible in many cases, by the collection of great masses of data, to straighten effectually the evidence and get some logical results. But it is certainly necessary to withhold any conclusions until we can get all of the evidence possible from every source, in expectation that when all comes to be considered together the truth may be plainly apparent. The wiser embryologists, therefore, have 
postponed formulating any more histories of animals, until such time as the abundance of evidence shall enable them to reach more legitimate conclusions. In short, although embryology is believed to be a key to animal history, it proves so difficult to use that many doors still remain locked.

\section{The Application of this Principle.}

Having recognized the parallel, and having considered its significance, we have stated the whole of the direct argument which embryology has to offer. It is impossible, however, to get a correct idea of the real force of the argument without examining some of the results of the application of the principle. We will now, therefore, proceed to consider what embryology has taught us of the history of animals.

All embryological discussion is now based on the tacitly understood assumption, that an animal's development is a repetition of the history of its ancestors, and that a complete knowledge of the former would give us an approximately perfect knowledge of the latter. By a complete knowledge of development is not meant simply the knowledge of the present actual course of embryonic growth, for when the possibility of the modification of the record is recognized, it becomes plain that the knowledge of the actual embryology is by no means a complete understanding of its development. A complete knowledge would imply a knowledge of the primitive type of development, and the method by which the modified type has been derived, together with the circumstances accompanying the 
change. Such a complete knowledge as this it is useless to hope for, but every day gives a closer approximation to it, and it is quite probable that the state of the science may reach a condition where it will be possible to sketch the general history of animals.

A short summary of the teachings of embryology is something as follows: All animals start together as a single cell, so that the man cannot be distinguished from the lobster or mollusk. An embryo arises from this cell, which shows itself to be a vertebrate in distinction from an invertebrate, but is as yet not a mammal, but more like a fish. With further development it shows a slight approximation toward the reptiles, but instead of becoming a member of this class, takes a little different course and declares itself to be a mammal. Next, it turns toward the direction of the primates rather than rodents or ungulates; then it exhibits the characteristics of an ape, in distinction from the Lemurs; and finally, just before birth, it takes on the features of man. And this same story is repeated in all cases, the line of development being the sub-kingdom, the class, the sub-class, the order, the family, the genus, the species, thus coinciding with one tree-like classification of animals. While this is the general history, some points demand more extended notice.

\section{The Abundance of Hypothetical Stages.}

Considering all of these difficulties, we are prepared to be somewhat disappointed when we try to take a general view of the positive results. The positive conclusions are few, the negative conclusions 
are many. The embryologist does not seem to know so much about the history of animals as he did twenty years ago. In reality the reverse of this is the truth, for these twenty years have seen a continual advance. While they have disproved many of the old views, they have taught the student to be cautious in founding conclusions on insufficient data. In the very infancy of the subject, Haeckel boldly traced the complete history of man from the simple protozoan to his present condition. Without hesitation he laid down the complete genealogy of man from evidence found in his development, with no attempt to get help from other sources. And inasmuch as embryology was in a very crude condition at that time, we are not surprised to find that this genealogy contained more errors than truths. He divided man's history since the appearance of life into twenty-one stages, which he thought were indicated by stages in his development. It is needless here to enumerate these stages, for little by little has it become evident that most of them were guesses, or at least founded on very insufficient data. Of these twenty-one stages, more than half have been proved to be wrong, and in regard to some of the others it is questionable. This attempt of Haeckel, made with such boldness as almost to inspire belief, is thus a failure. Nor has Haeckel been alone in this attempt, for others have essayed a like task. Darwin, with all his caution, was led in his "Descent of Man" to trace out his history, and he came no nearer the truth than did Haeckel. But to-day the wiser naturalists do not 
pretend to know so much about the matter, and although they do occasionally construct similar histories, they regard them only as tentative, and probably erroneous in many features. They have disproved Haeckel's phylum, but have put nothing in its place. They are not ready to say exactly what man's genealogy has been, but can say very definitely what it has not been, a conclusion which though not appealing so strongly to the imagination, is a much more important one.

But this conclusion is more than a negative result for its existence leads to one very definite and important deduction-perhaps the most important one which embryology has brought into prominence. Stated briefly it is this: Probably none of the stages through which man, or any other existing animal, has passed in his history, exist as living animals to-day. This point has been emphasized repeatedly. The parallel often drawn between the embryonic stages of higher animals and the adult stages of lower ones, proves upon close examination to be largely a delusion. The embryonic stages of higher animals resemble not the adult stages but the embryonic stages of lower animals. Embryo man, for instance, does not resemble the monkey, but at one stage in their development the embryos of these two species scarcely differ from each other. The human embryo does not resemble a fish, but both man and the fish pass through a stage in which they are much alike. Now the interpretation of these facts means simply this. Man is not descended from any of the man-like apes, but both man and 
ape are descended from a third form not living today, but which is represented by the stage which the two embryos have in common just before birth. Now this hypothetical form was neither man nor monkey, but midway between them. If we should find his bones in the rocks we might not unlikely call him an ape, but if we should know more about him we should find that he did not resemble any animal living to-day. Or again, man has not descended from an animal like our modern fish, but both man and our fishes have descended from a third intermediate form. This form doubtless lived in the water and would probably be called a fish were we to discover its remains in the rocks, but it was in reality very different from our modern fishes. For a time our fishes and mammals travelled together, but soon one group took one direction and the other another, both continuing to develop, getting farther and farther from each other and from this common ancestor. And so everywhere. The types of animals which were the common ancestors of our existing groups are all extinct. Embryology shows us that if we wish to trace the past history of animals, it must be mostly done through hypothetical forms, which have existed in the past but are now extinct.

The extent to which this principle is true, is excellently illustrated by a tentative ancestry of the vertebrates as taught by one of the ablest of modern scientists. If one takes the trouble to refer to vol. ii. of Balfour's "Comparative Embryology," it will be seen that he derives the mammals from the earliest 
vertebrates by six stages, every one of which he acknowledges to be hypothetical.

Here, again, it would seem that embryologists had abandoned a definite position for an indefinite one; but a little thought will show that this latter position is the true one. If evolution is true, animals are continually changing, either slowly or by occasional rapid advances, and that any single form should retain its specific characters for a great (geologically speaking) length of time, would be the exception and not the rule. These hypothetical stages which we are considering must have disappeared very long ago. To be sure, as already pointed out, time does not necessarily imply change, but in these cases we know the change has taken place. The very fact that the ancestor of man became modified in two directions, one toward man and the other toward the monkey, would preclude us from finding any representative of this ancestor living. Connecting links will, therefore, almost always disappear. Although living links between different groups are occasionally found, it is hardly probable that they represent the true ancestral forms. The demand for the "missing link," once considered so great an argument against evolution, ceases to be of any significance with this understanding.

But, nevertheless, granting all of this, it is evident that these hypothetical ancestors must have existed at one time, if the descent theory be true. Have they left no trace? If we can find no living representatives of them, we certainly ought to find them represented by fossils. We are thus brought back 
once more to the subject of paleontology, into which we need not again enter. To a certain extent, naturalists have succeeded in finding among fossils remains of animals which may well be these hypothetical forms, but it must be confessed that their success has not been very great. Aside from the general imperfection of the geological record, several distinct reasons can be given for this. Firstly, most of these stages, concerning which embryology teaches us, must have lived far back, in ages which have left few fossils. But, secondly, we notice that embryology can give us only the general characteristics of these forms, and says not a word as to their specific features. Now, every fossil must have specific as well as general features, and the presence of the former, which are often more prominent, may obscure the latter. Thirdly, all of these stages would resemble, more or less, one of the groups which they connect. If our paleontologist should, therefore, find an imperfect representative of such a connecting link, he would usually class it with one or the other group, without recognizing its immediate character. It is not improbable that the fishscales found in the Silurian age belonged to one of the very hypothetical stages of which embryology teaches, but how are we to know whether it be so or not? These scales come nearer to those of a fish than to any thing else we know, and they are therefore said to belong to a fish. The absence of these hypothetical stages is, therefore, not very surprising, though it is certainly unfortunate. 


\section{Embryological History.}

Having now noticed these various difficulties in the way of a complete history, let us begin with early stages of development and see how far any logical history can be traced. Of the early stages of development embryologists have made us well acquainted, for they have spent most of their time on this subject. Owing to the difficulties of observation upon older embryos, it is the early stages which have received most attention. But this necessity has not been an unfortunate one. It is evident, from the fact that all of the great groups of animals were already developed in the earliest rocks, that paleontology can tell us nothing in regard to the development of these groups, and their relation to each other; a fact which has been used as an argument for the primitive distinction of types. Now, embryology comes in to fill up this lost history. The early stages of the embryo must, of course, represent the first stages of this lost record, and ought to give the relation of the sub-kingdoms to each other. The later stages represent later history and the origin of smaller groups. The latest stages will represent the growth of the smaller groups of genera. Now, the study of classification gives good evidence as to the origin of small groups; paleontology enables us to trace the history of the origin of orders, etc.; but embryology alone can give us evidence as to the relation of the sub-kingdoms to each other. It is, then, a fortunate necessity which has led to a particularly careful study of early stages of the embryos of a very large number of animals; 
for no other branch of science is able to lead to any conclusions as to the union of the great branches of the animal kingdom into a common trunk.

All animals start together. At the beginning of life the highest and lowest alike consists of a simple single-celled ovum. This is the universally recognized starting-point. Interpreting this, therefore, the embryologist says that it means that we are to assume as the starting-point of life of the animal kingdom a single-celled ancestor, or protozoan, who lived long before the earliest record which the rocks give us. Next, we find that this ovum divides into a number of smaller parts, each consisting of a single cell, and all at first seemingly alike, cases where they are unlike being due to secondary modifying circumstances. This is called segmentation, and is a stage in development universally found in all animals. It is not alike in all, for the disturbing presence of food in the egg often prevents a regular division. Sometimes the whole ovum divides, sometimes part of it ; sometimes the segments are of equal size, sometimes of different sizes. But after a careful examination of all cases and circumstances connected with them, the conclusion seems to be that they are all modifications of the simplest type, and the regular equal division may be considered as primitive. Now, this division can mean but one thing to the embryologist. It is the repetition of a similar process taking place long ago in the primitive unicellular ancestor of animals, which is supposed to have divided in like manner, and thus to have formed a colony of unicellular animals. This same process is known to take place to-day in some low forms of life. 
We can take yet another step in the development and still find all animals to agree. We reach thus the much-discussed gastrula stage. In its simplest 3 form the gastrula is a two-layered sac, open at one end. The two layers of the sac are composed of the small cells into which the ovum has divided. These two layers are different from each other, for the outer one is the body-wall, and is sensitive, while the inner one corresponds to the digestive tract. The opening of the sac is the mouth, and is believed to correspond, partially at least, to the mouth of higher animals.

According to Haeckel, this gastrula is a universal stage of development, and represents the common ancestor of all animals. There has hardly been in the history of science a more happy prediction, founded on such insufficient data, as this gastrea theory of Haeckel. At the time it was made, embryology was a very young science, but comparatively few facts were known, and many of the then accepted facts have since proved to be erroneous. But Haeckel, finding that many animals which he had been fortunate enough to study passed through a stage resembling a two-layered sac, with his characteristic boldness he made the prediction that this stage would be found universal in the animal kingdom, and concluded that it consequently represented an animal, living in ages past, which was the common ancestor of the whole animal kingdom. And it is marvellous how this prediction has little by little been shown to be at least partially true. Taking a survey of the whole field of embryology to-day, it is 
a fair statement to say that there is not a group of animals, with the possible exception of the sponges, which does not show in its development some traces of this gastrula. It is true that the gastrula is formed in many ways; it is true that it has a very different appearance in different cases; that it is in some cases only dimly suggested; it is true that its original method of formation is still a matter of dispute, and that the relations of its various parts to the adult are not in all cases settled; it even appears under different names in some of its different forms (planula-plakula). But these points only make the case the stronger, for in spite of the various modifying circumstances affecting the development, so strong is the tendency to inherit this stage, that it is very difficult to find even general exceptions to the rule. The significance of this fact can hardly be overrated. For the embryologist it is sufficient proof that if we could correctly follow back the history of animals, we could trace them all back to a common ancestor which in fundamental features resembled this two-layered sac. And this represents the first multicellular animal which the evolution theory assumes ever to have existed. The stage before this was not a multicellular animal, but a colony of independent unicellular individuals. But now the independence of the different cells is lost. They become united into a dependent unity. Some of the cells have one duty to perform for the whole colony, and others have a different function. One set of cells does all of the digesting, and another has the function of sensation, etc. A division of labor 
has arisen, and this gastrula represents for our embryologists the first multicellular animal which ever existed, and which was, therefore, the common ancestor of all animals now living, with perhaps the exception of the sponges.

If it be asked whether this hypothetical ancestor is represented by fossils, the answer is that it is not and doubtless never will be; its body, having no hard parts, could not possibly have been preserved. If it be asked whether it is a purely hypothetical form, unlike any thing existing to-day, the answer is, while the gastrula as such does not exist to-day as an adult animal, there are some cœlenterates which approach quite close to it and are to be considered as direct modifications of this ancestor.

\section{The Separation of the Sub-Kingdoms.}

Thus far we have been able to trace the embryology of all animals over the same road, but we can do this no farther. From the gastrula the different large groups depart in different directions. This point has only of late years been recognized. The understanding of the animal kingdom at the first of the century was such that all of the different groups: were placed in linear order one above the other. If this were true the embryology of the higher animals ought to be much the same as that of the lower ones, as far as the adult condition of the latter. But this idea proved palpably untenable, and soon was replaced by the conception of the animal kingdom under the form of a tree, whose branches, as we go downward, continually unite into large 
ones and finally into a common trunk. And studies since Darwin have tended to show that the gastrula is the representative of this common trunk, and that from it all of the great groups branched off directly. It is one of the problems now before embryologists to decide as to the number of the branches which arose from this ancient ancestor, whether indeed the meaning of the groups which we recognize as sub-kingdoms, is not that each represents one of these branches from the gastrula, and if so to determine how many sub-kingdoms we should find. For instance, whether the Arthropoda (insects, etc.) and Annelids (worms) should be regarded as separate branches, or whether they arose in common from the gastrula and soon separated from each other.

This early divergence of the great types from each other is one of the important deductions of recent embryology, since it enables us to meet one of the problems we discoursed in the last chapter, viz.: the simultaneous appearance of the types in the Silurian. One extreme view derives seven or eight branches directly from the ancient common ancestor: I cœlenterates, 2 polyzoa and brachio. pods, 3 annelids, 4 arthropods, 5 mollusks, 6 echinoderms, 7 vertebrates, and perhaps another to include the heterogeneous group vermes. Now if any such conclusion as this is right, we immediately find an explanation for the Silurian fauna. All of the types which have been found in the Silurian rocks developed independently and simultaneously from the ancient common ancestor; and it is no 
longer a surprise that when the Silurian age opened they were all found well developed. It is more of a surprise that we do not find the vertebrates as well developed as the rest.

It is evident that we cannot trace the common embryology of animals beyond this gastrula. If we wish to go farther we must follow the sub-kingdoms separately. The difficulty increases as we attempt to take another step. In some way this gastrula was modified in various directions to give rise to the various sub-kingdoms, but the embryological record has been so much modified as to make it at present hardly possible to follow the history. In a few cases it can be done (cœlenterates, annelids, mollusks) but as a rule it is impossible; in most cases we find that our evidence leaves a chasm between the gastrula and the earliest form which can be regarded as showing an approximation toward the anatomy of the sub-kingdom to which the embryo belongs. All sorts of suggestions have been offered as to the filling of this chasm by theories regarding the exact manner in which the gastrula was elongated or expanded to form the various types arising. The vertebrates have received the most attention, and here theories are particularly abundant. But every thing is as yet only hypothetical and we need not take the trouble to examine the question.

After passing this chasm we can once more reach sure footing. We now find that embryos have assumed various forms, each conforming to the type of its own sub-kingdom. It is not our purpose to 
attempt to follow the various lines. The general history of the various groups is essentially alike. The embryos are at first fundamentally similar, but they soon become unlike, the time of separation depending on the closeness of relation of the adults. The more distant the relation of the adults, the earlier the embryo separates. The general embryological history of all divisions is thus parallel to their arrangement in a scheme of classification, a parallel which is always subject to modifying circumstances, as we have already seen.

\section{Vegetable Embryology.}

The embryology of plants is of little importance, since it illustrates none of the significant principles found in developing animals. The organization of plants is so simple that an extended history would be impossible, and seeds, moreover, are almost universally supplied with abundant food. Add to this the fact that the embryology of plants and animals has been studied in a very different manner and for different purposes, and we discover the reason why the vegetable kingdom gives us practically no evidence from its developing embryos.

\section{Summary.}

We have seen that the study of adult anatomy leads to an arrangement of the relations of groups in the form of a branching tree. While it is evident that this arrangement must be accepted, it is equally plain that the study of adult anatomy alone will never enable us to unite the various sub-kingdoms 
with each other. Adult anatomy seems to teach that although the various types are nearer together at the bottom than they are at the top, yet there is no evidence to show that they are united. And the same result arises from the study of fossils; for while undoubtedly the record of paleontology does prove convergence of lines and the union of many smaller groups, the great types are as distinct from each other at the earliest times of which we have any record as they are now. While, therefore, such studies indicate the common union of the animal kingdom at a starting-point, they leave it only a matter of inference.

The first assistance which embryology gives toward a solution of the animal kingdom, is in completing this chain of evidence. A long and careful study of development has brought to light the marvellous fact that the embryology of the individual is a brief repetition of the past history of the race, a law which, subject to certain limitations already discussed, is found to be in complete harmony with the facts as now known. The existence of this law is the argument of real significance which embryology has to offer, for it is a law readily following from the descent theory, but unintelligible otherwise. Using this law to interpret the past, it is found that all animals start together at a common point, all begin life to-day as a unicellular ovum. Not only this, but for some distance they can be followed over the same road, until a stage is reached which is called the gastrula. Now if the parallel means any thing, this indicates that all ani- 
mals had a common history up to the time of the appearance of the first multicellular animal, i.e., the first animal in which the cells had ceased to be independent, and had formed a unity, the various parts having different functions. From this point there is a divergence in many directions. And here the embryological evidence is lacking, for we cannot yet tell to how many lines of descendants this common ancestor gave rise, nor what were the sort of changes which converted this form into the subkingdoms which came from it. There is, then, at this point, a gap which, as yet, cannot be filled with any reliable stages. But the existence of this gap does not detract from the all-important conclusion that, by means of embryological evidence, it is possible to demonstrate a common starting-point of even the most diverse branches of the animal kingdom.

A second method by which embryology has assisted in bringing about an understanding of the animal kingdom is, by enabling the naturalist to discover the direction of development taken by the various orders within the types; or, in other words, to discover the relation of the different divisions of the various sub-kingdoms to each other. In this task collateral evidence can be obtained for some groups from fossils. The amount of evidence of all kinds is constantly increasing, and although, as yet, it is quite insufficient for the final solution of many questions, the general tendency is all in the same direction. Leaving the gastrula and passing the gap we have mentioned, the next step is the appear- 
ance in various embryos of the characteristics which mark it as belonging to one of the various types. A rudimentary nervous system appears, indicating the vertebrate type ; a peculiar mesoderm indicates the echinoderm sub-kingdom, etc. Next, it is seen that, having general characteristics, the embryo assumes those of the class to which it belongs. The vertebrate ceases to be a vertebrate in general, and becomes a fish or mammal; the echinoderm becomes a star-fish or sea-urchin. Next follow the characters of the order-the sub-order,-and, as development proceeds, the family, and finally the genus and species, the last distinction frequently not appearing until the fully adult condition is reached.

Embryology, therefore, forms the final link in the chain of evidence which proves that there is a fundamental unity in the organic world, for the fact that embryology repeats past history proves that there is some unitary bond uniting the present with the past. Evolution offers heredity and descent as an explanation of this bond, and although this is not the only possible explanation, it is certainly the simplest, and the only one yet offered which is founded on natural law; and while with advancing knowledge the evidence is growing more complicated and difficult to understand, there cannot be the slightest doubt that it is becoming continually more and more clear that this explanation is adequate to meet the facts. 


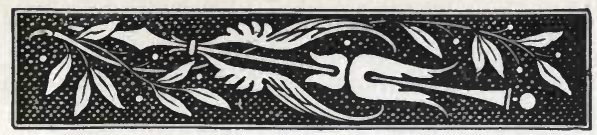

CHAPTER V.

GEOGRAPHICAL DISTRIBUTION.

THE geographical distribution of animals on the world to-day is another source of collateral evidence as to the origin of species. It is of particular interest, since it was the study of this subject which first led Darwin to the theories which have made his name immortal. It was this same class of facts also, accumulated by years of travel, which led Alfred Wallace independently to conclusions similar to those of Darwin. To-day, it is still the subject of geographical distribution which offers some of the most convincing proofs of the modification of species, while at the same time it presents some of the most puzzling problems for solution.

The subject is one of the greatest complexity, for not only are the species to be studied very numerous, but the various causes acting in the past and present to alter the distribution of any species are almost infinite. Consider how little it takes to produce a change in the fauna and flora of a given locality. The introduction of a few English sparrows into the United States has, in a very few years, caused great changes in our animals, driving away and almost exterminating some American birds. The increase in the cultivation of the potato has, in a short time, 
extended the range of the Colorado potato-beetle from small localities of the West over almost the whole of our country, and even into Europe. The presence of the tsetze-fly in Africa makes large territories uninhabitable by cattle, which are found both north and south of the infested regions. Many plants depend upon insects who carry their pollen from one to the other. The insects are dependent on the insectivorous birds, and these upon the abundance of bird-eating mammals. When we consider the multitudes of such modifying conditions which are known, it becomes evident that there must be even greater numbers unknown and unthought of. The accidental introduction of new animals into an old country; the slightest changes in climate; the changes in the course of river-beds; the disappearance or growth of forests; the abundance or absence of certain kinds of food; changes in the level of the land; the removal of slight barriers which have prevented free migration between contiguous localities;-all of these circumstances produce profound modifications in the inhabitants of any country, and teach us that we must not be surprised if it is frequently impossible to say why any animal is found in one locality and not in the neighboring ones. Moreover, the present distribution must be dependent on the past, and we know too little of past history to give any hope of a complete explanation.

\section{Animals not Distributed According to Climate.}

It might have been supposed, indeed would naturally follow from the standpoint of special crea- 
tion, that animals are exactly adapted to the localities they inhabit; and that the reason that different localities have different species is because they have different climate, etc. But this is not found to be true. Of course there is some general relation of animals to climate. Those accustomed to an Arctic climate are never found in the tropics, and those belonging to forests are never found in the open plains. It is by no means true, however, that localities differ in their inhabitants simply because of differences in conditions. There are many cases where localities with almost identical physical conditions have utterly different animals and plants. South America has a very varied climate, and many localities could be picked out which would match exactly, in their physical conditions, localities of Africa; and yet their fauna and flora are very unlike. Nor is this all, for there is abundant proof that the New World is as well adapted for Old-World species as is their native home. For instance, America possessed, when discovered, no member of the horse family, but as soon as this animal was introduced by the Spaniards, it ran wild, and increased with marvellous rapidity, and now exists in enormous numbers; indicating clearly that the absence of the horse from the western continent was not due to adverse physical conditions. An even better illustration is Australia. This strange land has a highly peculiar indigenous fauna, consisting, as far as mammals are concerned, entirely of marsupials and monotremes. But this is not because the land is not fitted for other animals, for every European 
species which has been introduced has flourished, and has caused more or less extinction of the native tribes. The people have a saying illustrative of this. "As the white man's rat has driven away the native rat, as the European fly drives away our own, and the clover kills our fern, so will the Maori disappear before the white man himself." All such instances, which are numerous enough, show that species are not created especially for the locality they inhabit, since many localities are better adapted to other animals than those which now inhabit them, and since some species flourish better in other localities than those in which they are found. Climate is a factor in regulating distribution, but since like habitats may possess unlike fauna and unlike habitats possess like fauna, it is evident that the influence of climate is only secondary.

Lawes of Distribution which would Follow from the Descent Theory.

All that can be expected from evidence on this subject is that the distribution of animals is such as would have resulted if the descent theory were true, and this will, of course, be only an indirect argument. Let us then first notice certain laws of distribution which the evolution theory demands and without which it cannot stand.

- (I) It follows from the descent theory that allied species should inhabit neighboring localities. If species are simply exaggerated varieties, and genera exaggerated species, it would follow that they must have a regular distribution. A given species must 
have arisen in some definite and usually restricted locality, either slowly or suddenly by a change in the conditions of its ancestors. This locality must then be the centre of distribution. It may subsequently extend its range so as to cover eventually a large area. But evidently this area must be, at first, a continuous one, such as may be accounted for by migration, for we cannot expect the same species to arise in two localities independently. If, therefore, we find the same species in two widely separated localities, evolution must assume that it formerly also inhabited the intermediate tract of country, and that, owing to causes which can seldom be explained, it has disappeared from the intermediate regions, while it still remains at the extremes. If, for instance, the central States of our country should cease to cultivate the potato, the potato-beetle would disappear from this region, while still continuing to live in the West and the East; and we should thus have a case of a single species inhabiting two separated localities. The same principles would be true in regard to the distribution of genera, although here they would be less exact, since the greater age of the genera would give greater chance for wide distribution and extinction; but we should still look for the distribution of the species of a genera corresponding to their relation to each other. In the case of families, still greater range of variation would be expected, since they are doubtless very old, and have had time during their existence to migrate to all parts of the globe, and to have become extinct in many localities. It will cause 
no surprise, therefore, if the different genera of the same family should be found to be sometimes widely separated from each other, particularly if fossil evidence show that the intermediate localities were formerly also occupied by the family. Larger groups than families are so old that no geographical relations could be predicted. (2) It would necessarily follow that barriers, which limit the migration of a species, must be the limits of the extension of the species. The same species ought not to be found on both sides of such a barrier, unless it can be shown that the barrier in question is of recent origin, or that it really does not entirely prevent migration. (3) The theory would require a close relationship between the present and past inhabitants of any country, since the latter have descended from the former. This would, therefore, make it desirable that a direct relation should be found between the present inhabitants of any locality and its recent fossils, after making deductions due to recent migrations. Geographical distribution should thus be a science by which the localities of species, genera, etc., could be explained from the consideration of the relationships and powers of migration of the organisms, and the changes in the configuration and climate of the land. Anatomical relationship should be parallel with geographical relationship. Unless these laws are found to be verified with more or less exactness, it would be impossible to accept evolution; if they are verified, evolution finds a certain amount of support. 


\section{The Relation of the Present to the Past.}

Speaking in general terms, it is found that the species of the most recent geological deposits are identical with those now living, although there are, of course, thousands of species now living which have never been found as fossils. Rocks somewhat older contain fossils related to existing forms, but specifically distinct; and going still farther back, the relations become less and less close, until finally we reach a fauna very different from that existing today. All of this is, of course, compatible with any theory of the organic world that we may form, agreeing equally well with special creation or with evolution. But when closely examined the facts are more significant. If the fossils of any one locality, sufficiently isolated to prevent free migration, be compared with its living animals, a striking likeness is seen. For example: it is found that the fauna of South America is peculiar in possessing a great number of the remarkable order of Edentata (armadillos, etc.), animals found nowhere else in the world, with the exception of one quite different form in Africa. Now the fossils of North and South America are also remarkable in possessing great numbers of Edentates, which will therefore naturally be looked upon as the ancestors of the present species. Another illustration is offered by the primates of the New and the Old worlds. The New-World monkeys are very different from those of the old world, although, so far as we can see, there is no reason for this in the physical conditions of the two worlds; but the species of the one locality form a very distinct group, 
which is radically separated from those of the other. And South American fossil monkeys are similar to the present animals found there; while the fossils of Europe are closely related to the order of OldWorld monkeys now existing. Perhaps the best illustration of this principle is afforded by Australia. This strange land has no mammals except marsupials, and, as we come to study the fossils of the country, we find that they in like manner comprise numerous marsupials, but no other mammals, and these marsupial fossils are of such a structure as to show a close relation to existing species. It cannot, of course, be claimed that the present species were created so closely related to the older inhabitants, because the climate of Australia is especially adapted to this form of animal; for, as we have already noticed, almost every European mammal is able, not only to exist in Australia, but also to exterminate the native inhabitants. But geology readily explains this peculiar fauna. Australia was formerly connected with Asia at a time when the latter continent was filled with marsupials. But the connection was soon lost, and when higher mammals appeared in Europe and Asia they were unable to get into the now separated Australia. The marsupials which this land had originally received from the north, had the whole continent to themselves, and they therefore multiplied and expanded, giving rise to the present marsupial fauna, unmolested by any of the higher mammals which were developing on the other continents. And numerous other instances could be given, showing conclusively that 
when any country possesses a peculiar fauna, the fossils indicate that the same peculiarity existed in times past, although it usually happens that no species found to-day exists as a fossil. That this fact is an indication of genetic connection between the present and the past, is evident enough.

When, however, we examine the great bulk of species on our larger continents, we soon discover that the present distribution of many of them is by no means similar to that of their fossil representatives. Many animals now confined to small localities formerly ranged widely. Species, genera, and families which have in the past wandered to and fro with varying conditions, have become extinct to such an extent as to obscure the general relation just noticed. Horses, for instance, were not found in America when discovered, although fossils tell us that they did exist here in the very recent geological times. Fossil camels appear in our rocks, although no living camel belongs to the New World. America formerly had a fauna composed of elephants, hippopotamuses, tapirs, and hosts of other animals now found in Africa or India. All this is, however, not surprising, for migration and extinction have been abundant. If it had appeared that America when discovered possessed a large family of horses, while its fossils showed no trace of them it would have presented serious trouble; but no case of this kind is forthcoming.

In this connection has appeared one result of special interest. The study of the fossils of North America and Europe discloses the fact that only a 
short time before the present geological epoch the northern continents possessed a fauna very different from that now found there. Over Europe lived a fauna closely resembling that now found in Africa and India, and North America similarly contained animals now belonging to South America. At this time the northern and southern continents differed very little from each other. Elephants, giraffes, hippopotamuses lived all through Europe; tapirs, great tigers, llamas, edentates, existed in great numbers in North America. Since that time there has been a remarkable change, and one which appears to have been quite sudden. But it is a change which has received a happy explanation, for this wide distribution of tropical animals occurred just before the glacial period. Geologists have agreed that not long before the present era the northern parts of the northern continents were covered with great sheets of ice which gradually travelled southward, covering much of Europe and North America, and producing great physical changes of every kind. This southward moving glacial mass is seen at once to be a perfect explanation of many of the differences between the present fauna of the northern continents and that of older times. With the advance of the ice and the consequent fall in temperature, all animals and plants must have been driven farther and farther south. Many were destroyed altogether, not being able to find a suitable climate. Some were driven into South America and Africa, and, finding here favorable conditions, they continued to live and multiply. When at last the ice once more 
retreated northward at the close of the glacial period, many animals would follow the retreating ice and thus once more come to inhabit their old localities. Others finding the conditions of their own home well suited to their needs, did not return north, but remained where they were, or even went farther south, And thus the southern continents came to be the habitat of animals and plants previously ranging into the northern continents. The glacial period, by causing extensive migration and extinction has profoundly modified the distribution of animals and plants.

The distribution of fossils serves in many cases as a key to the present distribution. There exists a wonderful relation between the living and the dead inhabitants of any country. It is often possible to trace quite exactly, by the study of living animals and fossil, remains, where a given order first arose ; how it dispersed in various directions, reaching widely separated regions; and how, finally, it became extinct in many places, leaving as its scattered representatives to-day families separated by wide tracts of land or sea. For example, such studies have revealed the following history of marsupials. The order arose in Europe as the earliest mammals with which we are acquainted. From this point of origin they spread all over the eastern hemisphere, even reaching Australia, at that time connected with Asia. They also migrated westward, and succeeded in reaching America, by what means we do not at present completely understand. But reach America in some way they did, and thus the whole world be- 
came inhabited by marsupials. Meantime, there appeared in Europe some representatives of the true mammals, which were of a higher order than marsupials, and quickly began to contend with and exterminate them. These new mammals began to spread from their point of origin over the eastern and western continents; destroying the marsupials as they came into competition with them. They thus caused the complete extinction of the latter group over all the eastern continent except Australia, which had in the meantime become separated from Asia. On the western continent, too, the victorious mammals destroyed all marsupials except one single family, which, for some reason, succeeded in maintaining its existence. This was the opossum, which is found in North and South America; and thus we see the final result to be that, of the formerly widely distributed order, representatives are left in only two localities, separated from each other by half the globe. All of this time the species and genera have been constantly changing, so that the families now living are very different from those of the earlier ages. And so in other cases. The tendency of the evidence seems to show that mammals originated in Europe, or north of Europe, and then migrated east, west, and south, finally thus filling the whole world, except oceanic islands.

\section{Zoölogical Regions.}

Turning now from the past to the present, let us first notice how far anatomical relationship is parallel with geographical relationship. One prominent fact 
first strikes our attention. The animals of a single group, belonging to one country, though they may consist of many species, yet show a close relation to each other, and thus form a unit. Every naturalist who has had the opportunity of travel, or of examining collections from different localities, has been struck with this fact. As he roams through the forests of South America, he finds many distinct species of monkeys, differing much from each other, and yet all having a fundamental likeness by which they can at a glance be distinguished from the monkeys of the Old World. A collection of beetles, of birds, or almost any other class of animals shows a like result. And this is not simply that the species and genera are different, but there is evident fundamental difference between the species of two separated countries. This fact has found recognition with all students of geographical distribution, and has been expressed by the division of the world into zoölogical regions, in each of which the fauna and flora are found to show a fundamental likeness. These zoölogical regions are always separated from each other by physical barriers, which effectually prevent at the present time any migration from one to the other, and although they sometimes have identical climate, the fauna and flora are always distinct. It is true that different students of distribution have not agreed exactly upon the extent, or even the number, of these regions, their limits varying according to the class of animals which is taken as a basis for the division. Wallace, using the mammals as a guide, distinguishes six, while others 
have recognized nine. But the important fact is not as to the number or exact limits of these divisions, but that they do exist; that it is everywhere recognized that organisms are grouped together in masses, which are separated from each other by barriers. The details are a secondary feature.

The question of course arises as to what is the cause of this bond of unity found in the inhabitants of the separate zoölogical regions. Doubtless, some of it may be due to like conditions affecting all alike; but this is not sufficient to explain all. The South American monkeys all have six molar teeth, while none of the Old-World monkeys have more than five; and surely unlike conditions can never account for this sort of difference. It was long ago pointed out by Darwin that the theory of genetic descent offers an explanation for such facts. Separated as these regions are from each other, the species of any comparatively small, recent group will all be somewhat close relations, and the common bond of union is that of inheritance. The first monkeys reaching South America from the north, for example, had six molar teeth, and the present species, which are their descendants, though in many features they have become distinct, have retained this feature of likeness; and since now the physical barriers prevent the immigration of other forms, it results that all of the South American monkeys show a fundamental likeness. Barriers will thus tend to confine within their limits, species somewhat closely related to each other. Australia contains nearly all of the marsupials of the world; 
South America nearly all of the Edentates and flatnosed monkeys; Africa all of the hippopotamuses and giraffes; Madagascar most of the lemurs, - and all of these facts receive a ready explanation in accordance with the descent theory.

\section{Present Distribution of Species and Genera.}

As a rule, it is found that the area occupied by any species is a continuous one. For instance, the habitat of the common European jay (Garrulus glandarius) begins in the British isles, and extends throughout Europe as far as the Ural Mountains, the jay being common in this region everywhere that the presence of forests gives it habitation. Beyond the Urals it is never found, its place being supplied by another species of the same genus $(G$. brandti). And this instance illustrates the very general rule. It is a rule to which very few exceptions occur, hardly more than a dozen good examples being known. The marsh-tit (Parus palustris) is found in Southern Europe and in China, while the intermediate country is inhabited by a different species. But most of these exceptions are readily explained, and only serve to confirm the general rule. A few peculiar cases will be noticed further on.

Practically, the same rule holds good in the case of genera, continuous generic areas being almost universal. As the localities inhabited by the different species of a genus are compared, it appears that they usually touch each other at these confines, or sometimes overlap; in either case, making an uninterrupted generic distribution. The genus of true 
jays furnishes again a good illustration. One could begin in the British isles, travel eastward to the Pacific Ocean, and then, turning south, return west again, south of the Himalayas, through Western Asia and Northern Africa to Spain, and be able to find jays in all of this region, except a few interrupted areas which do not form suitable habitat for the genus. The species has changed many times, no less than twelve distinct species being found in this region; but the specific areas either touch each other or overlap. And in America another genus of jays is found, with its appropriate distribution. Exceptions to this rule are rather more numerous than in the former case, and this, of course, we would expect, for evolution looks upon a genus as a highly devel oped species, in which the varieties have become distinct enough to rank as species. If this is true, genera must be older than species, and although originally they must have had a common, central starting-point, they have had more time and opportunity for their dispersal and extinction than species; and examples of discontinuity do occur, although they are very few compared with the abundance of instances of continuity in generic distribution. One species of magpie is confined to Spain and Portugal, while another appears in Northeastern Asia and Japan. One species of a mole (Ulotrichus) inhabits Japan and another British Columbia. Two species of thrush-tit live in the Himalayas, while a third is confined to Java. The genus Ritta (ground-thrush) ranges from. Hindostan to Aus- 
tralia, while a single species inhabits West Africa. And other good examples might be given, all of which, from the fact that they are considered remarkable, are to be regarded as exceptions to the rule which finds genera confined to definite, continuous localities.

Taking families now into consideration, we are prepared to find a much greater amount of discontinuity. Families are only highly developed genera, but so long ago was it that all the forms of a given family had a common starting-point, that the various genera will have had ample opportunity to wander perhaps all over the world; to have become greatly modified; to have completely disappeared in some localities, being displaced by other animals better adapted to the conditions of life; and even, perhaps, to have become separated by impassable barriers, which have arisen since the migrations, such as recent mountain ranges. We should therefore expect that some families may have an almost cosmopolitan range, particularly those with great powers of migration. It is hardly necessary to say that the facts bear out this expectation. Some families of bats and birds have a practically world-wide distribution; many have a remarkably discontinuous area at the present day, although fossils tell us that formerly they were widely distributed. The camels are divided by the Atlantic Ocean, one genus living in Africa, and a second in South America. One family of insectivora is found in Madagascar, Cuba, and Hayti. On the other hand, there are a few examples of restricted family areas. The birds of 
paradise, consisting of nineteen or twenty genera and thirty-five species, are confined to New Guinea and the adjacent islands. In this case, it is necessary to suppose that the entire family has arisen since New Guinea has been an island. Neither continuous nor discontinuous family areas can be considered the rule.

When we come to larger groups, the rule is reversed, and continuous restricted areas are never found. Orders are very old divisions, becoming separated from each other at the very earliest period in the history of mammals, and no instance can be found where there has not been very wide dispersion. If we take into consideration fossil remains, there is hardly an order which does not show worldwide distribution. To-day the distribution may be very different, for families and genera have been dropped out, leaving the present ones widely sep. arated.

In short, the present distribution of groups of organisms upon our continents is parallel with their anatomical relationship and their antiquity. Species, which are of most recent origin, have almost always a continuous area of habitation, as if they had dispersed from some central point. Genera, being somewhat older, show a wider distribution, with more frequent breaks in the continuity, but still give evidence of a central point of origin. Families, older still, have ranged much more widely, while orders, the oldest of all, have had always a world-wide distribution, which in some cases they preserve, but in others have lost by extinction. 
Such a distribution is not out of harmony with the view that species are specially created-for no distribution could be out of harmony with this idea,but it will hardly be denied that the geographical distribution of groups indicates a law of distribution: a law unexplained by special creation, but one which must inevitably follow from the genetic descent of animais and the origin of species from older varieties.

Do Barriers Limit the Areas of Specific Distribution?

To this question the answer is that, as a rule, species are not found on the opposite sides of impassable barriers. But to this rule there are some remarkable exceptions of species which are not thus limited by seemingly natural barriers. And while the instances of agreement with the rule outnumber the exceptions one thousand to one, it is the exceptions to the rule which must occupy our attention. The most important exceptions are the existence of the same species of fish on either side of the Isthmus of Panama; the presence of the same species of freshwater animals on the two continents; and the presence of certain Arctic species of plants on the mountains of Southern Europe and America. These cases will be taken up, therefore, as illustrations of the classes of difficulties and the method of meeting them.

Such cases of discontinuous distribution are not to be explained by assuming a formerly wide dispersal, for how can we suppose that with any amount of dispersal the barriers in question could 
be crossed? The only method of explanation is to show either that the barriers in question do not act as rigidly as at first sight seems, or to show that they have not always existed. One series of difficulties disappears when we remember that the physical conditions of the land have not always been what they are now. The Pacific Ocean and the Gulf of Mexico are now separated by a barrier impassable to fishes; but this has not always been the case. We have only to assume the depression of the land a few hundred feet from the isthmus, and we should have the two oceans united. Here is a ready explanation of the first difficulty mentioned. Africa was once connected with Europe, though now it is practically separated from it. Similarly Australia was formerly connected to Asia. Many of our mountain ranges are of comparatively recent origin, and although now they form effectual barriers, they have not always done so. If, therefore, a species is very old we might find representatives of it on either side of such a recently created barrier, and not unfrequently might we find species of this same genus thus separated.

To explain the class of facts illustrated by the second of the above examples, naturalists have studied with great care the means of dispersal of animals, with the result of proving that the so-called barriers are not always so rigid in their action as at first appears. It would seem that fresh-water animals would be very limited in their powers of migration; would be confined to a single river or system of rivers. For, unable to live in the air or in 
the ocean, their distribution seems at first an impossibility. But this is far from being true ; for every one knows that fresh-water species are not thus limited, and few would have the hardihood to claim that each system of rivers had created for it a pair of parents for every species. Indeed, the actual means of dispersal from one body of fresh water to another have been discovered in many cases. Changes of level in the land cause rivers once separated to unite either permanently or temporarily; and floods have from time to time had the same effect Again, the eggs of many fresh-water species can survive exposure to the air for a long time, and clinging as they do to weeds and grass, may frequently be carried from place to place by birds or shaggy-haired animals. Nor does the sea always prove an impassable barrier, for many cases are on record of fresh-water species enduring without injury, for a long time, immersion in salt water. Floating ice has been known to carry fresh-water organisms across bodies of salt water, and here is a means of communication between different continents. Particularly significant is this suggestion when we bear in mind that instances of fresh-water animals being found on both sides of a large body of salt water, occur almost exclusively in the colder regions of the world, where this factor could come into play and where the continents approach each other. Again, some fresh-water animals can become accustomed to salt water, and vice versa; so that actual migration through the sea may take place in some instances. And the significance of these facts is 
increased when we learn that no cases are known where the same fresh-water species occur on either side of a high continuous mountain range, except in cases where human agencies have come into play, and one or two instances of a remarkable distribution of some very old species. The sea is, then, not an absolute barrier even for fresh-water animals, and a certain amount of similarity of species in two neighboring continents is not inexplicable.

The last of the difficulties mentioned, viz., the agreement of Alpine and Arctic flora, receives quite a different explanation. The glacial period once more proves of assistance. At the time when the glaciers swept down over Northern Europe, they, of course, drove in front of them all of the animals and plants of the north, so that finally the southern parts of the continents with an Arctic climate came to be inhabited by a species belonging to the more northern latitudes. When at last the ice began once - more to retreat northward, the climate of the southern regions began to grow warmer, and the Arctic species could not endure it. Some of them were probably modified to suit the change in climate, giving rise to new species. Others followed the retreating ice once more northward, keeping thus constantly in an Arctic temperature; while still others, instead of going north, simply ascended the mountains, and in this way kept themselves in a suitable climate. Eventually the mountains and the Arctic regions came to possess similar species. And by extending the explanation, the occasional likeness of species in the northern and southern continents 
is accounted for, some species migrating south as well as north in search after a cooler climate. Wallace has very carefully followed out this explanation according to the accepted principles of geology, and finds it a happy explanation for great masses of peculiar facts.

But, with all of these suggestions, we must not imagine that the difficulties are removed; many facts still remain for which no sufficient explanation has been given. Most of them are isolated cases, each of which must demand its own separate explanation, and they are certainly becoming fewer in numbers as we become more acquainted with the present and past history of animals. Probably the greatest difficulties which the present distribution of animals offers to the descent theory, concern the wide dispersal of fresh-water organisms. Even when we have granted all that is claimed as to the occasional means of dispersal by changes in the level of the land, by floods, by transportation of eggs, by whirlwinds, by floating ice, etc.,- -even when we have granted that these means have accomplished much, it still remains a marvellous fact that a certain fresh-water fish, Galaxias attenuatus, is found in the rivers of Tasmania, New Zealand, the Falkland Isles, and the mainland of South America. How to explain such a case as this, it is difficult to say, unless it be regarded as a case where a former species of almost universal distribution has become extinct except in these localities; and this explanation is any thing but a happy one. A similar, though less striking, puzzle is offered by the occur- 
rence of the same species of fresh-water hydra in the rivers of the two hemispheres. The wide distribution of land animals is sometimes equally surprising. Two species of the genus tapir occur in South America, and another in the Moluccas. The trogon, a gorgeously colored, insect-eating bird, is abundant in Asia and Africa, and a single genus is found in South America. Two species of anthropoid apes are found in West and Central Africa, and two others in Sumatra. All such cases as.these, though not insuperable difficulties, are rather puzzling. The distribution of the edentates offers perhaps the hardest problem of all. These animals appeared in South America, Africa, and Asia long before they did in North America. And since we can' see no means by which South America could have received its inhabitants except through North America, it is very surprising to find edentates in the former country earlier than in the latter. To solve this puzzle, some naturalists have not hesitated to assume a hypothetical continent which formerly united Africa and South America; while others, among whom are Huxley and Wallace, suppose that there once existed a tract of land in the northern Pacific which was the birthplace of the edentates, and which being connected at times with South America and Asia, furnished them with their supply of this order. Negative evidence in paleontology is, however, of little value, and it may yet be found that North America had its edentates earlier than the southern continent; but at present we do not know what to do with this case. Something of a surprise, 
too, is it to find that America, when discovered, possessed no horses, a family which geology tells us originated here, and which did exist until recent times, and for which the country was most admirably fitted, as has been since proved. Though somewhat surprising to find this so, it is not to be wondered at that we are ignorant as to the cause of this sudden extinction, for we know almost nothing of the surroundings of the past. Difficulties there are, then, and some of them very puzzling ones; but, as a rule followed in a vast majority of cases, the distribution of animals on our continent is such as can be explained according to the supposition that species, genera, families, etc., have all arisen at central points, and have from here dispersed in various directions, giving rise constantly to new forms.

\section{Oceanic Islands.}

All the cases thus far considered are animals on continents. But there are many tracts of land in the ocean which are not and never have been connected with the mainland. Most of them are volcanic in their origin and are situated, at least this is true of the so-called oceanic islands, not less than five hundred miles from the neighboring continents. Now, such islands have their own inhabitants. The first question is, of course, as to where their original inhabitants came from. Only two answers to this question are possible. Either they were especially created for these islands, or they have been derived from the neighboring mainlands. Upon the former supposition we should not 
be able to make any predictions as to oceanic-island life, except to expect that we might find either the same species as those found on the mainland, or some entirely different. But upon the latter supposition, which is, of course, the more probable, and which is practically proved by certain facts, it is perfectly possible to predict what sort of life would be found. If the islands in question were so related to the mainland by winds and currents, that animals could very readily reach them, their fauna and flora would be expected to be practically the same as those of the neighboring continent, except in the absence of animals which could not cross the water. The species of the island should be all represented by those on the mainland. But when the island is so situated that it cannot be visited except in rare instances, the case will be very different. Here the few animals and plants which occasionally reach the island will be practically isolated from their relatives, the completeness of the isolation depending upon the frequency of immigration of animals - from the mainland. Now there is not the slightest doubt that such isolation will produce a very great influence upon the development of species. The descendants of these individuals are removed from competition with other species; they are removed from the certainty of cross-breeding. Under these circumstances every variety will have a chance to perpetuate itself. Having little competition with other animals, even the less favorable varieties will be able to live and reproduce their kind, and not having numerous unmodified individuals to breed 
with, these variations will have a chance to develop rapidly. To understand the effect of isolation one needs only to call to mind the result of domestic breeding. The pigeons, for example, have been in a condition of practical isolation in the hands of the breeders, since the varieties are mated together. The result of this is seen in the great abundance of varieties which have arisen. Indeed, so important is this factor of isolation that one naturalist is inclined to believe it the all-important factor, and to explain the origin of every species by the isolation of a few individuals. Now the isolation of species upon oceanic islands is by no means so complete as it is in the case of the pigeons, for new individuals may from time to time arrive; and, moreover, each variety which arises from the first immigrants is not separated by itself. Still it is complete enough to enable varieties to develop in a manner impossible on the mainland, where they are subject to severe competition. We may expect, therefore, that the species which arrive upon these islands will become rapidly modified, and soon be so changed as to deserve the rank of new species, assuming, of course, that species can thus arise by accumulation of variations. And these species will further be closely related to those on the mainland. The extent to which these new species are developed will depend on the completeness of the isolation and the antiquity of the island. If time enough is allowed we may find new genera or, in extreme cases, new families. Imagine, for instance, a single pair of individuals thus introduced into an island far from the 
continents. Their offspring would develop varieties, and by continued modification these varieties would become species, and the whole would thus form a new genus. Still later even greater would be the differences. All of the new species thus developed would, of course, be well enough adapted to the conditions of the island, but utterly unfit to contend in a struggle for existence on the mainland. Nor, indeed, could they contend with the species of the mainland should they be introduced into the island, since the continental species have developed under severer competition and are consequently the best of the many varieties which have appeared, all inferior varieties being exterminated on the mainland; but this has not occurred in islands.

The explanation of island life as here given has been the result of long study. It has been given here, however, in order to make more intelligible a few examples. I have selected three groups of islands to serve as illustrations of the principles here involved, which form a series showing very prettily that the above explanations are correct. The first is the group of Bermudas, situated some five hundred miles off the coast of North America. These islands are in the stormy Atlantic, and are subjected to frequent winds, making every thing favorable for the visiting of the islands by birds and insects and the consequent arrival of various plants - for birds carry many seeds in their toes and crops. Direct observation proves that these islands are thus frequently visited. No less than one hundred and sixty-eight species of birds are found; all of them 
except three are American birds, and most of them are known to be driven to the islands every few years by storms. These islands are, therefore, of the class most readily visited from the continents, and the fauna and flora are in exact accordance with this fact, consisting almost entirely of continental species which can readily cross the water. There are no mammals except bats and rats. And, indeed, mammals are always absent from oceanic islands, appearing to have no power of crossing large bodies of water. There are no frogs; and these animals also have no power to pass bodies of salt water. There are no snakes, but one single lizard is found, which is the only remarkable animal on the islands. It is a peculiar species, and strange to say is considered by Goode to have its nearest allies in Africa. There are one hundred and sixty-eight species of birds, all but three being American species which have crossed the water. The other three are European species which have been introduced from Europe. Insects are scarce, but all are either North American or West Indian species. Of land Mollusca there are twenty species, four of which are considered peculiar to the islands. Of the seven hundred and twenty species. of plants five hundred and seventy have been introduced since the advent of man. One hundred and fifty were native island species, and are either North American or West Indian plants. It is doubtful whether a single species of plant really deserves to be called a peculiar species, although there are some half a dozen which may possibly be so ranked. The whole 
fauna and flora is thus characterized by being strictly American, and, with the exception of two or three exceptional species, can be readily explained by the ease with which animals and plants can reach these islands during storms and high winds.

The second example we will notice is the Galapagos islands. They are situated at about the same distance from South America that the Bermudas are from North America, but with one important difference. They are in the quiet Pacific where violent storms are almost unknown, and where even strong winds are of rare occurrence. They are, therefore, practically much more removed from the mainland than are the Bermudas. This is further proved by the fact that visits from the continent are very rare; the only actual cases known are a few water-birds. The isolation is, therefore, much more complete. Here as in the Bermudas there are no mammals except rats, even the bats not having succeeded in reaching the island. The rats are doubtless derived from ships which have touched here. Reptiles are, however, quite abundant. There are two tortoises, five lizards, and two snakes. Just how these animals succeeded in crossing the water it is of course impossible to say. It is known, however, that reptiles do possess some power of migration across the ocean. A living boa-constrictor, for instance, has been known to have reached St. Vincent Island, two hundred miles from South America. That these Galapagos reptiles were derived from the mainland, is plainly indicated by their close relationship to the species now living in the conti- 
nent. Although they are related to continental species, they are all of them distinct from any found on the mainland, some of them being so distinct as to be sometimes ranked as different genera. The two snakes are very different from each other, belonging to two families, and it is necessary, therefore, to assume that two immigrations of snakes have occurred in the past to account for the present species. The tortoises, although related to those on the neighboring continent, are distinct species, and are very remarkable animals, having developed to an enormous size, doubtless from the lack of any dangerous enemies. Of the fifty-seven species of birds thirty-eight are peculiar to the islands, and of the other nineteen all but one belong to the waterbirds, which are always great wanderers; and seven of the water-birds are peculiar. The only land bird common to the islands and the continent is the American rice bird (bobolink), which ranges over the whole of North and part of South America. Only a few insects have been found, most of which are peculiar to the island. And the same may be said of the Mollusca. Of three hundred and thirty-two known species of flowering plants one hundred and seventy-four are peculiar, and about twenty more have been introduced by man. The rest are South American species. Considering, therefore, the close relation of all these species to South American forms, it cannot be doubted that they were originally derived from that continent; and considering that they are very distinct species from any on the continent, it is hardly possible to doubt that they 
have been derived by descent with modification, assisted by the isolated situation of the islands.

A still more interesting case is that of St. Helena. This is a small island wholly volcanic, very old, and situated more than eleven hundred miles from Africa and eighteen hundred miles from South America. Its isolation is therefore very complete. It can have received only a few immigrants, but these few finding the whole field to themselves have had abundant opportunity to develop; and since the island is very old, some of them will have had time enough to become very much modified. We may expect more peculiar forms than in the Galapagos islands. Within historical times this island has been much altered by human agency, and many new plants and animals have been introduced. Eliminating this factor, the fauna and the flora of the island are truly remarkable. There is only one vertebrate found-a wading bird allied to African forms, but a distinct species. The distance from the continent has proved too great for the passage of all kinds of vertebrates. There are no fresh-water animals. Of land shells a few species are known, more than half of which are extinct, and the rest so peculiar as to have no very near relatives anywhere. Of plants seventy-six species have been found, fifty of which belong to the island alone, and " cannot be regarded as very close allies to any other plants at all." The most interesting group of all is the order of beetles. There are one hundred and twenty-nine species of beetles, all but one of them found nowhere else on the globe. But this is not all; for while the specific peculiarity is greater 
than anywhere else, the generic isolation is equally remarkable. Of the thirty-nine genera twenty-five are peculiar to the island, and many of them such isolated forms that it is impossible to find their allies in any particular country. Even more remarkable is the fact that more than two thirds of the whole number of species belong to one group (Rhyncophora), beetles, which being wood-borers might readily be transported on floating timber for enormous distances. More than two fifths belong to one family. Of the twenty genera of Rhyncophora every one is peculiar to the island, and many have no near allies anywhere else in the world. If possible, still more interesting is the fact that all of these beetles are grouped around a few centres, as if they had only a few points of origin. If seven or eight beetles are assumed to have reached the island and to have given rise to varieties which later became species, this peculiar fauna is explained. The whole of this St. Helena fauna is thus exactly in accordance with the extreme age of the island and its great distance from the mainlands. It is an island so isolated that one bird, a few mollusks, eight or ten individual beetles, and a few plants or reeds, have succeeded in reaching it and establishing themselves. Those which did reach the island, however, found such favorable conditions that they rapidly multiplied, and soon gave rise to numerous species, all arranged around several centres, which centres represent the original immigrants.

The significance of the life on these islands is made stronger when we come to consider other 
islands which were once attached to the mainland, though now widely separated from it. In these islands we have practically the same conditions which are found in true oceanic islands with one exception. During the time that these tracts of land were attached to the continents they could have readily been supplied with quite an abundant fauna, the larger mammals having, of course, free access to them. When, therefore, they were finally separated from the land, it would usually happen that they would contain mammals and other animals which are unable to cross the water. Such islands are found almost always to contain mammals, though usually they are distinct species from those on the land. This fact wellnigh proves that islands are peopled from the continents. Upon any other supposition what possible reason can be given why such islands should have their own mammals, while true oceanic islands are universally without them? We thus see that Australia is to be regarded as such a fragment of the continents, which was separated from Asia before true mammals appeared, and contains, therefore, no true mammals.

The examples given above form no exceptional cases, for they only serve to illustrate the universal law regulating island life. It was by the study of hundreds of islands in all sorts of situations that such a law was clearly shown; but island life everywhere bears out the above conclusions. Considering all cases together, it has been abundantly shown that the likeness of species on islands to those on the mainland depends: (I) upon the former con- 
nection of the land with the continent, or the lack of such connection; (2) upon their distance from the mainland; (3) upon the prevalence of winds and currents to assist in immigration of individuals ; and (4) upon the antiquity of the island. The significance of these facts is plain.

It must not be supposed, however, that the life of oceanic islands offers no puzzling problems, for some cases occur where explanation is not yet found. We occasionally find upon oceanic islands species not related to the nearest mainland, but to more distant countries. The Bermuda lizard has its nearest ally in Africa, and three of the Bermuda birds are European species. The land shells of St. Helena are European in their affinities. Again, it is surprising to find that the different islands of the same group may have different species. The Galapagos islands, for instance, do not have a uniform fauna and flora, many species being confined to separate islands only a few miles from each other. It would seem that a few miles of the calm Pacific served as a more effectual barrier to prevent the crossing of individuals than the five hundred miles of stormy sea which separate the Bermudas from the continent. It has indeed been shown that in the Malayan Archipelago such narrow straits have the effect of practical barriers. A body of water of fifteen miles in width between Bali and Loudock separates effectually two radically distinct faunas, one belonging to Asia and the other to Australia. 


\section{Summary.}

The present distribution of animals over the world is the result of countless interacting factors both present and past. The present distribution is the outcome of the past, and the former cannot be understood without the latter. But unfortunately our knowledge is largely confined to the present, for the past distribution of species is almost unknown. Fossils only serve to give us occasional glimpses of the past, enough to make possible a fragmentary history of the general past history, but of the origin and distribution of species almost nothing is definitely known. In the past as in the present have occurred migrations to and fro in search of food; some of which we can get a few hints of, while others are absolutely unknown. All agencies operating to-day, with the exception of the influence of man, must have had equal force in the past. Every thing combines to make the subject one of the greatest complexity, and to confine our observations to general statements.

Such general conclusions in reference to past distribution as can be made, give great assistance in interpreting the present, and make it possible to create a science of the subject of geographical distribution. When the past history of a group can be read with any approximation to exactness, its present habitat becomes intelligible ; and it is even possible to make predictions as to the future discovery of fossils in definite localities. The fact that during all of their past migrations the species have been constantly changing, indicates that we are dealing 
with large families of genetically related species. It has appeared that, as a rule, anatomical relationship is parallel with geographical relationship: allied species inhabit contiguous areas, allied genera usually follow the same rule; while families and orders from their extreme antiquity have almost always lost all traces of this relation; that species, genera, families, and orders have had each a central point of origin; and that each has spread from this central point over a greater or less territory, depending on the length of time since the common union, and upon the powers of migration whicn the animals in question possess. All of this, it is hardly necessary to say, is in harmony with evolution. It is certainly not out of harmony with the idea of special creation, which might also assume that each species has arisen from a single pair. But it is difficult to see how any theory but that of descent would explain the unitary origin of genera, families, and orders, all of which are with about equal force traced back to a common point of origin. Geographical distribution is in harmony with evolution, and the fauna of oceanic islands very strongly indicate the derivative origin of species. But this is all that this source of evidence proves, for it could not possibly be out of harmony with the idea of special creation.

It remains to be pointed out, that although at present the subject of geographical distribution is capable of being made into a science, with definite laws, this possibility is disappearing. The influence of man constantly tends to destroy all of the relations above deduced. Man is transporting inhabitants from one 
country to another. Australia and America are becoming filled with European species, and Europe is also receiving many American forms. Barriers no longer exist, and it will require only a few more centuries to modify the distribution of animals to such an extent that the rules which are now found will have more exceptions than cases of agreement.

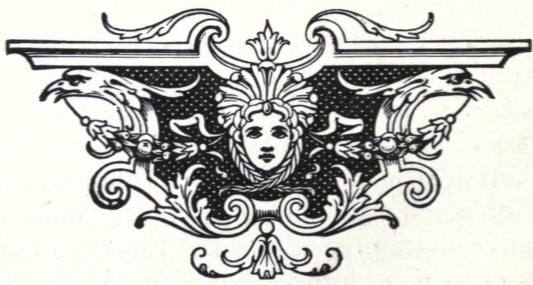




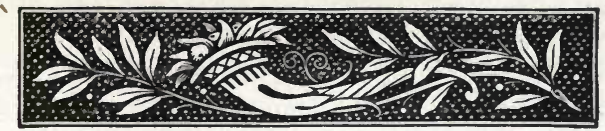

CHAPTER VI.

DARWIN'S EXPLANATION OF EVOLUTION.

Summary of the Evidence.

WE have now considered the chief sources of direct evidence which have been brought forward in favor of organic evolution, as the result of many years' investigation. It remains to consider the various scientific theories which have been advanced to explain evolution. Before proceeding to this subject, it will be well to notice what has been proved by the evidence already deduced, and what inferences can be legitimately drawn. It will in the first place be acknowledged that nothing has been positively proved as to the question at issue, for from its very nature evolution is beyond proof. But while no demonstration is possible, the evidence gradually accumulated has seemed so strong to scientists that it has led to an almost universal acceptance of evolution in some form. We have seen that the amount of variation possible in any species is undoubtedly very great, and, so far as can be discovered, it is practically unlimited; that species and varieties merge into each other in such a way as to be undistinguishable; that the only definition ever given of a species breaks down, since 
hybrids are not universally sterile, although they usually are so in animals, but the presence of a few exceptions is sufficient to show that there is no rigid law separating species. We have seen that the study of the animal kingdom reveals the fact of some fundamental bond of union uniting the whole together. This unity is shown by the possibility of a classification which is not artificial but natural, since actual relations between species are manifested in the organic world. This unitary principle is shown by the past history of the world as revealed by fossils. There has been from the earliest times a progression always manifesting itself. All the fossils of the earlier times are such as belong to the same types now existing, and many of them fall into gaps between existing species, making the whole history such as would have resulted from gradual growth. It is shown most forcibly of all by the fact that each individual of to-day in developing from the egg repeats more or less exactly the past history of its race as taught by fossils and such other sources of evidence as are at hand. We have seen that for this universal bond of union only two explanations have been offered. The first places it in the mind of the Creator, and leads to the theory of types. This theory when examined has been found so untenable in itself as to lead to its entire abandonment. The second explanation discovers the bond of union in heredity. This theory has been found to raise objections of its own, some of which are of no little importance. Most of these difficulties, however, are plainly due to a lack of 
evidence, and contain no contradictions. Some of them on the other hand, such as those considered under the head of homology, are not due to lack of evidence, but indicate that there are certain internal principles of life which we do not understand, and which are not covered by the heredity explanation, at least in its ordinary sense. But in spite of these obstacles the heredity explanation is the only one which has stood the test of examination, and it stands more firmly to-day than ever before. Finally we have seen that the present distribution of animals and plants is such as not only to be in accordance with the descent theory, but in some cases practically to prove the origin of species from older ones. Specialists, in all of the branches of study which we have considered, tell us that their department of science considers the question of evolution as no longer questionable.

All of the evidence is indirect evidence, evolution being simply an induction from the numerous facts. Granting evolution, and it is plain that the present condition of the world would be explanable by certain laws. The study of the present, which is all that we have to study, shows that the condition of the organic world is such as fully coincides with the necessities of the theory. But this fact does not prove the theory to be true. Proof is something never found in the inductive sciences, and the evidence collected here is of the same kind and nearly as cogent as that brought forward for other inductive conclusions. It is, for example, impossible to prove that the fossils in our rocks have ever been 
living animals; and it has been claimed, not many centuries ago, that they did not represent animal remains. It has never been proved that our fossils were ever alive, and it is to-day as possible as ever to claim that they were put in the rocks by the Creator in order to deceive men. But the good sense of the world has long since caused this claim to be given up. And so in regard to the question we are considering; although the evidence is such as would follow from evolution, and although all classes of facts are readily explained by it, the claim can still be made that the evidence is in harmony with the theory, but does not prove it. It is hardly possible to avoid the conclusion that the good sense of the world will soon give up this claim completely, as has already been almost universally done.

It must be noticed again, that if this evidence is admitted at all, it applies to the whole animal kingdom. It is not possible to say that evolution accounts for some species and not for all. The evidence is such that it must be extended to the whole organic world or rejected altogether. It is possible that there might have been several points of origin instead of one, but there is not the slightest evidence that such was the case. The same argument which indicates that species are descended from each other, applies with equal force to the origin of genera, families, orders, sub-kingdoms, and even to the two kingdoms of plants and animals. If evolution be admitted in one place from the evidence, we cannot in honesty deny it in any case where the evidence is found. It is true that a very few scientists have 
held that there have been several starting-points of origin instead of one, but this view is not called for by the facts, and is really of no value.

While the various lines of investigation which we have considered indicate strongly the fact of genetic descent, it is evident that thus far we have seen no indication of the manner in which this evolution has been manifested. It is consistent with the evidence we have considered to believe that the evolution of species has always been, as it seems to be to-day, an exceedingly slow process; that individual variations have gradually given rise to varieties, and these have slowly become species, each species thus taking thousands of years in its formation. But it is also consistent with the evidence to believe that there have been periods of rapid advance and modification, alternated with periods of comparative rest; the present time being one of the latter. It is possible that species have always been evolved by an infinite number of minute steps, so that the whole may be looked at as a continued growth; or, it is possible that there may have been some abrupt advances, by variations of considerable amount taking place in a single generation; or, it is even possible that these jumps may have been great enough to originate a new species at a single birth. It is possible that evolution may have been from the first a continued advance, or there may have been at times an advance, at times a pause, and at times a retrogression. All of these conceptions are logical, and each has been and is held to-day by various naturalists, as expressing in their opinion the nearest ap- 
proximation to the truth. We naturally proceed first to the consideration of the theory of Darwin.

\section{Darwinism.}

Darwinism and evolution are often considered as synonymous terms, but this is by no means true. Darwin's contribution to science was the principle of Natural Selection. Evolution, as a theory, had existed before, but by this principle Darwin offered to place the theory on a firm basis, by showing the laws regulating the production of species. He advanced an explanation for evolution. $\mathrm{He}$ "showed the possibility of discovering the path which Nature struck out in order to produce her endless variety of animal forms, and of detecting the means she has employed in her task." He first showed that evolution might be made a simple theory, founded upon the working of known natural law. His own explanation may or may not be true, without affecting materially the real question. While evolution is everywhere accepted, Darwinism proper is largely given up.

Darwin's explanation of the method by which species arise from others, is by a law which he calls Natural Selection, and which is called by Spencer the Survival of the Fittest. This law is so well understood by every one, that only a brief summary is here necessary. It is, in general, an attempt to explain how the various organs of plants and animals have become so admirably adapted to their conditions. (I) Darwin shows that animals have a tendency to vary. Child is not always like parent, 
but always presents some points of difference. This claim has been abundantly proved and universally acknowledged, both in regard to domestic varieties and animals under nature. (2) Darwin emphasizes the old idea that animals and plants multiply with much greater rapidity than the food upon which they live. Many more animals are born than can possibly succeed in reaching maturity. A single codfish, for instance, produces some 9,000,000 eggs in a season; and if all reached the adult state and reproduced in like manner, a very short time would serve to fill the ocean completely with codfish. A vast majority of the animals which are brought into the world must therefore be killed before reaching the adult stage. Owing to this constant over-production of young in every species, all animals are in a contest with each other, either directly or indirectly, for the food which is to be had. Every individual is, therefore, constantly engaged in a struggle for existence, and if he be weak and unable to contend with others, he will succumb in the struggle and die before reaching a condition to reproduce. (3) This struggle for existence is constantly affecting all animals, and it is evident that it is only the stronger individuals, or those especially favored by some advantage, which will come off victors in this struggle, and reach maturity so that they can leave offspring. If some individual has an advantage over others, it is plain that it would survive and leave offspring. If, therefore, in the infinite variations which are presented by all animals, as shown above, any individual chance to pos- 
sess a variation which gives it some special advantage for obtaining food or fighting with its enemies, this individual will have a much better chance than others for reaching maturity and leaving offspring. The animals best fitted to the conditions will survive, while others will perish. This is natural selection. (4) It is an unquestioned law, that animals transmit to their offspring their own characteristics, and, therefore, the individuals naturally selected by means of these favorable variations will transmit these same variations, and, as a result, we should find that nearly all of the next generation would possess the advantages of their parents. During the succeeding generations, the same selection will be enforced, so that shortly all of the unfavored individuals will disappear. As this process of selection goes on, the peculiarities which give advantage will become more and more prominent, and thus a new variety of the old species will arise, which, still later, will become more marked, and finally will be a new species.

In order to explain the differences which are frequently found in the two sexes, Darwin supplements natural selection with another principle which he calls Sexual Selection. He shows that among many animals there is a contest during the breeding season among the males for the possession of the females, a contest sometimes by actual combats, and sometimes by an attempt to attract the favor of the females by the display of brilliant plumage, or by singing. In all of these cases the victor in the contest mates with the more vigorous females, and 
will consequently be likely to leave numerous offspring. Now, evidently those males which have especially developed weapons for combat, or especially beautiful plumage, will be the victors, and will leave the most vigorous offspring; and the offspring will all have a tendency to inherit the same highly developed weapons or plumage. This process bring repeated, the males eventually develop organs like the antlers of the male deer, or the beauty of male birds. Occasionally also these features are acquired in a less marked degree by the females also, since each sex has a certain tendency to inherit from the other sex.

By means of these two principles, Darwin has attempted to account for the origin of new species from the old upon purely physical laws, easily understood; for evidently if peculiarities can thus be accumulated and increased, generation after generation, the final result will be new animals very different from the old ones. The strong point of this explanation is its simplicity. It is based upon universally admitted facts, and is readily understood. As soon as the "Origin of Species" made its appearance, it became evident that Darwin and Wallace, who had arrived at the same principle independently, had discovered an important principle, and the ready explanation which natural selection offered to large classes of facts, led almost immediately to its wide acceptance. Evolution was no longer a vague hypothesis which added nothing to knowledge, but a logical theory with an intelligible explanation. Natural selection was recognized as one 
of the laws governing living things, and at first sight there seemed to be no limit to its action, which seemed to lead directly to evolution. Darwin obtained at once prominent followers, who accepted his theories. Much opposition was, of course, aroused among those who, for various reasons, did not wish to give up the idea of the miraculous in the special creation of species. Among scientists, however, it was at first thought that the true explanation had been found. But before a great while objections began to appear from the world of science, which indicated that natural selection was not so complete an explanation as it at first seemed. These objections have, with further study, increased rather than diminished, until their accumulated weight has led all but two or three scientists to acknowledge the insufficiency of Darwinism. Indeed, Darwin himself did not claim to have found a complete explanation, and recognized the difficulties of his theory even more forcibly than did some of his followers. In his later works he did not hesitate to acknowledge that he had at first overrated its effects, although he still held it to be the most important law regulating the modification of animals and the development of species. To-day most naturalists, while acknowledging that natural selection is an important factor, would give it a secondary position, or at least modify it greatly before accepting it. We will now consider the chief reasons which have led to this conclusion. 


\section{The Incompleteness of Darwinism.}

It will be noticed, in the first place, that there are two factors in this theory which are simply taken as facts, without themselves being explained. The whole theory is based upon the fact that animals inherit the peculiarities of their parents, but it gives no reason for this fact. That animals do transmit their characteristics to their offspring is a fact, but why they do so we do not know. Without an explanation of this fact, the mystery of life remains as great as ever. Natural Selection has nothing to say upon this point. Darwin saw the necessity of meeting this factor in some way in any attempt to discover the origin of species, and consequently advanced an hypothesis for the purpose. A rather remarkable piece of pure hypothesis it was, for which there is or can be no direct evidence. This matter will be considered more at length in the next chapter.

A more unfortunate lack in the Darwinian hypothesis, is its failure to account for the variations which it needs. Natural selection works entirely by the selection of variations, but is itself unable to account for a single one. It can originate nothing. Given the variations and it readily preserves the favorable ones, but it does not of itself explain the appearance of any thing. Much literature has been written upon the subject of variation, but it only serves to emphasize our ignorance. Darwin assumed that animals had an inherent tendency to vary, and thought it in vain to attempt to show the cause of any particular variation. Each variation has un- 
doubtedly its cause. Changes of conditions certainly produce variations, but the changes of conditions are so infinite in number and quality, that the variations which they produce must also be looked upon as infinite. No law of variation has yet been discovered. It is possible, and even probable, that similar changes in condition should produce similar variations in individuals, but we can seldom understand why they should do so. In order that natural selection can act, it is necessary that there should be something to select. Now we may concede to the theory that the changes of conditions are sufficient to account for variation. No two animals have the same surroundings, and we well know that the different surroundings of animals produce their effect. We may also, for the present, concede that organisms have an inherent tendency to vary. If these two positions be granted, there will be no lack of variations, which can be selected. But these variations will, as a rule, be irregular and indefinite; will be usually of slight importance, occurring in any direction, and confined, as a rule, to only one, or at most a few individuals at a time. Now there is no doubt that such variations do occur. Any one who will take the trouble to examine a half a dozen individuals of any species, can convince himself of this fact. These variations then, minute, indefinite, irregular, form the foundation of Darwinism. Such variations may be readily believed to be due to the constantly varying conditions; and Darwin, perceiving them to be abundant, and unable to account for more important ones, believed the natural selec- 
tion of these minute, indefinite, irregular, haphazard variations has given rise, little by little, to the origin and development of species. The question which naturalists have been trying to settle is, whether selection from variations of this character are sufficient to produce the result ascribed to it. The answer which has been generally given is that natural selection of chance variations is not alone sufficient to account for the origin of species.

\section{Difficulties from the Slowness of the Modification.}

If species must be produced by the selection of such minute variations, change must have taken place very slowly, and the production of a new species will require a great amount of time. Now, making all allowance for error, it seems to be almost certain that the time since the appearance of life in the world has not been great enough to account for the development of the present species by any such process. The time since the Egyptian monuments were made, which represents 4,000-5,000 years, has not been long enough to produce any appreciable amount of change in domestic species. Even the much longer time since the glacial period has had very little effect, many species being precisely similar to those of that time. Darwin estimated that $300,000,000$ years at least would be required to produce the present world of species, while physicists will not admit the possibility of there being more than $100,000,000$ years since the world was inhabited, and of late years geologists have been shortening the length of their geological epochs. Whatever be the 
length of this time in years, it is evident enough that it has been sufficient to develop the present species, from the simple fact that they have developed in this time. This matter of time is no difficulty for evolution, but it does raise an objection to that form of evolution which evolves species by the slow process of selection of minute variations. If change has been more rapid in the past than at present, or if the modifications have taken place by periods of rapid advance, alternating with those of comparative rest, there is no trouble at this point; but if the slow change which has taken place since the glacial period is taken as a criterion, the $300,000,000$ years of Darwin do not appear to be a great demand; and if natural selection has had only such minute variations to work with as the theory assumes, the time of the geological ages appears too short.

Not only has this development of species been very slow, but it must also have been very gradual. Our present species have, according to this theory, descended from the older forms by slow selection of minute variations, which have always been in danger of disappearing by crossing. There have been no abrupt changes. New species have not arisen by the crossing of two other species, but all have arisen by the slow process of minute changes. It follows from this that every species has been connected with its predecessor by a very great number of intermediate links, each varying only slightly from the forms before and after it. If we could get a comprehensive view of the animals in the past and present, we would find no two species radically distinct, but all 
connected by a series of transitional links. It is of course plain that no such series of transitional links exists to-day. Two closely related species, inhabiting neighboring localities, are assumed to have descended from a common ancestor, which has become differently modified in the two localities, to fit it better for the different conditions there found. It might be expected, perhaps, that the tracts of land intermediate between the localities in question would be inhabited by intermediate varieties or species. This we do not, however, find. The species are usually distinct, and, except in rare instances, it does not happen that a tract of land intermediate between the localities inhabited by related species, is occupied by an intermediate species, even though the physical condition be strictly intermediate.

The fact that all of these finely graded transitional varieties, which are assumed by natural selection to have lived in the past, no longer live to-day, presents no great dfficulty. For natural selection and extinction go hand in hand. If any species be assumed to have been derived from an older one by gradual improvement, it follows that all of the intermediate, less-favored varieties must, by the action of natural selection, have been exterminated. The result will always be simply the preservation of only the most advanced forms. The development of a new form implies the extinction of the old. Nor could it be expected that, when two contiguous localities are inhabited by related species, the intermediate tract would contain an intermediate species. For this intermediate tract 
will always be a comparatively narrow land, and can at best only support a few individuals, while the larger areas can support many. We know that under these circumstances, the numerous species would replace the less numerous variety. For instance, if one species inhabited the low lands, and another the mountains, the intermediate land will be only a narrow strip at the base of the mountains. It is evident that this narrow strip would not support a separate species, but would rather be inhabited by stragglers from the two species living on either side of it, and the two species would thus overlap. Thus, it is easily understood that intermediate forms will tend to be exterminated.

But this does not alter the fact that these transitional forms must have at one time existed, and should, therefore, be found in the remains of animals living in the past. We have already discussed this question, and have seen that no such numerous transitional links exist in fossils. The reason for this has been found in the extreme imperfection of the geological record. It is, however, very questionable whether we are justified in considering this imperfection sufficient to account for the almost utter absence of these intermediate links. In one or two very exceptional cases the requisite amount of intermediate forms is found, but, as an almost universal rule, this is not true. The history of the horse family is about as complete as any history yet discovered, but even here it is impossible to discover the numerous links which we would expect. For, while we do find a number of intermediate stages in 
the change from a five-toed animal, we find that the stages are all well marked, and of the thousands of transitional forms between them nothing remains. It must have taken very many generations, judging from the slow modification of the horse family today, to have modified a four-toed animal into a three-toed one, and it is rather strange, if this process did last such a long time, that no trace of intermediate forms is found.

If, in this case, the expected links are wanting, still more forcibly is it true of others ; for nowhere is there found a fossil history at all approaching that which the theory would lead us to expect. It is, of course, impossible to say whether the imperfection of the record is sufficient to account for this lack. But it is certain that the transition links have not yet been found, and no one has much hopes that they ever will be. This was a surprise to Darwin, and must be considered as an objection to his theory; and it has also been a surprise to others who have wished to follow him in his belief in slow, gradual modification. It has, moreover, led some scientists to a different view of the origin of species, according to which changes have been rapid and short, while periods of rest have been very long.

\section{Specific Characters not always Useful.}

A difficulty of much more force than the foregoing, is one which emphasizes the fact that all variations, in order that they be acted upon by natural selection, must be useful. A useless variation could never be selected; but it is demonstrable 
that many of the peculiarities which distinguish species from each other are useless. There exist what are called morphological species, by which term is meant species whose distinction rests upon some slight difference in shape, size, or colordifferences which can be of no use to the individual. As instances of the point may be mentioned the length of the ears and tails of different rabbits and mice; the complex folds in the enamel of teeth; the peculiar sculpturing of the hair of different animals ; the extremely slight differences in the markings of two species, so slight, frequently, as to be distinguishable only with the closest scrutiny; the differences in the veining of the wings of different butterflies, etc. All such instances are features distinguishing species, and must, of course, be accounted for in a complete explanation of the origin of species; but, since they are of no use to their possessor, they cannot, by any means, come under the influence of natural selection.

In answer to such suggestions it is claimed that we never can say with positiveness that a given feature is of no use to its possessor. We are too incompletely acquainted with the lives of animals; and to say that a given feature is of no use is usually an assumption based on ignorance. This is doubtless true; for there are certainly many characteristics which have uses that we do not yet know. But, on the other hand, it must be remembered what the natural-selection theory means by a useful structure. In order that a peculiarity should be preserved by natural selection, it must be of so 
much importance as to cause its possessor to live under circumstances when other individuals die; or to flourish better and so leave more offspring. This fact is too frequently overlooked. When the fact of the great struggle for existence is recognized, it becomes plain that those animals best fitted to the struggle will have the best chance of surviving and of producing their kind. It soon becomes imagined from this that the very slightest usefulness in an organ is enough to bring it under the powerful influence of natural selection. But this can hardly be true; for natural selection acts by life and death, and a variation must be of some considerable importance to cause the survival of its possessors and the destruction of individuals not possessing it. It is beyond credulity to believe that the microscopic sculpturings on the hair of the rabbit are of enough importance to cause their perpetuation by selection. There can be no doubt, therefore, that many characteristics are of so little use that natural selection can have had no influence in causing their development. It is difficult enough to believe that the complicated functional organs of the body have been developed through countless stages, each of which is of sufficient use to its possessor to cause its exclusive preservation; and much less is it possible to conceive that the various characteristics of the morphological species were developed in this way.

The only other suggestion for meeting these cases is by what is called correlated variation. The organism is bound together in such a way that when one part varies other parts have also a tendency to 
change. As to what it may be that causes certain organs to be thus united we know nothing, but that such correlated organs exist is beyond question. It is not necessary, therefore, to assume that all variations must be useful in order that they be selected, but only that they are connected with others which are useful. It may be that many of these useless peculiarities are in this manner connected with others that are useful, and that the development of one implies the development of the other. The useful variation will be preserved by natural selection, and the useless variation will necessarily be preserved and developed in a parallel manner. Much is attributed also to the laws of growth, by which is meant the obscure laws which regulate the flow of nutriment, etc. Many important features may be thus explained. Some plants have their leaves opposite each other, others have them alternating; and this point, of no use to the plant, may be regulated by the flow of sap in the two cases. But at best these two suggestions are of little assistance, and simply serve to indicate that there is an unexplained difficulty here. That they do not sufficiently explain useless features is so well proved that even Darwin was at last inclined to admit the great potency of "spontaneous variation," and with this phrase he abandons all attempt to reach a clear understanding of the matter. Natural selection thus fails to reach this large class of features, which are of no use to their possessor, and does not help in understanding the origin of species whose distinctions are founded upon such features. 
Quite similar in their import are structures which are simply ornamental. For ornament in itself natural selection has no room. To be selected, a variation must be useful. The only chance for the development of ornament in the Darwinian hypothesis is by sexual selection. Among some animals, particularly birds, the most vigorous females select for their mates the most beautiful males, and this would, of course, enhance the beauty. But many of the most ornamental structures are met with among animals where this sort of selection is impossible. Some mollusks are among the most beautiful organisms in existence, the delicacy of the tints of the shell and the beauty of the sculpturing being exquisite; but sexual selection is impossible here, for the animals are mutually hermaphrodite. And, indeed, their sensory organs are so imperfect that it is impossible for them to see the beauty of their own shells, to say nothing of appreciating it. Moreover, many of them keep their shell entirely covered during life by the mantle, and the ornamental features only appear after death. Such features can only be regarded as due to the laws of growth, which regulate the absorption of nutriment in such a manner as to produce certain results, some of which appear to us as beautiful. Indeed, beauty is only a subjective feature, depending not on the object, but upon the observer. Why many animals possess features which seem beautiful to us, we do not know; but it is not simply for the sake of being beautiful, and it is equally certain that it is not due either to natural or sexual selection. 


\section{Variations Eliminated by Crossing.}

A still more serious difficulty amounts to a demonstration that, as originally conceived, natural selection is not adequate to explain the facts. It is the tendency of varieties to disappear by crossing. A reviewer in the North British Review in 1867 demonstrated the necessity of assuming that variations appear in many individuals at once, showing that it is mathematically impossible for a single variation to be preserved, no matter how valuable it be. He takes, for an example, the instance of an animal which produces two hundred young, of which only two survive the struggle for existence long enough to produce young. He assumes that one of the two hundred has, by a chance variation, some feature not possessed by the others, and which is highly valuable (it must be remembered that variations, as a rule, are so slight as to be of little use). Now, in the above case, the chance for the survival of this particular individual is not very great. Doubtless this animal would have a better chance of survival than any other individual, but the chances are much in favor of some other of the two hundred. This single individual, while having superior facilities, must contend with great numbers, and its chances for preservation are therefore not very great. But even supposing it to survive and produce young, it will, of course, be obliged to mate with some individual not possessing its favorable peculiarities, and its offspring will inherit the peculiarities in a less marked degree. "It will breed and have a progeny of, say, one hundred. Now this progeny 
will, on the whole, be intermediate between the average individual and the sport. The odds in favor of one of this generation will be, say, one and a half to one, as compared with the average individual; the odds in their favor will be less than that of their parent. But, owing to their greater number, the chances are that about one and a half would survive. Unless these breed together, a most improbable event, their progeny would again approach the average individual. There would be one hundred and fifty of them, and their superiority would be, say, in the ratio of one and a quarter to one." In the next generation the superiority by further crossing would be even less; and thus the variation which appears so strong in the first individual will dwindle away, and in a few generations practically disappear. While natural selection would have a tendency to select the favored individual, the necessity of cross-breeding would have a much more powerful effect in causing the variation to disappear.

To this difficulty no one has suggested any sufficient answer. Darwin acknowledged its full force, and admitted that very rarely is it possible for a single variation to be preserved. He thinks, however, that if a third, a fifth, or even a tenth part of the individuals be simultaneously modified by some cause (such as similar conditions affecting different individuals in a similar way), and if the variation should be of a beneficial nature, the original form would soon be supplanted by the modified form through the survival of the fittest. This will probably be admitted by all, but it is evident that with 
this admission on Darwin's part, his original theory has become so much modified that it is no longer simply natural selection. The fundamental cause in the change in species is something which produces simultaneous variations. Upon these variations natural selection may act, but it is secondary, the primal fact being the law or laws which produce simultaneous variations in many individuals.

It must, however, be noticed that observation teaches that crosses between two varieties do not always produce intermediate varieties; sometimes the offspring show all of the features of one parent. When the Ancon ram is crossed with the female of an ordinary breed, the young are of the Ancon variety, and not an intermediate form.

\section{Development of Organs by Small Steps.}

Not only has the necessity of simultaneous variations been clearly shown, but it seems equally evident that some of these variations must be of considerable importance. Many organs can hardly be explained as being developed by small steps, such as those of which natural selection is supposed to make use. In the first place, it is impossible to understand how certain organs could have originated in this way, for they are of such a nature as to be of no use until highly developed. After they get well enough developed to be used, it is easily conceivable that they may be preserved by natural selection, and even further perfected; but at first they are useless, and cannot therefore be selected. This point can be made more intelligible by an 
illustration, and I select for this purpose an example frequently used-the whalebone in the mouth of the Greenland whale. This organ consists of a large number of long horny plates, hanging down from the front of the palate on either side of the mouth. They form two longitudinal series of plates very close together. The inner edges of the plates are frayed into a hair-like fringe, and the whole forms a sort of sieve at the sides of the mouth. When the whale feeds, he opens his mouth widely, taking into it quantities of water, together with many small animals, which form his food; and then closing his mouth, the water is forced out through this sieve of baleen plates. The water readily passes through them, while the animals are retained in the mouth, and are now swallowed. The beauty of this contrivance is evident at once, enabling the animal as it does to feed upon small food under water. After it has once become perfected enough to be thus used, it is easy to see that natural selection could cause its preservation. But the question is, how such an organ could have arisen by small stages, since it would obviously be of no use until the plates became long enough to serve as a sieve; and there must have been a very long time, while the organ was developing, when it would not be large enough to serve in this way, and was yet preserved. How such an organ, or any similar organ, useful only when highly developed, could have been started on its line of development upon this theory, it is difficult to see, for it would seem that at first the variations would have been of no use, and consequently not under the influence of natural selection. 
Darwin has answered this objection in a manner partially, though perhaps not wholly, satisfactory. $\mathrm{He}$ says it is true that these organs at the beginning could be of no use for the purpose to which they are now applied, but it is easy to conceive that they might have been used for some other purpose, and thus even the rudimentary beginnings might be of use, and hence selected. To use the same example, which Darwin has also fully discussed, we may quite readily imagine that the early whale ancestor had upon the roof of its mouth a few horny protuberances, such as are found in the mouth of a goose; of no use for sifting food, but aiding in the seizing and tearing of food. They would be of use, and therefore preserved by natural selection, and may, therefore, be supposed to develop slowly until they became somewhat larger. After they became of some considerable size, they would be used both for seizing food and sifting water, a condition of things found in the Egyptian goose. A little further development would convert them into lamella, like those of the duck, and so onwards until they became large enough to be used exclusively for sifting, as they are in the shoveller duck. Now these lamella of the shoveller duck are relatively not much shorter than the baleen plates of some whales, and it is easy to see how the organs, now used exclusively as sifting organs, may be further developed by natural selection, until they reach the size of the whalebone plates. In this way we can see how even such an organ as the baleen might have been developed by gradual stages, each of which was of use for some purpose, though per- 
haps a constantly changing one,- a change in function accompanying a change in form. In a similar manner Darwin has treated other cases of this kind which have been suggested, and has had remarkable success in showing that it is possible to understand how by a change of function natural selection might extend to organs seemingly of no use except in their highly developed condition. His explanations are, of course, plainly hypothetical. Even granting them sufficient, it still appears that the very first beginning of such organs is difficult to account for. In the case given it may well be that, after the horny projections had become large enough and strong enough to aid materially in seizing and tearing food, they would be preserved by natural selection; but the ordinary variations are too small to account for the sudden appearance even of such protuberances. It is altogether too much for one's credulity to believe that the presence of one or two accidental roughenings in the mouths of one or two animals would be of enough advantage to lead to the survival of these individuals and the extinction of others which did not chance to possess them. If we can assume that at some time in the past there was a sudden great variation in the mouths of the whales' ancestors, affecting many individuals at once, the solution offered by Darwin may be accepted; but so long as it is only scattered, indefinite, minute variations which natural selection has to work upon, the difficulty herein lying is very great.

But even after the beginning of organs is accounted for, it is equally difficult to see how they 
could be developed by the accumulation of minute variations. The variations of animals under ordinary circumstances are very slight, so slight, indeed, that only one long accustomed to breeding animals can distinguish them; yet it is such minute variations that natural selection is supposed to make use of. Darwin, indeed, believed that natural selection is much more exact than is the artificial selection of breeders, picking out constantly features which the eye cannot detect. But while this may be true in some cases, it is hardly possible to believe that most of these small variations can be of enough importance to be selected. When accumulated they may undoubtedly be of importance, but in order that natural selection may accumulate them, it is necessary that each one must be of so much importance as to lead its possessor to a great superiority over other animals. To take one or two examples: The potto (a lemur) has the peculiarity of having only three fingers, the forefinger being a mere rudiment. Now whether this peculiarity be of any use to the animal, it is impossible to say: but granting that it is of use, it must be assumed that at one time in the ancestors of the potto this finger was equal in size to the others, and that it has gradualiy diminished in size. If variations are minute in extent, this shortening of the finger must have been very slow; and it is hardly possible to believe the shortening of the finger by a slight fraction of an inch at a time could have been of any use to the animal, even though the completely rudimentary finger is of advantage. When we consider that not 
only must these small variations be of use, but in order that they should be selected, they must be of so much use as to lead the individuals with this variation to flourish in conditions where other individuals will have difficulty in living, and thus to cause the modified variety to supplant the unmodified form; and when, further, we remember the results which must arise by crossing of modified and unmodified individuals, it is simply impossible to believe that this peculiarity could have been devel oped by the natural selection of minute variations. Or, take the case of the development of the horse's foot. Granting that it is of great advantage to the horse to have one large toe rather than five small ones, it is incredible that any single ancestor, happening to have a slightly larger middle toe, would so far surpass all others that it should eventually supplant the unmodified form. If we can believe that many horses have varied simultaneously and rapidly as regards the shape of the toe, it is quite easy to see that natural selection might have developed the modern horse's foot; but so long as there are only indefinite variations, it is no longer within the realm of possibility.

Similarity in Independently Acquired Organs.

Natural selection finds further difficulty in explaining the similarity of independently acquired organs. It is the verdict of one scientist that " it is so improbable as to be practically impossible for two exactly similar structures to have ever been independently acquired." It is found that, as a rule, 
animals not closely related do not possess similar organs, the same function being differently performed. But it is not impossible to find instances where organs bearing the greatest similarity are found in animals so distantly related as to preclude the idea of inheritance as an-explanation, and to make it necessary to assume that they are independently acquired. Probably the best illustration that can be selected is found in the eye of the vertebrates and mollusks. These two groups of animals are very widely separated from each other, and any organs which they possess in common, except those found in all animals, must have been independently acquired, since they separated from each other in the ancient pre-silurian times. Now the higher members of the mollusks (cephalopods) possess eyes which bear the greatest similarity to those of vertebrates, each having sclerotic, retina, choroid, vitreous humor, aqueous humor, and lens. The correspondence at first sight seems complete, and remembering the remarkable complexity of the organ, together with the fact that the various parts are only of use when the others are present, it becomes a marvellous thing to find such an organ independently developed in two different cases. This difficulty Darwin has answered as follows : "Beyond a superficial resemblance, there is hardly any real similarity between the eyes of cuttle-fishes and vertebrates. *** The crystalline lens in higher cuttle-fishes consists of two parts placed one behind the other like two lenses, both having a very different structure and disposition to what occurs in the vertebrates. The retina 
is wholly different, with an actual inversion of the elemental parts, and with a large nervous ganglion included within the membranes of the eye. The relations of muscles are as different as it is possible to conceive, and so in other parts. * * * It is of course open to any one to deny that the eye in either case could have been developed through natural selection of successive slight variations, but if this be admitted in the one case it is clearly possible in the other; and fundamental differences in structure in the visual organs might have been anticipated in accordance with this view of their formation. As two men sometimes independently hit on the same invention, so in the several foregoing cases it appears that natural selection, working for the good of each being, and taking advantage of all favorable variations, has produced similar organs, as far as function is concerned, in distinct organic beings which owe none of their structure in common to inheritance from a common ancestor."

It is generally admitted that this answer of Darwin is sufficient to meet the case, at least in part. A visual organ to have any high degree of efficiency must possess certain fundamental parts: must have a dark chamber, a spread-out optic nerve or retina, and a series of lenses to form an image on the retina. Beyond these necessary features there are hardly any common points between the two eyes. But some would still claim that the difficulty is not met. For it has indeed been increased rather than diminished by observation since the above answer of Darwin's was written. Another mollusk, Pecten 
(the scallop), belongs to a group very distantly related to the cuttle-fishes; it has around the edge of its mantle a series of eyes, which can therefore have no inherited likeness either to the cuttle-fish eye or the vertebrate eye. But here, too, is developed the same sort of complicated eye with its various parts, and here the likeness to the vertebrate eye is even more pronunced, the various coats being in almost exactly the same order in the two cases. Since Pecten, the cuttle-fishes, and the vertebrates are very widely separated from each other, we have in these cases three organs very similar to each other, independently acquired. It is enough to tax one's imagination to believe that such a complicated organ as the eye could ever have been developed by selection of minute variation; but when we thus find at least three cases where quite similar organs are independently developed, it is plain that we have considerable of a problem. That these organs could have been developed by chance is incredible, and it must be claimed that the conditions requisite for a visual organ are so rigid that all eyes must have developed in this way in order to be of any use. Now this type of eye is not the only type which is found, for crustacea and insects have visual organs made upon an entirely different plan. To make the matter still more perplexing, we find that some mollusks have eyes built upon the plan of insect eyes (Arca and Pectunculus). The whole matter is indeed a puzzle. Unquestionably the same sort of eye has been independently acquired in several cases, and since it can hardly be believed 
that the external conditions are so rigid as to limit the visual organs to one or two lines, it would seem to be a warrantable assumption that there is some internal condition which regulates the structure of such organs.

\section{Mimicry.}

Numerous other instances of independently acquired organs could be given, but none so striking as the one mentioned above, while many of them are readily understood upon purely physical laws. The likeness in shape between the wings of the bird and the butterfly, for example, is the result of the advantage which this shape possesses for an organ of flight.

But an interesting series of independently acquired likenesses must be mentioned, not because it presents any great difficulty, but rather because it is the best illustration of the action of natural selection. Reference is made to the subject of mimicry. Many animals, particularly insects, possess the form and appearance of other animals for the protection thus afforded. Some flies resemble wasps, and doubtless many thus escape destruction by being mistaken for the more dangerous insects. Certain butterflies seem to be distasteful to insectivorous birds, and others, which are not distasteful, acquire the same form as distasteful species, and thus the birds pass them by. Beetles imitate ants for similar purposes, and many animals have a similar protective resemblance to inanimate objects. Our grass snakes are green; one butterfly, with its wings 
folded, very accurately resembles the leaves of the plant on which it lives, the resemblance being carried even to the veining of the leaf and its petiole. In other cases the likeness may be carried to even a greater extent, spots appearing on the wings resembling injuries caused by fungi on the leaf. Or others may resemble dry sticks, their legs stretching out irregularly in various directions so as to resemble branches. The object of all this is evident enough. It enables the animals in question to avoid destruction. It is a clear case of natural selection. An insectivorous bird sits on the branch of a tree and watches for butterflies.' As soon as it sees one flying across an open tract, if it appear to be of the species which the bird knows, from experience, to be pleasant to the taste, the bird leaves its perch, pursues and captures the butterfly. If, however, the butterfly should appear to be one of the distasteful species, the bird pays no attention to it. If the tasteful species have individuals bearing slight chance resemblance to the distasteful species, these individuals will be the ones to escape destruction and to perpetuate their kind. Thus the beginning of mimicry is easily understood. As the mimicking species becomes more abundant, the birds will learn to look more sharply before rejecting any individual, and it will only be those having a very close mimicry that will be preserved. As the bird becomes wiser and sharper in its scrutiny, the mimicry must become more perfect, and eventually a remarkable perfection in mimicry may be reached. All this will result from the action of natural selec- 
tion, if it be granted that the shape, size, and coloring of the butterfly's wings are variable. It is, of course, questioned whether, even with this rigid selection, slight, indefinite variations are enough to account for the final completion of some of the wonderful pieces of mimicry, but this objection is so similar to one already discussed that we need do no more than mention it, and indicate that it is frequently regarded as a very great difficulty for natural selection.

\section{Sterile Insects.}

There is one special difficulty to the principle, of so much weight as to deserve notice here, although it is not our purpose to consider special cases. This is the difficulty in seeing how the working castes of various insects could have arisen, and it is so much of an obstacle that Darwin at first thought it fatal to his theory. Many insects, such as ants and bees, live in large communities, thousands of them combining to live in mutual dependence on each other. The labor of the colony is divided among different members, each being fitted to perform certain work. In the beehive is found the queen bee, who produces all of the eggs; the drones, whose sole duty is to fertilize the eggs; and, finally, the workers, who take no share in reproduction, but perform the manual labor for the colony, searching for food, building the hive, caring for the young, etc. It is this last class that concerns us. The worker bees are very different from the other classes. Not only have they different instincts, which impel them to 
entirely different modes of life, but the form of their body is entirely different. Indeed, workers differ more from the males and females of the same colony than do different species from each other. Nor is this all, for the workers may not only differ from the males and females, but also from each other to such an extent that several castes of workers are sometimes found. In some cases there are three castes of these workers, so that the colony contains five sorts of individuals. Nor do these castes, as a rule, graduate into each other; they are perfectly distinct, as much so indeed as any two genera of the same family.

Unquestionably all of this differentiation is of advantage to the colony; but how is natural selection to explain the origin of these castes of workers? The difficulty lies in the fact that the workers are sterile, and the possibility of their transmitting favorable variations to another generation is out of the question. If these individuals had been fertile, the explanation would have been that they were acquired slowly by natural selection, which preserved the favored individual and thus caused their peculiarities to be transmitted to other generations. But the insects are not fertile, never have any descendants, and consequently cannot transmit their peculiarities, and it would therefore seem that they could not be preserved. How then could these castes have arisen? The only answer is to consider the whole colony as an individual, and the various castes as organs. In other animals it is not difficult to see how any organ can be modified. If it is of advan- 
tage to the individual, that a certain part be modified in any direction, we can understand how this may be done by the selection of individuals with favorable variations. The various organs do not reproduce, and may be compared to the working castes of insects. It is possible thus to look upon the whole colony as an individual, the males and females as the reproductive organs, and the workers corresponding to other organs. If now it be of advantage to the colony that these working organs should be differentiated into castes, the colonies which presented favorable variations in this direction will be naturally selected, while those colonies which do not have such variations will be exterminated in the struggle for existence. Or, to put it in other terms, the females which have, in times past, produced young showing a tendency toward differentiation into castes of workers, will have been able to form colonies, while the females whose offspring did not show this tendency toward differentiation will not have been able to form colonies. Those queen bees which did produce differentiated young, and consequently did form colonies, would eventually give birth to other females, and these females of the second generation will in turn have inherited the same tendency from their parent. On the other hand, bees which could not form colonies would not have been able to produce other generations, and would thus have become extinct. When, then, we look upon the colony as an individual, and the castes as organs, the difficulty is not insoluble.

This explanation is certainly very ingenious, and 
is, moreover, perfectly logical and consistent. The only objection to receiving it is the same that we have seen in other cases. The results are too great for the explanations. It is hardly possible to believe that natural selection acting on only one individual of the colony, the queen-and not upon her directly, but only through her attendants,- could have had so great an effect. Individual variations could have here no influence. Indeed, Darwin, who suggested this explanation, probably had no idea that individual differences, or differences in a few workers, could ever have had any effect on the colony, but rather that those queens producing offspring, a large majority of which showed this tendency toward differentiation into castes, would be better fitted for forming colonies than those whose offspring showed no such tendency, or showed it only in a few cases. Here, therefore, Darwin would admit the necessity of assuming that the variations were considerable in amount, and occurred in many individuals simultaneously. Upon any other supposition this explanation is palpably insufficient, for individual variation can mean nothing; only those occurring in hundreds of animals at once can be of any moment.

\section{Summary.}

Natural Selection, or the Survival of the Fittest, was the first explanation ever offered to account for the origin of species according to natural laws. It was this explanation, so simple and intelligible, and yet so significant, which caused evolution to obtain 
such firm support and to be so intimately connected with Darwinism. But, nevertheless, natural selection has, with further study, proved inadequate to the task which it attempts to solve. No one will deny that it is a potent factor in nature, perhaps the most potent which has been yet discovered; but there is much disagreement as to the limits of its power. While Darwin would believe it the all-important factor, making every thing else subservient to it, other scientists would consider it as secondary and of little importance. We have seen that even when we admit the efficacy of the law in nature, it lacks a complete explanation. It is based upon the existence of variations which are themselves unexplained. To be sure these variations do undoubtedly occur, as any one acquainted with animals and plants is well aware, and it is easy to conceive that the infinite variety of circumstances under which different animals are placed should cause varieties in bodily structure. Such variations will have no relation to the needs of the animal, will be indefinite in direction, occurring in only few individuals at a time, and usually of slight importance. Unless we can give a more fundamental explanation, such indefinite variations are all that can be assumed. With these variations Darwin has attempted to account for the origin of species, but, as we have seen, he does not completely succeed. If species have always arisen slowly by minute variations, as they seem to be doing to-day, the time since the solidifying of the world has not been long enough to account for the present species. The numerous transitional links 
between species, which must have existed according to this theory, are not forthcoming in the fossil records, requiring thus a great burden to be thrown upon the imperfection of this history. Many species are distinguished by features of no use to them, and these never could have been developed by natural selection alone. It is mathematically demonstrable that single variations could not give rise to permanent varieties, but would tend to disappear in successive generations by crossing, and not to increase as would seem necessary on the theory. It is therefore absolutely necessary to assume that variations occur in numerous individuals simultaneously, and to find a reason why this should be so, before the question is satisfactorily answered. The evidence which indicates that we must look for some internal factor, is conclusive. The difficulty of accounting for the beginning of organs without some such assumption, the difficulty of seeing how minute variations could be of enough importance to be preserved by natural selection, the independent development of similar highly developed organs in widely separated animals, all serve to strengthen the belief that we must look to the organism itself, in part, for the laws governing the origin of species. Finally, when we consider that any variation, in order to be preserved, must be of enough importance to regulate the life or death of the species, it becomes almost impossible to see how various structures of morphological species, or how the various castes of sterile insects could ever have been developed upon this principle alone. 
Natural selection, or Darwinism, is therefore almost everywhere acknowledged as insufficient to meet the facts of nature, since many features of life cannot be explained by it. Even Darwin did not consider it as a final explanation, placing less credence upon it than did some of his followers. In his later works, he did not hesitate to acknowledge that he had at first overrated its influence. This admission, and the conclusion we have now reached, does not detract from the importance of the principle, which still remains as one of the important laws regulating organic life. The question now remains, since natural selection is not entirely sufficient, can any other explanation be offered as to the laws regulating the production of species which will supplement Darwinism, and thus bring us nearer the true solution of the organic world? To this question we now proceed.

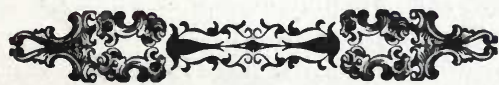




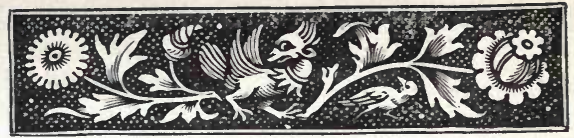

CHAPTER VII.

MORE RECENT ATTEMPTS TO EXPLAIN EVOLUTION.

THE objections against natural selection, sketched in the last chapter, are very formidable, and when taken together, amount to practical proof that this principle, as originally conceived, is inadequate to explain the organic world as we now see it. It is impossible to believe that the natural selection of indefinite chance variations could have produced the present species in their entirety. But indefinite chance variations are all that Darwin's theory supplies as its basis of development. Plainly, then, Darwinism must be supplemented by something else. We have seen in the first five chapters that, since the appearance of the "Origin of Species," the evidence for evolution has been growing stronger and stronger, while the objections have been disappearing. But we find also that during this same period the difficulties in the way of the acceptance of Darwin's explanation have increased rather than diminished. His theory, which at first seemed so readily to fill the need which was felt, has been found lacking in so many points that it can no longer be regarded as satisfactory. It must be remembered, however, that it was the followers of 
Darwin rather than Darwin himself who believed in the universal power of natural selection. Darwin did not even at first claim that his law would explain every thing, and in his later works he admits, with exemplary candor, that he had formerly overrated its power to produce changes. He still considered it to be the most important factor in the development of species, although he acknowledged that the difficulties were greater than he had at first thought.

While, then, the theory of evolution as a method of creation has become quite firmly established, the explanation offered for the theory has almost disappeared. But it is little satisfaction to admit the theory if it is no longer intelligible. If it is impossible to tell any thing about the laws which have governed the modifications of the animal kingdom, science is not much better off than it was before. It was natural selection, and not evolution, which made Darwin a leader in modern science: Since this principle can no longer be regarded as satisfactory, naturalists have been everywhere searching to discover some laws which may supplement it, and enable it to meet the difficulties raised. No one would be inclined to-day to deny that natural selection is a law of nature, and that many changes are induced by it. But while some believe it to be the all-important law of organic life, others would consider it a secondary and very subordinate principle, whose effect is of little importance. Between these two extremes all grades may be found.

It is much easier to raise objections to theories 
than to improve them or make new and better ones. No writer has had any difficulty in objecting to natural selection, but very few have been able to suggest any valuable supplement, or still less to advance any new theory better suited to the facts. Most scientists, while declining to accept the selection principle, acknowledge their inability to offer any other. Not a few, however, have offered suggestions and hypotheses as to the workings of nature in producing species, suggestions sometimes of value but sometimes worthless. To-day hardly two scientists would exactly agree in their belief in the method by which the evolution of species is brought about. It is our purpose now to consider several of the most important additions which have been suggested as aiding natural selection in producing the present species, or as acting by themselves independently of Darwin's law.

It may perhaps seem like a hopeless task to attempt to answer these questions. Science has little expectation of being able to explain life. It is quite probable, therefore, that after having investigated this question of the origin of species to the utmost, it will be eventually necessary to fall back upon some unexplored land, just as has been found necessary in all other departments of science. But this should not hinder us from following the problem as far as the ability of human reason permits.

It is first necessary to notice that there are still a few scientists who accept natural selection to its fullest extent. They refuse to admit that the diffculties are more than superficial, and they carry the 
theory even further than did Darwin. The only scientists of note who advocate this autocracy of the selection theory are Haeckel and O. Schmidt. But Haeckel is always too full of startling theories to be a safe guide, and Schmidt, from certain statements recently published, would not be disinclined to admit the inadequacy of the selection principle in some cases. Besides these scientists, there are the extreme materialists, who, reducing every thing to matter, are obliged to find in natural selection and the theory to be mentioned in the next paragraph, the efficient causes of all organic phenomena. But with these exceptions pure Darwinism is no longer accepted.

\section{Theory of Migration.}

The first additional bit of explanation which we notice is that of Moritz Wagner. We have seen that one of the greatest difficulties with the selection theory is due to the fact that crossing always tends to eliminate variations. An individual with a favorable variation will almost always be obliged to cross with an unfavored individual, and this will cause the variations to diminish rather than increase. Wagner attempts to avoid this difficulty by his theory of isolation by migration. It is a demonstrable fact that when an animal or plant is isolated from other members of the same species, there is an increase in the development of varieties. Pigeons, in the hands of pigeon fanciers, are in a condition of practical isolation, since the varieties are prevented from crossing with each other. A glance at 
the numerous breeds of pigeons indicates the value of such isolation in producing change. Wagner, therefore, believes that the only conditions where new species can arise is where one or two individuals are by some sort of isolation prevented from crossing with others of the same species. He suggests that if we suppose a small number of individuals, or perhaps a single pair, to migrate into a new country, and be prevented from returning, such an isolation will be obtained. All injurious crossing will be prevented. The offspring of this pair will be obliged to breed with each other, and thus any variations which may appear will have the chance to accumulate. For a time all of the offspring will tend to have the same variations, since produced under the same conditions by the same parents. These variations will not then be eliminated by crossing, and the result will be; therefore, a rapid development of a new species. In this manner, by eliminating the factor of crossing favored with unfavored varieties, one of the most fatal objections to Darwin's theory is avoided. Wagner uses his theory to account for the origin of man something as follows: The progenitors of man, some sort of an ape, lived in tropical Asia. One pair, or perhaps a few pairs, migrated from their home in the northern part of the continent, and their return was prevented perhaps by glaciers. This pair were now in a very different climate, and were obliged to struggle more severely for their existence than they did in the luxurious tropics. This active struggle produced rapid changes, and since they were not able 
to breed with the original unmodified stock, the variations were transmitted and augmented. This finally resulted in the development of man, the possibility of his origin arising, according to Wagner, from the early isolation of a few individuals.

Considering the series of facts already discussed, it is impossible to doubt that isolation would have something of the effect which Wagner supposes. Not only do the results of breeding domestic animals show this, but it is more conclusively shown by the fauna of oceanic islands. In many of these islands, as we have seen in Chapter V., there is almost a complete isolation of the inhabitants from the main land. These islands have been originally peopled by migration, and the individuals have been subsequently isolated, exactly as Wagner's theory assumes. We have already seen that the result of this isolation is the production of new species. In all cases where the isolation has been tolerably complete there has been a remarkable production of new species, and, if the time has been long enough, of new genera. In those cases, however, where the isolation has been less complete and there has been a chance of continual crossing with continental species, new forms have not arisen. Without doubt isolation has had its influence in the past, and we must believe that Wagner's theory expresses a truth. But to ascribe to it any thing more than a subordinate position is not possible. There are some 300,000 known species of animals living to-day, and to suppose that they all could have arisen by such 
isolation implies an amount of geographical change which is absurd. Moreover, many facts tell us that such isolation is not necessary. It is not difficult to find examples of the formation of two or more varieties in the same locality, and if varieties are incipient species, evidently isolation is not necessary for their formation. In the Steinheim lake already referred to, we have an instance of a number of new species being formed in the same locality without the remotest possibility of isolation. Or if it be claimed that the Steinheim species are simply varieties, the argument is still the same, for cross-breeding will prevent the formation of varieties just as truly as it will prevent the formation of species. Wagner's theory of isolation, which finally led its author to reject natural selection entirely, must be admitted as a factor in the production of species. Isolation will in many cases be a true cause of the production of species by preventing the interbreeding of modified and unmodified varieties. Still no one but Wagner would claim for it any thing more than a subordinate position.

Meehan has suggested that a practical isolation of individuals occurs in the extreme limits of the distribution of any species. Consider, for instance, any plant extending in great numbers over a large territory. In the centre of this region, so numerous will be the individuals that any variation will be immediately checked by cross-breeding. But upon the boundary of the territory the individuals will be so few in numbers that the offspring of the same individual will breed with each other, and thus would 
arise a practical isolation equal in its efficacy to an actual isolation.

\section{Internal Factors in Evolution.}

Most of the other theories of evolution which exist at the present day attempt to answer a more fundamental question than that covered by natural selection. Natural selection is impotent unless it has something to select, and all later theories attempt to explain the origin of variations. American scientists have, more than any others, emphasized the fact that the survival of variations is a matter secondary to their origin, and it is becoming realized more and more that this is the point to be explained. Darwin hardly attempted to answer the question at all. He recognized the existence of variations, and as an explanation assumed that animals and plants have a tendency to vary. It must not, however, be understood that he was satisfied with this explanation. He recognized that each variation had its cause, and thought that these causes existed in the environment. But his inability to discover them caused him to make the above assumption provisionally, and to call the variations due to chance. We have, however, seen that it is no longer possible to believe in an evolution founded on the selection of chance variation. It becomes necessary, therefore, to reduce this material to law, and the theories which we are now to consider endeavor to do this.

It is plain that if evidence can be found for believing that variations have been definite in direction, and have effected numerous individuals simul- 
taneously, a step is taken toward the solution of the problem. If any reason can be found why variations should thus be definite, nearly all of the objections above considered will disappear. To do this, scientists have thought it necessary to find some internal forces regulating the organism. That some internal force exists seems to be quite conclusive. It is found that the same circumstances do not always produce the same variations. Some animals vary much under circumstances where others vary very little. Variations of any species are not absolutely indefinite, but, while they may be quite diverse, are still found in definite directions; the horse, for example, has no tendency to produce horns. It seems hardly questionable that there have been periods of rapid modification alternating with those of comparative rest. We have seen that it is necessary to assume the existence of some sort of internal factor to explain the homology of serial organs, such as that of the arm and the leg. Something of the kind is needed to explain the independent development of the same complicated organ in different animals, such as the vertebrate and mollusk eye. Many instances are known of a large number of animals in very diverse circumstances varying in the same direction. All Australian marsupials, for example, have shown a tendency toward the reduction of the second and third digits, and since they live under very different circumstances this cannot be due wholly to the environment. All such facts as these, and numerous others might be mentioned, which certainly indicate that there is something be- 
sides the external conditions regulating the variations of organisms.

\section{The Theory of Nägeli.}

In regard to these internal laws governing the origin of variation, science is profoundly ignorant. Since it is not yet possible to say why a child is like its parents, it is certainly difficult to understand why it should be different. Most theories are therefore little more than suggestions thrown out as perhaps indicating a truth, but as requiring more evidence before they can be accepted.

The first attempt to find an internal force, which we notice, is that of the German botanist Nägeli, which is really little more than a statement that such a force exists. He assumes the existence in the organism of an internal tendency toward progression and perfect development, and believes that in accordance with this tendency organisms are constantly varying in such a manner as to rise in the scale of nature. Here is postulated an internal force, which, if it exist, is certainly able to explain all the facts. The only questions are whether there is any evidence for the existence of such a force, and what can be our understanding. of it if it does exist. Nägeli advances, in favor of his view, various series of facts already considered, which indicate some internal force. He thinks that the fact of a continual progression from the lower to the higher in the modification of species is evidence that some definite tendency to advance exists. Natural selection only seems to make animals better fitted to struggle with 
their enemies, and does not cause them to rise. $\mathrm{He}$ emphasizes the existence of the development of structures which are of no use to their possessor, and believes it utterly impossible that the whole complicated organism of higher animals and plants could have been built up from unicellular organisms without an innate tendency to rise.

But no one of these points, nor all of them together prove Nägeli's innate tendency toward progression. Most of them we have already sufficiently considered. While they do raise difficulties for Darwinism, they do not by any means show the existence of any law similar to the one assumed. The only argument which needs special attention is the one which claims that the fact of a progression in the past requires such a tendency to rise. To this Darwin has answered that natural selection would also imply a progression. The best definition which has been given to a grade of organization, is the degree to which the parts have been specialized or differentiated. Now it is of undoubted advantage to animals, as a rule, to have their parts specialized. Since this is of advantage, natural selection will produce an advance in specialization. It is not necessary, therefore, to assume any innate tendency to rise to account for an advance in organization. Moreover, the existence of such a constantly acting tendency is disproved by the fact that in many animals there has been a degradation in structure. Many individuals living to-day are lower in their organization than their ancestors. Parasitic animals in general are examples of this class. 
The chief objection to Nägeli's theory is, however, that the theory is more difficult to understand than the facts which it attempts to explain. When we attempt to imagine to ourselves what is meant by an innate tendency, or how organisms can possess it, we see at once that the theory is of no value toward helping to an understanding of the problem. The statement that organisms have an innate tendency toward progression is simply another way of saying that they have advanced, and are still advancing, toward greater complication. Nägeli recognized that organisms were advancing, saw that natural selection was not sufficient for an explanation, and, to comprehend the facts, assumes this tendency, of which he knows nothing and can know nothing. At best, therefore, it gives no better understanding of evolution. It is of no assistance to say that this tendency was placed in animals by the Creator, until we can get some idea of what the tendency is and how it can be transmitted from generation to generation. While we may admit that such a tendency, if it existed, would explain many difficult problems, we must realize that there is no good evidence for its existence, and that its very meaning is obscure. To attempt to explain species on such a theory is to abandon the attempt altogether, and to admit the problem to be insoluble.

\section{Theory of Extraordinary Births.}

Somewhat akin to this idea of Nägeli's, is the theory of St. George Mivart. Similar, because in like manner it appeals to internal causes acting on 
organisms, of whose workings we know nothing. Mivart, after marshalling in battle array ali of the possible objections against natural selection, comes to the conclusion that it is a law of nature of little importance, and playing only a secondary and very subordinate part. He advances in its place a theory, of which he is not, indeed, the originator, though he is its chief exponent. Owen, Kölliker, the Duke of Argyle, and other well-known scientists, share his views. He thinks species have arisen sud. denly, by extraordinary births and not by slow modification. He grants that a very great amount of variation may occur in any species: experiments with domestic animals prove this too conclusively for denial. But he thinks that these variations are not indefinite and not unlimited. They are, in his view, always in certain directions, and always confined within certain bounds. By variation alone, he says, no new species ever arise. By ordinary variation many cases may be developed, differing from each other in very marked degrees, but they form simple varieties, are always within the bounds of the species, and never become so different as to be sterile when crossed. Mivart does not believe, therefore, that varieties are incipient species. Species arise by sudden extraordinary births. An animal is born which differs from its parents, in certain respects, so much that it is from the first a new species. It is a " new chord in nature." As to the laws regulating such births, Mr. Mivart acknowledges complete ignorance, but he thinks that enough strange births are known to indicate them to be the factor sought. 
Examples of such births are sufficiently common arising from causes not at all understood. Some of them are to be considered as malformations; but it is not impossible that even such features should occasionally be of enough importance to be the origin of a new species. But many such births cannot be considered as malformations. Two or three of the best instances it may be well to give here.

The Ancon sheep is a breed with dwarfed legs, and it made its appearance thus suddenly : A Massachusetts farmer found a single ram in his flock in 179I which possessed dwarfed legs. Thinking that such a peculiarity might be valuable in preventing the sheep from jumping fences, he preserved this ram to breed from. The result was that the Ancon sheep thus arising soon supplanted the original variety. It was found that when the Ancon ram was crossed with a ewe of any other variety, the offspring was not an intermediate variety but of the pure Ancon type, a fact which will be seen at once to be of extreme importance, since it shows that crossing will not always eliminate variations. Dr. Godron, of Nancy, upon sowing some Datura tatula, whose fruit is covered with spines, discovered among the plants raised an individual whose seed capsule was smooth. The seeds of this plant were preserved and again sown, and all of the plants coming from them showed the same peculiarity. The seeds of the next generation were again sowed with like result ; and so on, so long as the experiment continued. It was also found that when the smooth variety was crossed with the original form hybrids 
were produced resembling true hybrids; and in the second generation they reverted to the original type, just as is the case in true hybrids between species. A more remarkable case still, is the appearance in five distinct cases in England, of a special new breed of peacock known as the black-shouldered variety, which was so different from the ordinary form that Dr. Sclater regarded it as a distinct species This animal was produced in flocks of peacocks composed entirely of the ordinary kind, making its appearance suddenly by ordinary generation. This variety was allowed to remain with the others and breed freely with them, but even under these conditions, in some cases, it increased in numbers until it replaced the previously existing form. These three instances will serve as illustrations of extraordinary births. Many others might be given, most of which have been collected by Darwin, who is the greatest authority on variations of all kinds. Naturally all of these instances occur in domestic animals or in plants, for it would be impossible to distinguish them among wild animals. If such an individual were found in nature there would be no means of knowing how it arose. It would, of course, be set down as a new variety or species and that would be all that would be known about it. Probably many such individuals have been found and are in our collections now; but since there is no means of telling how they arose they are called examples of rare species.

These extraordinary births do then occur, and Mr. Mivart thinks they represent the beginning of a 
new species. He believes further that all species arise somewhat in this way. He recognizes as the foundation of these births an internal law presiding over the action of every part of every individual and of every organism as a unit, and of the entire organic world as a whole. "By such a force from time to time new species are manifested by ordinary generation." A sudden extraordinary birth takes place, and the animal thus born becomes the progenitor of a new species.

Such a theory would avoid most of the difficulties enumerated in the preceding chapters. The difficulty of geological time is evidently no longer of any importance, since species appear suddenly. The absence of transitional forms between existing species, an absence which we have seen both among fossils and living forms, is no longer so much of a surprise, for the infinite number of transitional forms assumed by the selection theory have not existed if Mivart's view be true. The difficulty of conceiving the rudimentary beginning of organs and of understanding how organs could be built up by minute stages is completely avoided. If it be conceded, as Mivart believes that there is an internal bond uniting animals and regulating their development, there is an immediate explanation of serial homology, and of the independent origin of similar structures. Highly complicated organs no longer become a trouble, since in these extraordinary births considerable changes occur at once. Finally, the difficulty of the elimination of variations by crossing is largely done away with, since observations have 
shown that these extraordinary variations may be propagated truly even when the individual crosses with unmodified forms. Indeed, the theory of sudden births succeeds in meeting nearly all of the difficulties which we have enumerated in the preceding chapters, while at the same time it fills equally well the necessities of the evolutionary argument.

This theory of Mivart is a sort of compromise between evolution and special creation. It grants the genetic connection of species, and is thus evolution; but it assumes this sudden and separate origin according to unknown laws, and is therefore, in a sense, a special-creation theory. Mr. Mivart's views are brought forward with a clearness and force seldom found in scientific writings, and can scarcely fail to carry a certain amount of conviction. But it cannot be considered that this theory is much more satisfactory than the others. Unless his jumps are enormous, such, for instance, as the sudden development of the wing of the bat or the bird, no light is thrown on the origin of complicated organs or the absence of transitional links. Such jumps as these even Mr. Mivart would hardly assume. Moreover, the facts of classification, the relationship of species, the many cases of fine gradations existing between species, the impossibility of distinguishing species and varieties, the arrangement of species into groups and sub-groups, are facts which indicate that in some instances at least species have arisen by small steps. The idea of sudden jumps is not in accordance with such facts. Mr. Mivart claims too 
much for his sudden births. That this factor may have had its influence will hardly be denied by any one, and in some cases new species may have arisen in accordance with these extraordinary births. This theory has so many facts in its favor that it seems as if it must have a certain amount of truth. But at the same time it will not account for all of the facts of nature and some of the difficulties which we have seen are just as forcible even when we substitute these sudden jumps for the minute variations of Darwinism. While every one acknowledges that natural selection is a potent factor in the modification of species, scientists refuse to consider it as more than one factor. And in the same way, while it seems probable that sudden extraordinary births may have had their influence in the origin of species, here too it must be recognized that we have only a single factor.

Indeed, after all, this theory of Mivart does not very much help toward a solution of the problem of the origin of species, for, like the theory of Nägeli, it does not explain, but refers every thing to unknown internal forces. To be sure, in this case, it is a demonstrated fact that some internal force exists, for it cannot be questioned that these extraordinary births do sometimes occur. Since we believe nature to be univcrsally governed by law, even these irregular occurrences must be under the influence of some law. But of its working and significance Mivart can tell us nothing. We have seen that natural selection is lacking, since it is founded on variations which it cannot explain. The same ob- 
jection is even more forcibly urged against Mivart's theory since these extraordinary births are more difficult to understand than are simple variations. The appeal to an internal law regulating them is no explanation, but simply a method of avoiding the question.

Neo-Lamarckianism : Use and Effort.

A theory more intelligible than the preceding, and more logical, since it appeals to known rather than unknown factors, is the old idea of Lamarck. This theory finds in use and effort the active forces causing the modification of animals. It is, perhaps, the simplest explanation which has been offered. Not only this, but it was the first suggestion. Lamarck, who first formulates a definite evolution theory used this idea as its foundation. But the theory did not find favor with Darwin, and it has, consequently, received little support until within a few years. It has of late, however, been taken up by various American scientists, who, having made some slight modifications, have ably supported it. The theory as held to day has been called neoLamarckianism, and may be regarded as the American school of evolution, since its chief supporters belong to this continent. Its most prominent advocates are Cope and Hyatt.

Neo-Lamarckianism finds the primal modifying factor in the activities of animals in their endeavors to meet the requirements of changing conditions. Something is attributed to the direct action of chemical and physical forces produced by changes 
in food or physical conditions. But the chief agencies in producing variations are habits of use and disuse of various parts. Darwin, indeed, recognized this factor, but believed it of slight importance. NeoLamarckianism regards it as by far the most important factor.

That the use of an organ has great influence upon its development in the individual so using it, is a fact too well attested to admit question. The size of the blacksmith's arm, the general development of the body of the gymnast, the delicacy of the blindman's feeling, the acuteness of the musician's ear, the degeneration of any organ whose use has disappeared-as a paralyzed arm,- are all conclusive proofs of this fact. Now, if continual use of an organ results in an increase of its efficiency, and if, further, the offspring of the animal so using it inherits this increased efficiency, it is evident that it is no longer so difficult to understand the develop. ment of organs. Physiology teaches us why it is that increased use has this effect. Any use of a part above the normal, causes an extra amount of blood to flow to that part, and an increased activity of its various cells. If, therefore, any organ become of new value to its possessor, by reason of any change in conditions, it will be used more, and so long as it is thus used, its activities will increase, and, consequently, its size and efficiency. If, now, the offspring of such an individual has a tendency to inherit the peculiarities of its parents, the second generation will have the organ in question better developed to start with than did its parents. During 
the life of this generation, if the same conditions remain, use will still further increase the perfection of the organ, and the third generation will be better endowed than the second. And so on, by continual use any part will increase in size, and there will thus constantly arise variations or, better, regular modifications in just those organs where development is needed.

This theory finds the modifying cause in the activities of the organism. Any form of motion, conscious or unconscious, will produce its effects. But most of the motions of animals are regulated by consciousness and effort on the part of the animal. This school, therefore, finds in the efforts of the individual one of the most important factors in producing variation. The statement that effort is an important factor in evolution is liable to a misunderstanding. It is frequently thought that the theory implies that animals develop certain organs because they make an effort to do so; but this is so much beyond the power of animals as we know them, that it is absurd. But the theory of effort and use is very different. Organs develop as the result of effort, it is true, but the effort is directed toward the satisfying of certain wants, and has only an indirect relation to the development of the organ in question. An animal has the consciousness of hunger, and, in order to remove this painful feeling, strives to reach the food on the branches above its head. As a result from the continuation of this effort and consequent strain, the neck is lengthened. Or an individual endeavors to escape from its ene- 
mies by running from them. This is the effort on the part of the animal; but the result is the strengthening and increase in size of the muscles of the legs, and the individuals become better adapted for running. And so in general. The effort is to satisfy certain wants, and the result is the development of new activities. Hence the modification of organs by use.

To make this theory of use and effort of any significance (the same may be said in regard to Darwin's theory), it is necessary to assume that the child has a tendency to inherit these peculiarities at an earlier age than they were acquired by the parent. This law, which is called the law of accelerated development, causes the variations arising by use or otherwise to be inherited at earlier and earlier ages as generations go by. An increase in the size of an organ first acquired in middle life would, after a number of generations, be possessed by the young. For example: the large arm of the blacksmith is acquired during manhood, but, according to the law in question, the children would have a tendency to develop this large arm at a slightly earlier period. If they followed the same trade, their children would inherit the same peculiarities still earlier. And if the family continued to follow the trade of blacksmith, the peculiarity would be carried back to the young, and the children would show from their birth that they were blacksmiths. This principle of acceleration is believed by some to be universal. By others it is regarded as not universal, since in certain cases they think an 
actual retardation has taken place. It is evident enough that acceleration must be the general rule. The fact that embryology repeats past history, is a sufficient proof of this, for such a repetition would be impossible without such a law.

Neo-Lamarckianism would, therefore, tell us that one of the most important factors in the modification of organisms is consciousness, which is the cause of various activities. Cope regards consciousness as one of the fundamental properties of protoplasm. He thinks that all activities, even those now automatic, such as the circulation of the blood, were originally acquired by conscious effort. But at all events it is plain that consciousness does regulate the use or disuse of organs, and hence if this theory is true, it is a very potent factor. Food becomes scarce in any locality, and animals, driven by their hunger, migrate into new regions, where they find new conditions and new enemies to contend with. In their endeavors to meet the new conditions they acquire new activities, and these cause, by the principle of use, variations to appear. All individuals thus circumstanced will be affected in the same way, and there thus arise simultaneous variations, which may be preserved or rejected by natural selection.

It is plain that this theory is more applicable to animals than to plants. The motions of plants are slight, and their consciousness is very questionable. Use and effort would have little effect here. Still to a certain extent it is believed to apply even here. Plants do have a certain amount of motion of their various parts, leaves, tendrils, etc. The sap is con- 
stantly in motion. Low plants move freely from place to place. The visitation of insects produces indirectly a certain amount of motion which has its influence. Even in plants, therefore, the activities of the individual may be the important origin of variation.

This whole theory is very simple and logical. But there is one point which must be more definitely proved before use can be accepted as having the farreaching influence here supposed. It must be more surely demonstrated that animals do inherit the effects of use and disuse. That use does increase the size of organs in the individual using them can not be questioned; but it is by no means so certain that this effect is transmitted to the next generation. The blacksmith develops a large arm, but the arms of his children are no larger than those of other children. 'It is indeed very seldom that any direct evidence can be obtained of the inheritance of acquired variations of this character. Darwin, with the vast amount of evidence at his command, was inclined to think that they were not, as a rule, transmitted, and that, therefore, this principle was of little importance. He has given some instances, however, which he ascribes to the effect of use or disuse. Rudimentary organs, for instance, can be explained in no other way. But the direct evidence of observation would hardly be expected, even if the theory were true, since the effects of inherited use would be so difficult to distinguish from those of actual use. In order that a blacksmith's children should show any marked difference, it would be 
necessary that the trade of blacksmith should be followed by the same family for many generations, and who could tell at first how much the young smith owed the large size of his arm to inheritence, and how much to direct use? But our American scientists have collected many instances which show that the effects of use are inherited. One example is the shape of the teeth of ungulates. A careful study has shown that the shape of the tubercles of their teeth is exactly such as would have resulted from the motions of their jaws. Different groups of ungulates have different shaped teeth; but the motion of their jaws is also different, and the two are found to be correlated. Now since these tubercles appear while the animal is very young, they must be due to inheritance. And since it is hardly possible to conceive them of enough importance to be developed by natural selection, it is claimed that they are instances of the inherited effect of use. A number of cases of similar import have been advanced as proofs of the fact, so necessary for the neo-Lamarckiann theory, that the effects of use and disuse are inherited.

This brings us to a final question, which really lies at the bottom of the whole matter. What are the laws of heredity? What sort of characters does an animal inherit from its parents? We can certainly find abundant variations arising either from the indefinite variability of Darwin, the extraordinary births of Mivart, or the effects of use and effort. Are these variations all inherited? The final question is thus the explanation of heredity. 
If we can find out the reason why a child is like its parents, we shall doubtless know why he is different in certain respects. Scientists are searching to-day after some explanation of heredity. Already several hypotheses have been advanced; but it will be admitted that they are only hypotheses, more or less probable, but usually created to fit the facts, instead of being called for by them. None of them are far enough advanced to be rightly called theories, and it would as yet be impossible to find any two scientists who agree upon any positive conclusion on this matter. Of the various hypotheses, probably not one is fully accepted by any person but its author. These theories are, however, a necessary part of the explanation offered for evolution, and it is desirable before closing this account of the theories of evolution to consider at least two of them which bear particularly upon the subject we are considering.

\section{Heredity.-Theory of Weismann.}

In looking at this question of heredity, we find, to start with, that not only are the explanations of the law in dispute, but even the facts are by no means agreed upon. That an animal cast inherit from its parents, is everywhere admitted; but beyond this very general statement there is little unanimity of opinion. Whether it can inherit all sorts of peculiarities, or only certain definite kinds; whether it inherits from both parents alike, or from only one; or whether one sort of traits is inherited from the male parent, and another from the female 
parent, are points yet in dispute. More important still is the question whether an animal is able to inherit from its parents any features newly acquired by them, i. e., any peculiarity which its parents acquired after reaching their adult condition, such as accidental mutilations, etc. These variations are known as acquired variations, and it is still a question not definitely settled how far they can be transmitted from one generation to another. It might seem that these points wonld be easy enough to settle by simple observation, and doubtless every one will call to mind instances which seem to prove the truth of some of these positions. But so many modifying circumstances arise to vitiate the results, and so contradictory are the various facts observed, that it has been found thus far impossible to come to any unanimous conclusion even on these simple questions of fact.

The first hypothesis which we notice is that of the German naturalist Weismann. This we consider first, not because it is the oldest, for it is the most recent theory; but because it is the simplest, and has a direct bearing upon the theories of evolution. In his explanation Weismann turns for assistance to the lowest animals and plants-the unicellular organisms, in which reproduction is the simple result of growth. In these animals-the amœba, for instance-the body consists of a small bit of protoplasm, without much differentiation into parts. Having no mouth nor respiratory organs, they must absorb all of their food and gases through the surface of the body. Now, by a well-known mathe- 
matical principle, when the body increases in size, the surface increases as the square of the dimensions, while the bulk increases as their cube. The bulk of the animal increases, therefore, faster than the absorptive surface. The animal continues feeding and growing, until it finally reaches a size when its bulk is too great to be kept supplied with the nourishment absorbed by its surface. When this limit is reached, the body simply breaks into two pieces, each of which becomes independent, and goes on feeding precisely as did the original animal, until once more the limit is reached. Here is a simple form of heredity, and there is no difficulty in understanding it. Each of the resulting individuals is like the other, and like the original, because each is half of this original. And there is, therefore, no reason why they should be unlike. Now, with this simple case in our minds, it is not difficult to explain heredity in higher animals. Every animal, let us for convenience say man, is derived from an ovum, which is, like the amœba, a single cell composed of a mass of protoplasm. Of course, this ovum differs from the amœba in possessing the power to develop into a complicated man, but, nevertheless, it is a single cell, and in this sense the two are strictly comparable. When this ovum begins to develop toward the adult, the first change that takes place is its division into two parts. Now, remembering the former case, Weismann says that, just as it was not difficult to see how the two halves of the divided amœba were alike, so it is not difficult to understand here how each half of the divided ovum is like the 
other half, and hence like the original ovum. The original ovum was capable of developing into a new man, and so each half which has resulted from this first division is in like manner capable of developing into a man. But, although both of these segments possess the power to develop, only one of them does develop at once. This one begins immediately to undergo changes resulting in its speedy development into an adult, which we will call the first generation. The other segment, however, instead of developing, remains unchanged. It becomes inclosed in the body of the embryo developing from the first segment, and there it remains even after the individual is born. Suppose, now, this individual, born from the first segment, be a female, the dormant segment finds its way into the ovary of this female, and remains there as an ovum. Years afterward, when maturity is reached, and the proper conditions present themselves, this ovum ceases its dormant condition and begins to divide, just as did the previous ovum. One half of it develops into an individual-the second generation,- while the other half remains dormant in the body of the second generation, to develop in like manner in its turn. And so on; half of the ovum is carried over from one generation to the next. It is, with this hypothesis, easy to see why the second generation should be like the first, since each is developed from half the same ovum. And so it is just as easy to understand why the third generation should be like the first and second, since all have arisen by direct de-scent from the same ovum. Thus every generation 
is like the preceding generation. This is heredity according to Weismann. A child does not inherit any thing from its parents directly, but only from the ovum. It is like its parents not because it has inherited any thing from them, but because both itself and its parents are derived from half of the same ovum, an ovum existing in the body of its grandparent.

This is of course all hypothesis; but it is very simple, and has in its favor certain embryological facts. But it will be seen that it absolutely precludes the possibility of any animal inheriting any thing directly from its parents, and consequently acquired variations cannot be transmitted to succeeding generations. According to this view, every child would inherit exactly the same peculiarities which its parents inherited, without reference to any features which were developed in its parents by mutilation, or use and disuse. Such acquired variations would only affect the adult and not the ovum, and since the child inherits from the ovum only they could not be inherited. Weismann accepts this conclusion, and goes to some length to show that there is really no evidence that acquired variations are inherited. He says that the only variations which can be inherited are variations which affect the ovum. If this should vary from any cause, all individuals arising from it would of course show the same results of the variation, and since all future individuals do arise from this ovum, by repeated division, it is evident that the results of an ovum variation would affect all future genera- 
tions. Thus an individual, A, may show in its adult condition some new feature, and its offspring, A, ${ }^{1}$ may show the same. The ordinary interpretation would be that $\mathrm{A}$ transmitted this feature to $\mathrm{A}^{1}$. But Weismann would say that the ovum from which A developed varied in such a manner that this new feature appeared in the adult. And since A was developed from one nalf of this ovum, and $A^{1}$ from the other half, the same feature would appear in both, and would then seem to be transmitted from one to the other. Weismann further believes that the ovum is especially subject to variation, being readily influenced by many circumstances. There are constantly arising variations which are transmitted from generation to generation, but they are all derived from variations of the ovum and never of the adult.

It is evident that with this explanation of heredity no chance is left for the inherited effects of use and disuse. Since no acquired feature is inherited, it would make no difference how much an organ was increasd by use or diminished by disuse; it would have no effect on the next generation. Congenital variations alone-i.e., those arising in the egg-can be inherited. But to accept this position Weismann is obliged to explain away many cases of wellattested facts. The blind eyes of some animals is only explained by a loss of function and size by disuse. There are a number of cases on record where accidental mutilations are inherited, although this, as a rule, is not the case. The numerous instances of this kind are sufficient to show that Weismann's theory is not wholly correct. But even more than 
this, - the only principle left upon which Weisman can explain the modification is selection. Having banished inheritance from parent to child, the accumulation of variations must be by the selection of such chance varieties as appear in the ovum. Even though it be claimed that the ovum is particularly subject to variation, it is plain that all of the objections urged against natural selection return with redoubled force. When in addition we remember that there is in some cases positive evidence of the inherited effects of use and disuse, it is evident that this theory of Weismann must be somewhat modified before it can be accepted. It only adds difficulties to the problem without removing them. While it may be that Weismann has found the explanation of heredity, he has failed to find the explanation of variation.

\section{Haeckel, Fager, Darwin.}

A number of other explanations of this fundamental fact we pass over with a word, since they only profess to be explanations of heredity, without materially assisting toward the solution of the problem which we are considering-the modification of species. Haeckel has a theory which he calls perigenesis, but it is little more than one of words. He thinks that the individual atoms of the body remember. The essence of his theory is that heredity is an unconscious memory, the various parts of the body remembering the corresponding parts of the ancestor. This, with the suggestion that reproduction is the transference of a wave motion 
from one individual to another, something like the transference of fire, is his explanation. But this is of little assistance. To call a principle heredity, or memory, or a wave force, gives about the same idea in any case; and no one of them helps to understand why child is like parent.

Dr. C. Jager has a very different view. He says that all parts of the body are giving off from themselves an immaterial essence, which he calls soul stuff. It is this soul stuff which gives to each animal its own specific odor, and it is different for every individual. The reproductive products, he says, collect this soul stuff, and store it up in themselves. When now these reproductive bodies develop into new animals, they take the form of the parents, since they are filled with a like soul stuff. The essential feature of this explanation is the supposition that every part of the body is giving off from itself a substance which is transferred to the next generation through the ovum and the spermatozoön.

Darwin has also advanced an hypothesis, which he calls pangenesis. He assumes that "the whole organization, in the sense of every separate atom or unit, reproduces itself." Each part of the body is constantly giving off from itself minute atoms, which he calls gemmules. These gemmules circulate around the body, so that there are present in every part millions of them, some being present from every other part of the body. When, therefore, the ovum gives rise to a new individnal, it develops into the parent, since it has within it gemmules from every part of the body of the parent. Thus every peculi- 
arity of the parent, either congenital or acquired, might be inherited by the child.

\section{Theory of Brooks.}

A more recent theory requires more extended notice, since it not only attempts to explain heredity, but also variation ; and not only variation, but simultaneous variation affecting just those parts which need change. If this theory can expain the occurrence of numerous simultaneous changes in those organs which need change, and can demonstrate the inheritance of the effects of use, it is plain that a large portion of the difficulties which have arisen in the way of all theories are removed. The theory in question is that of an American scientist, Brooks, and is in some respects a combination of all the others, but chiefly of the pangenesis of Darwin and the theory of Weismann. Brooks takes into account the two sexes, believing that they have a different share in heredity. Like Weismann, he explains heredity proper by an appeal to the division of the ovum. He also would say that early in the development, the ovum becomes separated into two parts, one of which develops into an embryo immediately, while the other remains dormant in the ovary of the developing individual until maturity, when it in time goes through its development. It may, meantime, of itself, divide into many parts, each like every other, so that the ovary may at maturity contain many similar ova. Heredity is then due to descent from the same ovum, and if the ovum were the only factor to be considered, every child would 
be exactly like its parents and grandparents. Thus far the theory is similar to that of Weismann, al. though Brooks arrived at the hypothesis independently. To continue with Brooks. Since, therefore, the ovum is confined to the female sex, an animal inherits from its mother the characteristics of the race which have been long continued, and which its mother inherited from remote generations. If reproduction were confined to the female sex, there would be no chance for the inheritance of acquired features. (Exceptions to this rule will appear presently.) Congenital variations might appear, but this would be all. Brooks has collected a large amount of evidence, which he thinks proves this point. He finds that in animals where parthenogenesis occurs, i.e., reproduction through the female sex alone, there is almost no variation, all individuals being almost exactly alike for generation after generation. $\mathrm{He}$ thinks, therefore, that were reproduction confined to the female sex, variations would be comparatively rare.

But reproduction is not confined to the female sex, and variation is, according to Brooks, due chiefly to the influence of the male. To explain this, he supplements his theory with a modification of Darwin's pangenesis. Like Darwin, he assumes that the various parts of the body are capable of giving off from themselves little bodies called gemules. But, instead of imagining them to be scattered indefinitely through the body, he assumes that it is the especial function of the male element to collect them. The gemmules arising from the various 
parts of the body have a tendency to accumulate in the male generative organ. The spermatozoön may be regarded as a store of these gemmules. Now, when these spermatozoa unite with the ovum in fertilization, there is introduced into the ovum a store of gemmules from the body of the male. The introduction of such a lot of new organisms into the ovum must change its constitution, and this, of course, would cause it to develop in a different manner from what it otherwise would have done. In this way is induced a tendency to variation in the offspring of sexual reproduction. The ovum itself would develop in the same manner as did the previous generation, but the fact that it has united with the male element of another individual has introduced into it a lot of new elements. These introduced gemmules so alter the ovum that it develops somewhat differently from the previous generation. The theory goes on to say that these gemmules do not affect the whole ovum, but each its own special part. Suppose, for instance, that certain gemmules from the parts of the eye of the male enter the ovum in fertilization. These gemmules will be attracted by some internal affinity to that part of the ovum which is to give rise to the eye of the next generation, and hence the eye will become variable. So with other parts, an internal affinity is supposed to cause the gemmules from the different parts of the body to unite with corresponding parts of the ovum. In this way a child might inherit acquired variations from its father, though not, as a rule, from its mother. 
It may sometimes happen, however, that gemmules arising in the female might find their way into the ovum directly. If so, the ovum would be directly modified without the interference of the male, and an acquired variation of the female would be transmitted. The male element is, however, specialized to collect these gemmules, and therefore the variations arising through the male will be much more numerous. Finally, Brooks assumes, and this is the important part of the hypothesis, that, although every part of the body has the power of giving rise to these gemmules, under ordinary circumstances this does not occur. So long as any part of the body is in perfect harmony with its surroundings, it simply performs its functions without giving off gemmules. But just as soon as unfavorable circumstances occur for the organ, gemmules arise, which, finding their way into the male sexual bodies, and hence into the ovum, affect the corresponding organ of the next generation. For example, let us suppose some terrestrial animal to change its habits of life and begin to live in the water. Its eyes, which had previously been adapted to the air, are, of course, unfitted for water. These unfavorable conditions cause the animal to strain its eyes in using them, and this strain causes the various parts to throw off gemmules. These gemmules find their way into the spermato. zoön, and hence, at fertilization, into the ovum. Here, by their affinity, they affect that part of the ovum which is to give rise to the eyes of the next generation, and this will cause an immediate development of a large amount of variability in the eye. 
Evidently this would happen to all the offspring of individuals in the same circumstances. Many individuals would thus vary simultaneously. Now, natural selection, having simultaneous variations to work upon, may preserve the favorable varieties and destroy the unfavorable. Every organ placed out of harmony with its environment will thus begin to vary, and the variations will appear where they are needed. Moreover, the inherited effects of use and disuse receive explanation in the same way; for an organ, used either above or below its normal amount, will be out of harmony with its conditions, and will throw off gemmules.

In a word, it is from the fact that a child and its mother are both developed from part of the same ovum, that is due the inheritance of the long-continued characteristics of the race. This is heredity. But the origin of gemmules, and their introduction into the ovum by fertilization, cause the ovum to become different in its constitution, and the individual arising from it is therefore in some respects unlike its mother. This is variation.

The important features of this theory are, first, the claim that the male is an individual which has become specialized for the production of variation, while the female transmits race characteristics; and, second, the claim that the laws of the organism are such that variations appear in abundance in those organs where they are needed. The suggestion of gemmules is simply an hypothesis to explain these two laws. It is an important theory, because it is the first attempt to explain the origin of simultane- 
ous variations for successive generations in those parts where change is needed. If it can be believed that these laws are real ones, it is plain that a long step is taken toward the solution of the problem of the modification of species. The various objections urged against natural selection, from the indefiniteness and minuteness of the variations, all disappear. The views of those who believe in the great effect of use and disuse receive much support, and even the extraordinary births of Mivart are somewhat more easily understood. This theory of heredity is therefore an addition to all of the views we have examined.

It would be premature to attempt to draw any positive conclusion in regard to this theory of Brooks. There are certainly many objections which arise and will preclude its acceptance in an unmodified form. While it very aptly explains certain series of facts, it will not apply to all. But that this theory may have reached one of the important laws of heredity seems highly probable.

\section{Summary.}

The theories noticed in these two chapters are not the only ones which have been advanced with a like object, namely, to explain evolution. The others are, however, of less importance, and need not detain us. It will probably appear to many readers that none of them are satisfactory, and that, granting evolution to be true, the explanation is not yet fully obtained, not even by a satisfactory hypothesis. Let us notice again the problem to be 
solved. Practically, all scientists accept evolution as expressing a fact of nature. Having thus by their theory eliminated special creation of species, it becomes a logical necessity to show how the working of natural laws could have produced an evolution. To admit that the present species are descended from older ones is no advantage, unless it can be shown that new species can arise from old ones by the working of acknowledged laws of organic being. Two series of facts, it is plain, must furnish the data for all explanation: heredity and variation. By heredity, species reproduce their own kind; by variation, they produce offspring somewhat different from themselves. These two series of data are not theoretical, but actual. It is a universally recognized fact that animals and plants inherit from their parents, and it is also universally acknowledged that they vary very mnch. Out of these two series of facts, then, must the explanation arise.

Darwin turned his attention to the facts and selection of variation. This subject he patiently studied for many years, collecting a vast amount of material. With all his work he was unable to discover any important laws which regulated the appearance of variation. So irregular are they in their appearance, so indefinite in direction, and so completely beyond the realm of prediction, that he expresses his conclusion by saying that organisms have an innate tendency to vary, and that the variations are chance variations. By this he simply means, first, that though they all have an efficient cause, the causes are com- 
pletely hidden to the naturalist; and, second, that they are primarily unrelated to any advantage resulting from them. They arise indefinitely, and some of them chance to be useful. Darwin spent many years in trying to prove to himself and others, that it was the natural selection of such chance favorable variations and their transmission to succeeding generations that forms the fundamental explanation of the gradual modification of species and the consequent production of new ones. He admitted that other factors had a certain though subordinate part, such as use and disuse, or the direct effect of physical conditions. He thought that ornamental structures and sexual differences were due to the interaction of the sexes. To make his theory complete, he forms an hypothesis to explain heredity, which, however, really forms no part of his general theory, and is of little importance. But aside from this, natural selection has been found inadequate in many other points, so that even its author, in his later writings, was induced to think it of less importance than he at first believed. Wagner suggested that species were formed by isolation of a few individuals, and this theory eventually led him to abandon natural selection. Isolation avoids many difficulties met by the theory of Darwin, and probably has had its influence. But while isolation may have been a factor in many cases favoring the modification of species, it is impossible to believe that all species have arisen in this way. The theory is too small a conception for the facts.

Since the simple selection of chance variation 
is insufficient to account for evolution, Nägeli has thought to help the explanation by the assumption of an innate tendency toward progression, which regulates the variations and modifications of individuals in such a way that a continual advance is the result. This hypothesis is, however, not only uncalled for by the facts, but it is inconsistent with some of them, and it has the further disadvantage of being completely incomprehensible. No one can form the slightest conception of what a tendency is which may continue to reside in animals for millions of years, and can be transmitted from one generation to another. Although we may doubtless be obliged to accept facts which we don't understand, there is no need of accepting such a one as this unless the facts unquestionably demand it. Mivart thinks that species are sudden in their appearance, having their origin in extraordinary births. He further assumes, as a regulation of these births, a unitary bond running through nature. Of this bond he can tell us nothing, not even whether it is the result of natural law or not. He would probably consider it a supernatural bond. This view is an evolutionary one, since it admits genetic descent; but it is, to a certain extent, a view of special creation, since it assumes that each species has had a sudden origin regulated by some unknown force. Some American naturalists have resuscitated the old Lamarckian theory, that it is the inherited effects of use and disuse which contain the explanation sought. Consciousness and effort come in here as an important factor. But. 
although the collateral evidence for this view is not wanting, there is some difficulty in getting direct evidence, since it is even denied that the effects of use and disuse are inherited at all. In order that this explanation should hold, it is therefore necessary to show that such features are transmitted from one generation to another. It is therefore necessary to study carefully the other series of data which we have to work with-viz., heredity. In doing this Weismann has found an explanation of heredity, which causes him to believe that the effects of use and disuse are not transmitted. $\mathrm{He}$ is, consequently, obliged to fall back upon the principle of natural selection acting upon the variations of the ovum. This view is open to even greater difficulty. than that of Darwin. Finally, Brooks has advanced a theory of heredity which, if true, is of assistance to all of the explanations considered. By an hypothesis he explains heredity and variation. He shows that we may understand how simultaneous variations can appear in such organs as need change. The theory thus offers to natural selection the simultaneous variations which are necessary. It aids the theory of Mivart in showing how extraordinary births may be explained, and it is of great assistance to the Neo-Lamarckian view, by showing how the effects of use and disuse may be transmitted from father to children. But, at the same time, this theory of Brooks, though valuable, is only an hypothesis, and many objections arise to prevent it from being accepted in its unmodified form.

Perhaps all of the factors enumerated above have 
had their influence. Nature is not a simple matter, and there have doubtless been many laws at work in producing evolution. Each of our investigators has probably discovered a truth, and each is only in error in believing the law he has discovered is of more importance than the others. Certainly no one of all these explanations is sufficient to account for the question of the origin of species. But they are not contradictory, and all may act together. Whether with them all it can be believed that the origin of species is cleared up, it is impossible to say. There seem to be certain difficulties still existing, which none of the above suggestions fully meet. But neither of the series of data, variation or heredity, are yet fathomed. Many laws have been discovered, but there is yet room for others. And it is highly probable that future study of these two subjects will reveal factors yet unthought of, which have aided in the origin of species. At present it must be acknowledged that the problem is not solved, even though evolution be accepted as a fact. 


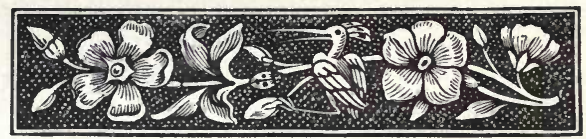

\section{CHAPTER VIII.}

THE EVOLUTION OF MAN.

THE question of man's relation to the rest of the organic world has been reserved for a special consideration, since in many respects it stands by itself. The subject is involved in preconceived notions and sentiments, and is so plainly related to theological ideas, over which discussion has always been quite fierce, that the debates upon the question are somewhat bitter. Although in Darwin's first book nothing was said as to man's origin, the tendency of his theory was immediately perceived. If it had not been recognized that the first acceptance of evolution would include the evolution of man from the lower animals, doubtless the theory would not have been so severely disputed. But this was recognized, and it was soon definitely stated that man was included in the scheme. Darwin claimed that man, with all his faculties, intellectual and moral, had been derived by slow growth from the lower animals. Against this conclusion many thinkers have demurred. The objections have been due partly to a dislike in accepting the belief. It has been thought to be contrary to the teachings of revelation, to be at enmity with a belief in man's immortality, etc. 
These questions it is not our purpose to discuss here, beyond noting that many careful students of theology are of the opinion that the ground is not well taken. The objections to the inclusion of man in the evolutionary scheme are, however, not entirely of this character, many of them being purely scientific arguments.

To the scientist who has accepted evolution in its general sense it seems, at first sight, hardly possible to question the position that man is simply one species of animals evolved in a similar manner with all others. Nearly all of the arguments which have been applied to the rest of the organic world, as indicating evolution, apply equally well here; and it seems a matter of cowardice to exempt man from the law. Of course, the origin of man is a matter of more interest and importance than that of any other animal, for it is the question of the origin and destiny of man that forms the most vital of all questions for study. But this is no reason why he should not come under the law of evolution. When, however, the matter comes to be examined carefully, it is seen that the questions of man's evolution is quite a different one from that of other animals. It has its own special arguments and difficulties. It is soon seen that evolution may be true in regard to other animals, and yet be only partly applicable to man. That this is true is sufficiently shown by the fact that several of our best scientists, among whom stands Wallace, who shares with Darwin the honor of discovering the principle of natural selection, exclude man wholly or in part from their 
evolutionary system. The argument is in brief as follows :

Evolution may apply to all other animals, because all possess the same fundamental characteristics, the difference being only in relation of parts. But man is not only an animal; he is more. $\mathrm{He}$ is an intellectual and moral being, and these qualities are new in kind. They are qualities which are not represented in animals, and could not, therefore, have been derived from them. Just as there is a break in continuity at the beginning of life, which has not been bridged, so here, at the introduction of human nature, there is another break. There is much difference of opinion as to whether this argument is a legitimate one. Let us, then, notice the position held both by those who accept and those who deny the cogency of the argument.

\section{Man's Physical Nature.}

It may be well at the outset to acknowledge that, so far as man's body is concerned, there is no valid reason for exempting him from an origin such as has been ascribed to the rest of the organic world. Man is just as truly a member of the vertebrate subkingdom, and of the order of primates, as is the monkey. Bone for bone, muscle for muscle, nerve for nerve, can his body be compared with that of other vertebrates. From this side of his nature it appears, according to the best authority, that not only does man not have a sub-kingdom to himself, but he does not belong to a distinct order or even family. He forms simply a genus of primates 
closely related anatomically to the chimpanzee and gorilla. The difference between man and the apes is anatomically less than that between the ape and the ordinary monkey. It is true that some of the older naturalists have attempted to make for man a distinct order of mammals, founding the distinction on the size and structure of the brain. This position is not, however, held to-day. Man has certainly a very large brain, but it is contrary to every principle of nature to found such distinction on a single character. We find organs present as rudiments in man which are well developed in other vertebrates; organs developed as rarities in man which are always present in certain other animals; we find the human embryo developing in like manner with other mammals, passing through the same ancestral stages. There is, in short, nothing in the physical nature of man which exempts him from the general principles which regulate animals. If evolution applies elsewhere, it applies here also. When we find man agreeing in bodily structure so very closely with other vertebrates; when we find in him rudiments of organs present in the lower orders; when we see that the abnormalities of his body are explained by reference to other vertebrates; when we find his embryology showing all of the remarkable ancestral features seen elsewhere; in short, when we see that almost every argument hitherto used to prove genetic descent in animals in general applies equally well to man, in logical honesty we cannot hesitate to admit that if evolution exists elsewhere it exists here also. 
From geology there is practically no evidence either for or against this view. Fossil primates of all kinds are very rare, and fossil human remains are rarest of all. In geological formations, which, it is known, were cotemporaneous with man, there are no traces of his bones. The oldest human remains which have been found are certainly much more like those of the apes than the man of to-day, particularly in the shape of the skull. But these unquestionably old skulls are so few in number that it is impossible to draw any conclusions from them, particularly when it is pointed out that even to-day there are occasionally found skulls which are about as low as these fossils. One point, however, geology has definitely settled, and that is, that man is a very old animal. Instead of existing only a few thousands of years, there is positive eviderice that he has lived many thousands. History traces him for about six thousand years, but archeology and geology carry him much further. $\mathrm{He}$ has been traced into the early quaternary times, and some would think even earlier. In years it is impossible to estimate this time. Although the tendency of recent observations is to make this time less than was formerly believed, it can hardly be possible that it is less than twenty thousand years, and probably much more. But the almost utter absence of bones either of man or of primates, makes it impossible to say any thing from this source as to its origin. It is unfortunate that just where this evidence is most wanted it is lacking, for the absence of this connecting link has been, and still is, one of the standard 
arguments against this phase of evolution. Your primitive half man, it is said, is only hypothetical, you cannot prove his existence, nor even find any evidence of him in fossils. The fact that the origin of the human race is so much more important than that of any other animal, makes this argument very forcible in its appeal, and it is sometimes regarded as insurmountable. But as a scientific argument this fact has no more weight than the absence of certain other connecting links, of which every one admits there is an abundance. We may be more anxious in regard to finding evidence of this connecting link between man and his supposed ancestors than we are to find evidence connecting the elephant with his ancestors, but we have no more reason for expecting the one than the other. The absence of fossil half-man is unfortunate for evolution, but it is scientifically only an instance of the imperfection of the fossil record, which we well know to be great.

\section{Man as an Intelligent Animal.}

It is useless to attempt, as far as man's body is concerned, to exempt him from the general principle of evolution, and few would think of doing so today. It would be simply to deny the cogency of the arguments which are conceded elsewhere, and consistency requires us either to deny evolution altogether or admit it here.

But when we come to consider man as an intelligent, moral being, the question assumes a very different aspect. If man's mental qualities be taken 
as a basis for classification, he demands a whole kingdom to himself, instead of a simple generic rank. Even the lowest man is immeasurably superior to the highest brute. Between them is a vast chasm which no one has yet been able to bridge. It is true that between the lowest men and the higher classes there is perhaps an even greater difference. But in this case there is no chasm, for a complete series of higher and higher grades of intelligence unites the two extremes. It is plain that this difference is one of degree, and not one of kind. The lowest men have the same sort of intelligence, the same kinds of emotion, which are found in the highest races, except that they are less developed, and turned into different directions. The difference between the intellect of a Newton and a Hottentot is even greater than that between the Hottentot and the ourang-outang, but the former difference is filled by steps of development, while the latter difference is a chasm, seemingly an impassable one. Experiment has shown that a savage, if taken when young and brought up among civilized people, develops into a very good member of community, about as intelligent as many people among civilized nations. But such an experiment would fail if tried with the ourang-outang. Here then, we begin to see the grounds for the claim that man is more than animal. Many students hold the position that in regard to the mental nature-by this term is meant both intellect and moral nature-the difference between man and the other animals is one of kind, and that the chasm between man and animal indicates 
that something has been introduced. Evidently if these factors are absolutely new in kind, they could not have been evolved, for evolution does not create. If animals possess nothing equivalent to this new nature, man could never have been produced wholly by evolution. If this is the conclusion to which we must arrive, man must be looked upon as something different from other animals, as a new departure. Just what may be meant by a new departure is not so clear. Perhaps at the appearance of man the Creator implanted in him a new spirit, "breathed into his nostrils the breath of life, and man became a living soul." Perhaps He so influenced some previously existing animal as to cause his development in a new direction. "An unknown cause accelerated the development," says Wallace. Either of these views would recognize the evolution of man, but would, at the same time, regard man as more than an animal, and hence in a sense a special creation. The significance of either of these two views it is not our present purpose to discuss. The question which we must consider is one preceding this. Is it necessary to assume that man differs from animals in any thing except the degree of development of certain faculties? Is the mental nature of man such in its character that it must be considered different in kind from that of animals? or is it possible to believe that the intellectual nature of animals contains the rudiments of man's mental attributes, so that human intelligence, morality, etc., could have been derived by development from that of animals? If the former be the truth it is plain that there is a 
break in the series of continuity. If the latter be true, then it is possible that man has been both physically and intellectually evolved from lower animals. If possible, it immediately becomes probable from the general lines of argument already considered.

Method by which the Evolutionist Explains Human Intelligence.

The evolutionist has attempted the burden of proof, and has attempted to show that the mental nature of man could have been derived by the development of the mind of animals. He says that man differs from animals only in the fact that his intelligence is more highly developed. He even goes so far as to give reasons why this intelligence was developed somewhat as follows: Every animal must have some means of defence against its enemies. Through all the geological ages this defence was entirely in physical attributes, in muscular strength, in great size, and low organization which made great injuries possible without death. But with the advance in organization higher methods of defence made their appearance. As we have noticed in considering paleontology, there has been, since the tertiary age, a gradual increase in the size of the brain, affecting all mammals. This increase does not probably mean much increase in intelligence, but rather an increase in the nervous control over the muscles, and hence increased vigor. But it was at the same time making a development of intelligence a possibility. The primates finally ap- 
peared with a brain larger than had before existed. Now, these primates were endowed physically with almost no means of defence, but, at the same time, they were obliged to contend with many powerful enemies. To accomplish this, different courses were taken. Some individuals escaped their enemies by becoming arboreal, and gave rise to the arboreal monkeys. But others began to depend for their means of defence and subsistence upon their superior cunning. Thus intelligence becomes the most important feature in development. The brain has already reached considerable size, but now it rapidly increases. Intelligence comes in contact with intelligence, and this is all that is needed to cause rapid advance. The contests of these early intellectual beings with each other is the means of continued advance in intellect.

When this intelligence has begun to contend with intelligence it immediately becomes the only important feature to develop. The development of the body of this hypothetical creature is of little or no importance. He needs no natural weapons, for he manufactures artificial ones of more efficiency. His body will therefore remain little changed except in such particulars as relates to his advance in intelligence. The continued use of the hand causes it to become more delicate; the growth of his brain causes his skull to increase in size. But except in a few such features his body remains much as it was. While the body remains practically stationary, the intelligence continues to advance, until, finally, the race in question comes to differ from its early an- 
cestors, in this respect, enough to make the vast difference which we see between man and the brute. Anatomically, he has all the time remained a primate, but intellectually he has developed for himself a new kingdom. Meantime, all of the intervening half-intelligent animals have been exterminated, for this animal will have its severest contests with others like itself. In their contests all races of less intelligent beings will be blotted out. Just as civilization is exterminating savages, so savages in their time exterminated earlier half intelligent races. Advancing thus, and destroying all behind it, this hypothetical race finally became man, with only an unbridged chasm between him and the brute, to indicate the road over which he has travelled.

It would not, of course, be claimed by evolutionists that this was the actual history of man, but simply that it illustrates the general line of development. Whatever we may think of the sketch, and however fanciful it may appear, two important points are brought out which are of great moment. First, in the minds of the evolutionist, the advance in intelligence from lower animals to man has not been a continued one. Up to a very late geological age, when the higher primates appeared, intelligence was a very secondary feature in development. The lower vertebrates differ not very much from the higher in this respect. But the elements of intelligence were present all of the time, and, finally, when other means of defence were wanting their rudiments were unfolded under the influence, Darwin would say, of natural selection; Wallace would say, of an un- 
known cause; the Christian evolutionist would say, of God. Secondly, the half-intelligent races would be exterminated, since they could not contend with the higher races.

\section{Evidence from Fossils is Impossible.}

Unfortunately it is impossible from the very nature of the case to get any evidence of the origin of human intellect from fossils. Mental qualities leave no fossils. It is not until mind is so far advanced that animals are able to make artificial weapons or other instruments, that it is possible for intellect to leave any traces of itself. But when it reaches this condition it is human. And hence the first possible traces we can get of mind is after it has reached the grade which evolutionists are trying to explain. Half-intelligent man could have left no traces except his bones. It is, however, significant to notice the character of the earliest traces of man which are found. They consisted of the rudest possible implements of stone, being nothing more than pieces of stone clipped in such a manner as to give them a manageable shape. It is impossible to conceive of any thing simpler which would give any evidence of mind. But the very fact that they do indicate mind shows that we have here evidences of men. From this simplest condition archeology has been able to trace a slow advance in intelligence. First, little better-shaped tools, still made of stone, and then the gradual introduction of metal implements, more and more perfect in their shape, until historical times. Man 
has, then, certainly developed from a very low condition. He cannot be traced back to the animals, but he can be traced back to the lowest condition in which he could exist and yet be a man. Earlier than this evidence cannot exist.

It must be noticed, however, that even this conclusion is in part denied. The position is held by the Duke of Argyle and a few others, that these low conditions of the human race were not primitive conditions but the result of degradation. Argyle would believe that primitive man was neither the lowest nor the highest race, but was possessed of a civilization midway between the two. He was created with human faculties well developed; and from this primitive condition he has diverged in two directions. On the one hand advancement has led to the modern civilized race; while, on the other hand, degradation has led to the savage tribes. Argyle would not believe that stone implements necessarily indicated the primitive condition of man, but rather a degraded condition. The reasons given for this conclusion do not appear very cogent to scientists in general. The chief argument seems to be that many of our savage races to-day show evidence of being degraded from a former state of advancement. This fact can hardly be denied, and is indeed admitted by all. But it is far from being sufficient to offset the great weight of the counter evidence obtained from the study of archeology. Among scientists Argyle stands almost alone, although Mivart holds a view somewhat similar. Other scientists, however, believe that man can be traced back- 
wards through simpler and simpler grades of intelligence until the very lowest possible man is reached, and this man they regard as primitive. Now it only requires a little imagination on the part of the evolutionist to take one or two steps more, and man's body will become ape-like; his intelligence will dwindle away until it is no greater than that of animals, and consequently all of the special human attributes, which depend on this intelligence, will disappear altogether.

The evolutionist believes, then, that the human mental nature is such as could have developed from animal intelligence. In order to substantiate this claim it is necessary to show one of two things: either that all of the qualities of human mental nature are present in animal minds in rudiment and only require development, or that they are such as can have been developed from qualities which are found in animals. Let us now notice the attempt which Darwin and others have made to do this, and, at the same time, the objections which their opponents have raised against their arguments. The force of these arguments and objections is largely a matter of opinion, and this leaves much room for dispute. We shall therefore find that almost every position held by either side is combated by advocates of the opposite view.

\section{Instinct and Intelligence.-Emotion.}

A popular distinction between man and animals is that man possesses reason while animals are provided with instincts. But a very little consideration shows 
that this distinction is only a relative one. In the first place, few would be inclined to doubt that animals possess a certain amount of reasoning power. At all events this is true if we are allowed to use the same rules which we apply to human actions. Animals certainly perceive the relations of means to the end in certain cases, and this, if we can judge from appearances, is reason. Whether those acts are the results of association of ideas, or of a deeper reasoning process, is immaterial at this point. They are at all events not instinctive. On the other hand man possesses instincts. As such may be mentioned the actions of a new-born child before the slightest dawn of intellect, sucking, etc. Darwin also tells us, as we shall see later, that the feeling urging us to do right and avoid wrong is an instinct.

The chief authorities upon the matter of instinct are Darwin and Geo. Romanes. They tell us that instincts are simply inherited habits, and may, therefore, be possessed by men as well as by animals. Animals acquire a certain habit either by accident or by intelligence. If this habit proves of use to them it will cause their prosperity and preservation. The same habit will be acquired thus for many generations, until at last it becomes so firmly established in the race that it is transmitted from one generation to another, and is, therefore, an instinct. That instincts may be acquired in this manner, is shown by the instinct of the shepherd dog. These dogs have been taught to herd sheep. Generation after generation has this habit been acquired, until 
it has finally become an inherited instinct ; for young dogs will herd sheep in a proper manner the first time they are taken into the pasture. In this case the habit is one which has been taught the animal by man. But it is evidently possible that habits which animals learn of their own accord may, in a similar way, become instructive. This, too, has been in many cases directly observed. After a very extended series of observations Romanes has concluded that this Darwinian theory of the origin of instincts is perfectly satisfactory in most cases. We cannot here consider his arguments but only the result. If this conclusion be accepted, it is evident that the difference between the minds of men and animals is only one of degree, so far as concerns the possession of instinct. Each can acquire inherited habits. But in animals, owing to the fact that the general intelligence is small and the reasoning powers almost absent, the instincts become the factors of life. In man, the development of reason has caused instinct to become secondary. And in most cases reason has entirely superseded instinct in adult man. Man has discovered that reason is a better guide than blind impulse-i.e., instinct. Man's mind is mostly intellect and little instinct ; animals' minds are mostly instinct and little intellect. The difference is certainly vast. Whether or not it is more than one of degree depends upon the answer to the question whether animal intelligence and reason are similar in kind to faculties of the same name in man. If they are, it is plain that it is only necessary to suppose these qualities, rudimentary in 
animals, to develop, in order to have an explanation of the mental characteristics of man.

In the first place it is hardly possible to doubt that animals possess most of the same emotions which characterize man. Every one knows of instances of love and hatred shown by animals for each other and for man. A dog will follow his master through every possible hardship; is unhappy when separated from him; is jealous when another is petted in his place. In what is this different from the love which a servant bears his master? A tiger will defend her helpless young with her life. Is this not maternal love? It does not alter the facts to claim that such love on the part of animals is an interested love. For human love is in the same way influenced by circumstances. A dog will endure as much ill treatment from his master and yet retain his love, as will one human being from another. The significant fact is not what may cause or destroy the love of animals, but that, so far as we can judge, it is love, similar to that found in man. It is true that the love shown by animals is not of the highest type, since it never passes beyond love for. friends. Love in man in its highest sense is directed also towards his enemies. But such a feeling is seldom possessed by man, only the higher races even having a conception of the idea. Savages cannot even understand it. The love of animals is certainly equal to that of a child whose regard extends only to father and mother, and perhaps one or two others from whom it receives favors. If animals show the emotion of love, they also conceive hatreds and jeal 
ousies. They possess the feeling of curiosity as much as certain savage tribes. They have the power and habit of attention and imitation. They certainly have memory, as is daily shown by their ability to learn and repeat tricks. Who can see two kittens at play without feeling that their emotions are quite similar to those of playing children. Animals have a sense of beauty; witness the gorgeous display of plumage in birds during the mating season. Darwin even believes that animals possess imagination, which he thinks is proved by their dreams. In all of these various respects then, judging from their actions, animal minds are similar to those of man.

\section{Knozvledge of Tools, ete.-Language.-Power of im- provement.-Consciousness.}

We now come to certain qualities of man more difficult to deal with from the standpoint of the evo. lutionist. And they are points of distinction rather than points of likeness between the mental qualities of man and brute. First, we notice the frequently urged distinction that man alone makes and uses tools, can build a fire; he alone plants seeds and gathers the harvest. The position taken by the evolutionist on this matter is, that these points do not indicate any new mental quality but simply new discoveries on the part of man's greater intelligence. Animals understand the use of tools and of the fire. Every one has heard of the monkey using a stone to crack nuts, or a stick as a weapon. The use of tools is a great step toward their production. Evidence 
in the possession of archeologists seems to show that the first tools were simple stones which possessed a peculiar shape. From this stage to their artificial manufacture is but a step, provided we grant the continual growth of intellect. Observation would soon lead an intellectual being to discover that plants came from seeds, and this would lead to the habit of planting them. Fire is more difficult to account for. It is very difficult to see how a half intelligent race knowing nothing about fire could have learned to produce it. But the myths of Greece tell us that at one time man was without this servant, and that finally it was stolen for him from the gods by Prometheus. Our evolutionists believe, therefore, that even this power was a discovery of man's growing intellect, due originally, perhaps, to chance.

A somewhat similar explanation is given of the possession of language. This endowment forms perhaps, the most noticeable distinction between man and animals. There is no doubt that every race of men has an articulate language, although some tribes have been considered, upon insufficient grounds, to be exceptions to the rule. But no animals show any approach to it. Language is, therefore, regarded as another discovery of advancing intelligence. Its rudimentary beginnings Darwin finds in the various cries of animals expressive of emotion, such as joy, or pain. These are not language, but may be its foundation. As intelligence increased, the necessity of communication between individuals became greater. This resulted in the 
first attempts to associate sounds or signs with objects. Once begun in this way, the possession of language would rapidly increase the development of intellect, and this would react upon language. The two would thus develop side by side. This conclusion is substantiated by philologists, who have studied the matter from an entirely different standpoint and for a different purpose. Foremost among them may be mentioned our own Whitney, who has reached the conclusion that the origin of language has been one of growth and development. Language, he has concluded, was at first very simple, consisting of only a few words, expressive probably of emotions. The origin of these words is not clear, but they came as soon as intellect needed them. Some perhaps were imitations of certain sounds; more were probably arbitrary association of words with definite ideas. Original language, he tells us, was largely assisted by signs. In some simple way man contrived to communicate with his fellow as soon as he became intelligent enough to have any thing to communicate. Language is thus a necessary concomitant of intelligence. Darwin is thus strongly supported in his theory of language, by those who have made it a life study; for this conclusion is now almost the universal consent of leading philologists. Language is thus only a tool which man has fashioned for his use, and indeed the most important one he has made. It is something new, and even new in kind, but it is not a mental endowment. It is a manufactured article, which man has made as he needed it. If it be conceded that intelligence in 
general could have been derived from animals by development, language presents no difficulty. Language is impossible without a considerable degree of intelligence, and intelligence is impossible without language. Each has been the result of a slow growth.

Great stress has been laid upon consciousness as a distinctive factor of the human intelligence as compared with that of the brute. But it is hardly necessary to say that nothing is known about this factor. We know that we possess consciousness, but we know nothing as to this in animals. Memory certainly implies a certain amount of consciousness, and animals possess memory. There is about as much evidence for its existence in some animals as in some people. Consider, for instance, a low savage woman whose sole thoughts in life are eating, sleeping, and producing children. She gives no evidence of any consciousness beyond that of existence, which even dogs possess. Evolutionists tell us, too, that it is no more difficult to say when consciousness comes into the human race than to say when it is developed in the child. The infant has certainly less consciousness than animals, and no one can say when it appears in life. Just as it develops in the child as a result of contact with the world, so it has developed in the human race. Here, again, development is a repetition of past history.

Very much stress has been laid upon man's power to improve, for here does a difference between man and the brute manifest itself in a remarkable manner. Unlimited power of improvement in man, and 
no power of improvement in animals, would certainly imply as radical a distinction as it is possible to conceive. But neither of these two statements is correct, and here, too, it is claimed the difference is one of degree. On the one hand, animals certainiy have some power to improve. For instance, the dog is usually regarded as the most intelligent animal, and compared with the wolf, from which our dogs have probably descended, his intelligence is very great. It is, therefore, highly improbable that when first domesticated dogs were as intelligent as they are now. They have probably increased their mental power owing to contact with man. Or even better is this possibility shown by a gradual improvement of certain instincts. It has been observed that birds have within a few years improved their method of nest-building. On the other hand, the unlimitedness of man's power to improve is even more questionable. Of the limit to the improvement of the race we can, of course, know nothing as regards either man or animal; but the limit of improvement in the individual is soon reached. An illustration will best indicate the evolutionist's position on this point. If a new-born chimpanzee be compared with the child of a negro and of a white man, at the same age, little difference will be seen between them so far as intellect is concerned. If any thing it will be in favor of the ape. Compared again in a few months, the ape will be found to have distanced the other two. But now the mental development of the ape becomes slower, and stops; while the two human children soon catch 
up with him. The ape can even after this be taught to do many things by imitation, but he becomes thereby no more intellectual. The two human children go on for some years, when, as a rule, the men. tal growth of the negro stops. He can also be still taught many things, but he is merely receptive and not creative. The white child continues the unfolding of his mental powers for some time longer, but eventually he reaches a limit, at an age varying with different persons. Some reach their intellectual growth by their fifteenth year, others even earlier, while others still continue their mental unfolding for twenty, thirty years, or even more. By intellectual advance, it will be understood, is not meant the accumulation of facts of knowledge, but the growth of mental powers. A study of our public schools reveals the significant fact that from the time the students enter the high school, one by one they seem to reach the limit of their advance. With such facts does it appear that even this distinction is one of degree. Man has simply carried the limit of his advance higher.

The various suggestions above enumerated were offered chiefly by Darwin to explain the facts in question. By some they are regarded as sufficient. But by others they are considered insufficient to explain all that is claimed for them. Against each position we find objections urged from various sources. But since all these objections are subsidiary to the general argument of those who deny Darwin's position, we will not stop to consider them here. 
Abstract Ideas.-Idea of Causation, Time, and Space, etc.

Finally, we come to certain qualities which constitute the essence of the human intellectual process. Foremost among them stands the moral nature of man. Of no less importance is his power of forming abstract ideas and thus classifying thoughts. Here, too, are found various intuitions, time, space, the idea of force, of causation, etc. It is at these points that those who believe man to be a distinct creation, in any sense, rest the force of their argument. Unless the origin of these factors is explained, the whole argument of Darwin as to man is worthless; for they are the really essential parts of human intellect. I have neither the knowledge nor the inclination to deal with these questions, except in a very superficial manner. They belong rather to mental philosophy than science. Nor is it particularly desirable to do much more than state the positions held by different thinkers, since the conclusion which one forms is little more than a matter of opinion.

The power of forming abstract ideas is one of the most important possessed by man. Human thinking consists in analyzing and classifying ideas, and without this power thought is impossible. From concrete objects man forms abstract ideas: he combines and classifies them, studies their relations, and reaches other abstract ideas as conclusions. This is thought. Even language is impossible without these ideas, for language is the association of sounds with ideas and not with objects. It is perfectly evi- 
dent that no language is possible until intelligence has reached a condition where it can conceive abstract conceptions. It is almost equally evident that as soon as this condition is reached language will appear. Here, then, is a fundamental condition of the mental life, of man. Can this factor or its rudiment be found in animals? Darwin is inclined to think so. A dog, he says, seeing another in the distance recognizes it immediately as a dog. Upon coming closer he perceives it to be a particular friend or foe. The two conceptions, Darwin says, are very different. If the dog had language he would have one sign for dog in general, and another for a particular friend. Or, again : a man takes his gun and calls his $\mathrm{dog}$, when the dog immediately perceives that they are going to hunt, an idea of a class and not of a concrete object. A few such instances as these constitute the only evidence of this power in animals. But few will believe that this is sufficient to be regarded as a beginning of this fundamental factor of human thought. It is even improbable that any thing like an abstract idea is formed in these cases. Association is a simpler and equally probable explanation. The sight of a dog recalls by association other concrete dogs. The sight of the gun in the master's hands recalls the former pleasures of the chase, without any necessity of the idea of chase in general. The conclusion here is little more than a matter of opinion. Darwin, who has chiefly studied animals, and who accepts from general grounds the evolution of man, believes such instances sufficient to indicate in animals the rudiment of the power of 
forming abstract concepts. Others who have chiefly studied human mind, deny that these instances can be regarded as a sufficient foundation for this fundamental quality.

And thus with the idea of causation. The conception that every thing must have an adequate cause, is a universal factor of the human mind. Even the lowest savages have the conception, as is shown by their assuming the existence of numerous gods to explain natural phenomena. Yet this is not the result of observation. We perceive sequence of events, but never causation. The idea that one has caused the other is a necessity of thought, not of facts. It is indeed a law of human thought, and is the basis of true reasoning. But no one has ever been able to find any evidence of its existence in animals, and it is extremely improbable that they have the slightest conception of any thing more than sequence. Even in the human race this idea only comes with a certain maturity of intellect, and it is impossible to believe that animals possess this quality while children do not. If animals do not have this concept, it follows that true reasoning is impossible for them, and that what seems to be reason is simple association of ideas. In the same way the conceptions of time and space are necessary laws of thought, and not the result of observation. They constitute part of the data of thinking. It is, of course, impossible to deny positively that they may not be present as rudiments in animals, but it is equally impossible to find any evidence of them. Here again it is a matter of opinion whether 
it be necessary to find more traces of these intuitions in animals in order to make the evolution of mind a possible belief.

\section{Moral Nature.}

A more extended consideration is required of the moral nature of man. This phase of man's nature is the most important of all, and has taken the most prominent position in all discussions as to the relation of man to the lower animals. More than any other subject has this question been open to the odium theologicum and odium anti-theologicum, and the discussion has ofttimes been more bitter and dogmatic than candid and logical. Frequently it is difficult to see what the various disputants are trying to prove. It is plainly evident that this factor of man's nature must be explained, or the whole argument is valueless.

First, a word as to the various phases of the moral nature comprised under the terms religion, reverence for God, a belief in the supernatural, a belief in immortality, etc. All of these factors are almost universally present in men. Almost universal, but probably not quite, since a few savage tribes seem to be lacking in any ideas of this kind. To be sure, it is almost impossible to say positively that this is so. Our only information must be derived from travellers, and they are very apt to be deceived, as is shown by the different conclusions different travellers have reached in regard to the same tribes. It is, however, the general belief of ethnologists that some few tribes are utterly devoid of any idea of the 
supernatural. But this is of little importance, for

- the fact still remains that the human race is characterized by these beliefs, even though some few degraded tribes have lost them.

We are told by Spencer that such beliefs have had a purely natural origin. A belief in life after death arose from dreams, in which those who had died reappeared to their friends. Primitive man, knowing nothing of the nature of dreams, naturally concluded that his friends were still in existence and had returned to him. A belief in the supernatural arose from the attempt to find an explanation of natural phenomena. Every phenomenon which was not understood must have been caused by some power, and these unknown powers were the gods of primeval man. Religion was simply the attempt to propitiate these unknown powers by offerings. The feeling of reverence is only such feeling as any animal feels before beings which he acknowledges superior to himself. It is closely akin to the feeling which the dog has for his master, if not identically the same. All of these beliefs and feelings are thus, according to this evolution school, simply the result of man's inability to explain the world around him.

But the important factor of the moral nature is quite different from any of these. It is what is known as moral sense, or conscience. This is the factor in his nature which causes him to distinguish between a right and a wrong. This law of thought is unique. It stands at the foundation of all codes of morals, and upon our belief as to its origin will depend our whole conception of human nature. 
In the first place it must be noticed that this moral sense is a universal possession of mankind. There is no race so low as to be devoid of conscience. But just here has arisen a misunderstanding. The intuitionalist, seeing this universal factor, claims that all men are born with the intuition of right and wrong; meaning by this an intuition of a difference between right and wrong. But many scientists imagine that this claim is that men are born with a knowledge of right and wrong actions. They think, therefore, if they can show that different people have different ideas as to right and wrong, they have disproved the claim. Now every one knows that different races have different codes of morals. It is possible to find races of men who consider as praiseworthy acts, those which we look upon as the greatest crimes. Cruelty, dishonesty, theft, murder, are all believed by some people to be deeds of great merit. On the other hand, acts which we consider of no importance whatever are by some races looked upon as crimes. Moreover there has been a gradual development of our moral nature. Civilized man is much higher in the grade of morals to-day than he was a few centuries ago. Not many generations ago our forefathers considered it a duty to burn the Salem witches; but we recall such acts with horror, and would consider them not only barbaric but wrong. Thus from the earliest times there has been a constant growth of morals. Now there are many who think that such facts as these prove that the moral sense is not alike in all men. As soon as this is admitted the signifcance of the intuitionalist's argument is lost. 
But this rests upon a complete misunderstanding of the subject. All of this sort of argument is interesting and valuable, since it indicates the development of our ideas as to what is right and what is wrong. But instead of showing the moral sense to be different in different people, it proves its universal existence. No intuitionalist even for a moment pretended that men are born with a knowledge of right and wrong acts. The point is not that all men believe the same things to be right or wrong, but that all men believe something to be right. No matter how differently conditioned be the races of men, no matter how diverse their ideas as to right and wrong actions, every person believes that there are some things right to do and some things wrong to do. A right and a wrong exist for every race, and the imperious word ought, is everywhere understood. It makes no difference to what specific acts men apply these terms so long as they apply them at all, and recognize that those things which they consider right ought to be done. Nor does it make any difference here, how we attempt to account for the reason for doing right. It is a widespread conception that we are to be punished for wrong-doing either spiritually or temporarily. Students of ethics tell us that it is necessary to assume some ultimate good as the final justification of rightness. Now this may indeed be of importance when we consider the origin of this moral sense, but it has no significance in considering its existence. People throughout the world act in certain ways because they feel it is right, and not because they feel it to 
be for their greatest happiness. It is only the higher classes who ever think of these questions. The vast majority never ask what the meaning of right is, beyond that it is something that must be done.

Understanding then what is meant by moral sense, it cannot be claimed that there is any race of men destitute of it. Some may have a greater development of this sense than others. Some may scarcely feel any uneasiness at any amount of crime; some may feel uncomfortable from wrong-doing; some may feel repentant, and some may feel remorse, over some very trifling misdeed. Some may have so far disregarded this feeling that it has almost disappeared. There has been and still is a continual growth in the application of this principle to concrete instances, leading to a development of morals. There are as many different codes of morals as there are races of men. But no race confounds the ideas of right with any thing else, and every savage distinguishes between right and expediency.

This being recognized, the next question to consider is whether there is any thing corresponding to a moral sense in animals. This question is a difficult one to answer, but it will usually be decided in the negative. It is a well-known fact that some animals, particularly dogs, can be taught to refrain from certain acts. Even in the absence of their master, they remember the prohibition, and exhibit shame when caught in doing those things which are prohibited. This certainly resembles a sense of 
right and wrong. But there is an important difference. No animals ever developed this quality spontaneously, for it must always be taught to them by man, and it is found only in exceptional cases. But it is universally present in man, and since he is the highest animal, he must either have developed it himself or have received it from some superior being. We send missionaries to the savages, but no one ever conceived the idea of sending them to a zoölogical garden. If then our evolutionist is looking for the equivalent of the moral sense in animals, he must look for it among the qualities which they have developed spontaneously. Now we do find habits among animals somewhat difficult to understand. They carefully protect their young, they frequently will defend each other when attacked, they sometimes, though not frequently, care for the injured; they warn each other of danger, and assist each other in various ways. All such actions are regarded in man as praiseworthy, but certainly not as moral. It is of course impossible to say just what may be the feelings of a dog who risks and loses his life in rescuing his master. Very likely they are similar to those of a man who, upon a sudden impulse, risks his life to save a person from a burning building. Neither act would be moral, for its opposite would not be wrong. But both would be heroic. Most people will not regard any of these actions on the part of animals as in any sense equivalent to moral actions in man. The Darwinian school, however, as we shall presently see, does regard them as similar, both in their nature and origin. 
At all events here is a factor to be explained. A moral sense has been universally developed by man, and its existence in animals is more than questionable. This seems a very little matter, the simple ability to distinguish between right and wrong, but it is in reality the foundation of the whole moral nature. Is it possible to give a natural explanation of this quality of the human mind? Can any process be discovered by which the ordinary relations of animals could ever have given rise to the conception of right as something which ought to be done at whatever sacrifice, and wrong as something which ought never to be done whatever the seeming good? Here we find a most serious disagreement among thinkers. On the one hand stand the extreme evolutionists, foremost among whom are Mill, Darwin, and Spencer, who claim that this moral sense is nothing more than a modified form of animal instinct, and has been developed through natural causes. On the other hand are many thinkers, among scientists Wallace, Mivart, Argyle, Quatrefages, most all theologians, and the intuitional school of philosophers in general, who deny the position of the evolutionist in entirety, claiming that no case has been made out, and that the whole question as argued from the standpoint of the evolutionist is misunderstood. Let us first notice the Darwinian theory, as an illustration of the evolutionist's standpoint.

Darwin's Explanation of the Origin of the Moral Sense.

The foundation of this explanation is the fact that any line of action to be morally right must result in 
some good. This point is universally agreed upon by all schools, though there is the widest difference of opinion as to what this good may be. Some would call it a happiness, some pleasure, to the individual; some would say it is the good of the race, or the tribe; some that it is the greatest good to the greatest numbers; some would say it is the good of both the individual and the race; some regard it as temporal, some as eternal, happiness. But though varied in their idea of good, all justify the rightness of actions by their producing more good than their opposite. That this is so, will be evident by supposing that something now considered a crime should be found to be for the permanent good of the world, when it would cease to be a crime, and be regarded as a meritorious action. Murder is believed to be wrong, yet most persons will consider the execution of criminals right if it be productive of the best results.

Starting now with this principle, that any action to be morally right must be productive of good, it is claimed that the habit of regulating life by right actions would be gradually developed by natural selection. All animals have instincts and impulses of various kinds, some of which are of use and some of which are doubtless of direct injury. For the bird who cannot endure the rigor of a northern winter, the instinct to migrate is doubtless of great importance. In a modified sense, therefore, the bird ought to migrate. Now, of these various instincts, some are stronger than others, so that when they come in contact the stronger ones 
master the others. The migrating instinct is stronger among birds than their maternal instinct, for they will leave their young to perish when the migrating time appears. Now if these instincts are transmitted from one generation to another, it is easy to understand their preservation and development. Evidently those animals with instincts best calculated to preserve them will be the ones to survive the struggle for existence, while those which have deleterious instincts will be destroyed. By natural selection, therefore, those animals whose strongest instincts are best calculated for the good of the individual will continue to exist, while others will disappear. Further, turning to the instincts of man, the instincts which developing man possessed will be assisted by his intelligence. He will be able partially to understand the results of his customs and habits. He will slowly learn to follow lines of conduct which he finds best adapted for the preservation of his life, and will, moreover, soon discover what gives him the most pleasure. Such habits will be repeated and handed down from generation to generation, until they finally become firmly fixed in the race as inherited habits or instincts. Such instincts become the moral sense.

But this is not reaching the bottom of the matter, even if it be granted for a moment that such instincts can become a moral sense. They would make duty and pleasure the same thing, or at all events would make man's duty to preserve his own life his only duty. But every one realizes that many acts which we feel an obligation to perform are not 
only productive of no pleasure (except the pleasure of feeling that we do right), but they sometimes induce lasting misfortune or even death. A person who possesses a fortune which belongs to another and restores it to the rightful owner, performs an act which every one will consider right, even though he entail privation and suffering on himself and family for years. No one questions the moral rightness of the sacrifices of martyrs. Such acts as these, of which there are thousands, do not come under the explanation given above, for they neither produce pleasure nor preserve life. Most of our duties are indeed sacrifices. A theory of development of the moral nature from a grade of the brute must, of course, include this class of actions, which is after all the most important. Natural selection of instincts would lead to the preservation of those individuals who best take care of themselves, but our moral sense teaches us to care for the weak and to help each other. Our ideas of duty, and particularly the teachings of Christ, have largely reversed the law of self-preservation which is universal among animals. Is it possible for Darwin to explain the origin of this feeling, which places the good of others before our own?

The origin of the feeling of obligation to perform this class of duties, he tells us, was in the social instincts of primeval man. All that is known of primitive man, or the primates from which he is supposed to have descended, indicates that the earliest men lived, as they do to-day, in companies or tribes. In these social communities the individ- 
uals are dependent on each other, as we always find among social animals. The success of the tribe is the success of the individual, and the defeat of the tribe is the defeat of the individual. In such communities, therefore, while the individual may have independent pleasures, he cannot have an independent existence. Now, as we can judge from savages, these tribes have always been in conflict with each other, and in these contests it is the strongest tribe and not the strongest individual, which conquers and is thus able to leave posterity. Natural selection will have the effect then of strengthening the tribes rather than the individuals. Now, strength in such communities consists of mutual dependence and union. It will follow, therefore, that those tribes of primitive men (before any idea of right had appeared) which, either from intelligence or blind instinct, chanced to have the greatest union and mutual reliance, would be the tribes to conquer in the struggle for existence. Those tribes in which individual happiness was not made subservient to the good of the community would be exterminated. History is full of illustrations of this fact. In this way the good of the community becomes a superior feeling to the good of self. Habits which increased this union would be developed. And the result would be the gradual development of various social instincts, all tending to the advantage of the community, though often to the disadvantage of particular individuals. Patriotism, valor, generosity, sympathy, justice, etc., all in behalf of the individuals of one's own tribe, 
would make their appearance. For the tribes with these instincts would have firmer union and a better chance in the struggle for life. They would, therefore, be more flourishing, and would gradually supersede the others. Spencer has elaborately discussed this subject, and has ingeniously tried to prove that this conception will explain all of our beliefs as to our duty to others.

Having in this manner accounted for the origin of inherited habits, all tending to the good of the community, and thus secondarily to the good of the individual, one more step is taken, and man is supplied with his moral nature. These habits continue to develop, are taught to children, and thus handed down from generation to generation. Finally, by long-continued inheritance, they come to occupy a position in the mind, where they demand obedience. "Activities, originally proved to be only useful, were inherited as traditional instincts by the offspring, and were thus freed from the sensation of the useful and acted as authority." They eventually cease to be impulses or acts of reason, and are conscientiously performed as acts of duty. The sense of obligation to act in certain ways, and the idea of right and wrong, are simply the results of long-continued habit. The foundation of man's duty is first the preservation of the tribe. Then, when the tribe becomes absorbed by the nation, it is the preservation of the nation, and finally it will be the preservation of the race.

Such is the development theory of the moral nature, a theory which amounts in brief to saying that 
the moral sense is an instinct similar in nature and origin to other instincts. Indeed, the explanation given here is almost exactly the same that is given for the origin of instincts in general among animals, with the single exception that intelligence has played a larger part. If the theory here given be compared with that which we have noticed in Chapter VI., explaining the origin of the various neuter castes of insects with their instincts, great similarity will be seen. Indeed, the development of the instincts of the members of bee communities is, so far as Darwin's theory goes, the same as that of the moral nature of man. It is difficult to see how Darwin can make any distinction between the instincts of these animals and the moral nature of man. It is just as much the duty of the queen bee to kill her fertile offspring, as it is for man to give bread to the hungry. Each act is the result of an inherited habit.

It is hardly nesessary to say that this explanation of Darwin's is rejected by a large number of thinkers. It is said that Darwin has misunderstood the problem, or at all events has failed to account for the very essence of the whole matter. He has given interesting suggestions as to the development of codes of morals, and consequently as to the development of the moral nature, but he has not accounted for its foundation, $i$. e., conscience. He has described the possible origin of various instincts, and then says that they constitute man's moral nature. But is it possible to accept the conclusion that the moral sense is simply an instinct of this kind? Most 
people would unhesitatingly answer no. A person who performs an act because he feels it to be right, is conscious that this act comes under a category entirely different from what he calls instinct. It is an instinct for a child to suck, but no one calls it a moral act. Indeed, none of the actions of children are considered moral, and yet they have instincts. We feel a great difference between these two classes of actions, though it may be difficult to define it. The one is followed blindly; the other is debated over, and not unfrequently the question arises as to which of two courses is right-a question impossible in regard to instincts proper. This difference is seldom appreciated by the evolutionist, though it is not entirely overlooked. When or how the instincts which are at the base of the moral nature became changed in their nature, they do not clearly indicate. But in some way, they say, long-continued repetition from generation to generation caused them to become regarded as authoritative, and thus to constitute duty.

So long as this change in nature is not explained, development cannot be considered as meeting the question at issue. It is of no use to trace the development of the moral nature or the origin of social instincts, unless it can be shown that they are the same. Darwin has not yet shown this, and few would be inclined to admit it. It is hardly worth while to pursue this matter further. Enough has been said to indicate the position of the two sides. The evolutionists claim that conscience is simply a modified instinct, that the moral nature has arisen 
from social instincts, and that the idea of right is simply a generalization of a class of actions which have been found to be productive of good. But on the other hand, the opponents of this view deny that conscience is a simple instinct, and claim, therefore, that Darwin has only described the origin of codes of morals without explaining why there should be such morals. Between these two views each must decide for himself.

\section{General Considerations.}

We have now considered the chief points in the Darwinian argument concerning man. It consists entirely in showing a similarity between the mental nature of men and animals. The arguments found in nature for believing in general evolution of animals, have been sufficient to convince scientists that evolution is true. The close agreement of the human body with that of other vertebrates, makes it evident that if we accept evolution elsewhere we must also do so here, unless some valid reasons to the contrary appear. But if we consider man in any other relation than anatomically, the difference between him and animals is enormous. The magnitude of this difference has, therefore, arisen as an obstacle to the application of evolution to man. The only course for Darwin and his followers to pursue is to show that this difference is not so great as it seems; that it is only a difference in degree. We have seen the method by which this is attempted; but whether the attempt has been successful, is a matter of dispute. His arguments have not con- 
vinced his opponents, who are quite numerous, upon this question. On the other hand, his followers claim that he has shown the animal mind to be essentially like that of man, and this is all that can be expected. A majority of scientists would hold this position. The question, therefore, resolves itself into a simple one. Are the characteristic qualities of the human mind, such as the power of abstraction with its accompanying power of language, the intuitions of causation, time, space, etc., and its unique moral sense,- - are these qualities, with the powers they provide, of such a nature that they could have been developed from the mental qualities of animals? To this question each man must, after careful consideration, give his own answer.

A more general objection to the views of the Darwinian school, than any of the above is, perhaps, the most important of all. Even if it be granted that a development such as supposed might have taken place, no sufficient cause has been given for the remarkable and rapid development of man. All through the long geological ages this factor of intelligence remained comparatively undeveloped. Somewhat of an advance there was. With the beginning of the tertiary age, as we have seen, there was an increase in the size of the brain. This increase, however, in most cases, amounted to little. But in man it was so great and so rapid that in a comparatively short time his brain became twice as large as that of other animals. His intelligence became so great that the difference between him and other animals became prodigious,-so great indeed, that, 
judging by results, it amounts to a difference greater than any other distinction found among animals. What could have been the cause of this remarkable development in this one case alone? As an explanation we have offered to us natural selection, together with the suggestion that when intelligence had become enough advanced to create language, progress would be very rapid. But this explanation appears to most people entirely insufficient to account for such a development, even supposing the development possible. Natural selection seems inadequate anywhere, and it certainly seems so here. It has produced this result in no other case, although the intelligence of other animals than primates indicates that there was equal foundation for advance elsewhere. It must assume that chance produced the beginning of intellectual advance in the human ancestors, and by chance Darwin simply means an unknown cause. Here, as elsewhere, even if evolution be a fact, its explanation is yet undiscovered.

Another point must be mentioned as of great significance, though we might not find all scientists agreeing. It is, however, a growing conviction among scientists that evolution is not unlimited. There has been in all ages a growth from the general to the special. An unspecialized form is capable of very great development in numerous directions, but as soon as it becomes highly specialized in any one, the development practically ceases. A pocket-knife is a generalized instrument, and may be used for almost any purpose from cutting down trees to carving images. It is capable of modification in 
any direction to suit these purposes. But when it reaches high specialization in any one direction, it loses its power to develop further. The graver's tool can cut only one kind of line, and does this so well that further advance is impossible. And so in the organic world. An unspecialized animal is capable of great development in various directions, but after it has become specialized its advance soon becomes limited and practically ceases. A tree cannot grow forever. After reaching a certain size it ceases to develop further growth, producing only leaves and twigs. Now, it follows from this principle that evolution is limited, and applying the principle to man it will become probable, not only that he is the highest animal which has appeared, but also the highest that will appear. The last generalized feature which becomes developed is the mental power. So far as we can see, this is the highest power; including in the term mental, the moral powers as well as the intellectual. The mental nature was at one time an undeveloped feature, but it has now become developed, and the specialization of this last and highest quality has produced man. Now this mental nature may go on developing and becoming more specialized. This we see is constantly taking place. But the result can never be any thing but man, since the distinctive characteristic of man is the possession of highly developed mental powers. Man stands at the top of the animal kingdom, not because he has a more highly developed body than other animals, for this is only partly true. It is because his distinctive characteristic is the great develop- 
ment of the highest quality which animals possess. With this understanding, that man has developed the last and highest realm of his nature, evolution is seen practically to end with him. He may go on becoming more and more specialized. Other animals may also continue to produce new species. But unless there is some other and higher ungeneralized feature to be developed in the future, man stands as the highest order of beings which this world will produce. Of such unspecialized quality no one has conceived. Look at it as we will, the advent of man must be regarded as the development of a new realm in nature. Man is thus radically separated from other animals, even though he be derived by descent from them. It is practically immaterial what we may believe man's origin to have been, his distinction from other animals is radical, and we may accept the views of Darwin and Spencer without altering this conclusion.

\section{General Summary of this and the Preceding Chapters.}

Let us now briefly consider what may be regarded as the present result of the discussions of the last twenty-five years upon the question of evolution. It is plain that the different theories and suggestions have met with very different success in receiving support. Some have been so well authenticated as to be almost beyond question; some have been left very uncertain; and others have been disproved.

In the first place, the candid consideration of the subject of evolution-at least as we use the term, meaning organic evolution-has shown that the the- 
ory is not, as was at first thought, an alarming blow at theism. It is simply one step more in a direction in which thought has long been tending. In the early ages of thought every phenomenon of nature was looked upon as the direct result of supernatural agencies. A god was assumed to account for every unexplained fact of nature. But gradually this crude conception has been replaced by the idea of a single God governing nature by law. Now the theory of evolution is simply a part of this general tendency, assuming that law has also produced the present organic world. It has met naturally with a momentary opposition, as did the Copernican theory, or the theories of geology. But, like the other theories, it has been found to demand rather than do away with the necessity of a Creator. It is, then, a purely scientific theory concerning the laws of the organic world.

As a scientific theory it is now generally regarded. Scientists claim that though the theory has not been proved, and probably never will be, it has been rendered so probable that it is almost beyond the reach of question. Every possible source of evidence which has promised results has been studied. The effects of domestication and the changes of conditions in wild animals have been noted. The results here have proved that species are not rigidly fixed, but are subject to a very great amount of variation. It has been proved that the differences between the varieties thus arising may be greater than that between species, except in the single character of sterility; and for this exception an ex- 
planation partly satisfactory has been offered. The classification of animals and the relation of species to each other have revealed a bond uniting the organic world into a unit. They have proved that there has been some connection between all organisms, and the assumption that this bond of connection is heredity has been found to meet the requirements of the case. The order of appearance of animals in the past has further testified to this assumption, since they have been found to appear in the order which the theory would expect. Although the sudden appearance of a highly diversified fauna in the earliest rocks which give us any record is somewhat of a surprise, yet the evidence elsewhere has been conclusive. Still more forcibly has this same uniting bond been proved by embryology. Here, too, in a marvellous manner has the evidence pointed to heredity as this bond. Unitil to-day the subject of classification, paleontology, embryology, and genetic descent are so intimately combined that it is no longer possible to separate them. Finally, the geographical distribution of animals has offered its evidence, and in some cases, $i$. e., oceanic islands, has presented a practical demonstration that new species can arise from old ones.

All of this evidence together forms an argument that no one who has carefully studied the matter has been inclined to deny. It is true that all of the difficulties have not yet been cleared away, and that some of them seem to indicate that there are other laws of life not comprised in the theory of evolution. Beyond difficulties of detail, which of course 
can probably never be fully explained, the objections to evolution in general are very few, and are gradually disappearing. The conclusion of science is, therefore, that organic evolution is a fact, and we may regard it as one of the theories of science which is to remain as a foundation for future advance.

When we next ask as to the limits of evolution, we reach a question whose answer is much less certain. Recognizing that the essence of the theory of evolution is the substitution of natural law for miracle, it is evident that if applied to its fullest extent it would include the whole universe. Consequently we find Spencer and others do carry the principle as far as it is logically possible for them to do, and comprise within its far-reaching influence the development of every thing from the nebula. But even this extreme reaches no satisfactory stopping-place, for the nebula could not have been evolved. Indeed, a logically complete theory is impossible. Recognizing this, most scientists prefer to leave out of consideration the question of speculation, and confine the term evolution to the realm where evidence demands it. Now a break is found at the beginning of life. Most scientists would doubtless be very glad to be able to prove that life can originate from inorganic matter, but they do not claim to have any evidence that it can do so ; nor, indeed, have they any evidence, except the logic of the evolutionary theory, that it ever has done so. This matter is therefore generally omitted from the discussion, as at present impossible either of proof or disproof. 
Another break is found, according to the opinion of some, at the other end of the series. Man is by them exempted wholly or in part from the general law of evolution. This break is a more debatable one than that at the origin of life. The close relation of man to other vertebrates anatomically, renders it almost beyond question that so far as his body is concerned, he has been subject to the same law which has regulated other animals. But his peculiar mental powers made him something different. Darwin, and many followers, do not, however, look upon this as a break, but sim ply a difference in degrees of the development of mental powers. They claim to find the same mental powers in animals which are found in man, and would say that when the ancestors of man reached a certain stage in their development, their intellect began to grow. The start was due to accident, but, once started, natural selection rapidly increased the growth, until, in a comparatively short time, man, with all of his mental powers, was the result. Others would say that while this difference is only one of degree, the degree of difference is enormous; too great, indeed, for Darwin's theory. While, then, it is possible that man has arisen by development, no sufficient cause has been discovered for the sudden rapid growth of mental power in man. They would say that "some unknown cause accelerated development," meaning by this unknown the Creator. Others deny the possibility of man's origin by development, considering his powers as new in kind. They would say that at the appear- 
ance of man new qualities were given him by his Creator. But all agree that man is radically set apart from the rest of the animal kingdom by his mental nature. While anatomically he is an ape, mentally he is not only a new order of being, but probably also the highest and the last.

When, finally, we come to ask what has been the cause or causes producing evolution, we find a great many answers. No two scientists, perhaps, fully agree. The theory of natural selection, advanced at the outset by Darwin, has proved to be an important factor, but inadequate to reach many classes of facts which require explanation. Not only is it open to difficulty, but it has become evident that at best it is only secondary. The selection of the fittest forms can only come after their appearance, and the origin of variations has demanded more and more attention. Darwin's explanation hardly touched this question, or, at all events, only accounted for indefinite, irregular variations, which have been plainly shown to be insufficient. A number of other theories have attempted to avoid the difficulties which natural selection meets. But none of them are in themselves really satisfactory. Some are more difficult to understand than the facts they try to explain; some do not meet the facts; some would, if granted, explain the facts, but have little evidence in their favor. Yet all of them, probably, express some truth. The fact is that the organic world is not simple, and there are a great many factors at work. The origin of species has been the result of not one but many causes. Some of them 
have been discovered, and probably others remain yet unthought of. The reproduction of organic beings is the result of two somewhat contradictory laws, Heredity and Variation. In accordance with the first, species tend to produce offspring precisely like themselves. In accordance with the second, they tend to produce offspring differing from themselves. These two laws, and the forces governing them, must be the factors which have produced whatsoever evolution there has been. Naturalists are now at work endeavoring to reach a better understanding of these laws, and out of their work we may hope for further knowledge. At present, then, while it is well to admit with the scientist that organic evolution is probably true, and that it may or may not include man, it is also evident that the complete explanation of the theory has not been reached. Above all, the investigations have not brought scientists much nearer to the real significance of life itself, which, like all other first principles, becomes the more inexplicable the more it is studied.

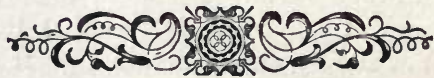




\section{INDEX.}

A

Abbreviation of embryological history, I3I

Aborted organs, 80

Absence of generalized forms, 99

Abstract ideas, 3 II

Accelerated development, 265

Activity as a modifying cause, 262

Agassiz and classification, 55

Agassiz, A., work on embryology, 124

Age of the world, 97, 215

Air-bladder of fishes and lungs, 83,84

American birds, change in color, 25

Amœba, 270

Amphioxus, 64

Ancon sheep, 226, 257

Annelid development, 129

Apes, 188, 291, 310

Application of embryology to whole animal kingdom, 147

Archeopteryx, I IO

Arctic and Alpine flora, I83, I86

Are species stable? 32

Artemia, 26, 33

Ascidians, 64

Australia, I 72, 175, 184, 198

\section{B}

Barriers limiting specific distribution, 183

Bats, 1991,34
Beginnings of life, 7

Beginnings of organs, 226

Bermudas, 192

Bermuda lizard, I99

Birds of paradise, I8I

Blind cave animals, 274

Boa-constrictor crossing the ocean, 194

Bobolink, 195

Brain of mammals, development of, II 4

Breaks in continuity, $7,8,9$

Broca, on fertility of human race, 35

Brooks' theory of heredity, 277

C

Camels, distribution of, I8I

Carnivora, 66

Causation, 313

Cetacea, 66

Classification, 55 ; significance of, 53

Colorado potato beetle, 166

Comparison of arguments of $\mathrm{Ag}$ assiz and Darwin, 57

Composgnathus, IIO

Condylarthra, rio

Congenital variations, 274

Connecting links, 63 ; among fossils, 65, 91, 107; geological position of, III

Consciousness, 266, 308

Conscience, 315

Contradiction between embryological histories, 127 
Cope on consciousness, 266

Correlated variations, 221

Crosses, 37 ; eliminating characteristics, 224

Crustacea, 73, I1 2

Cuvier, 12, 55

D

Dakota formation, 116

Darwinism, 208

Datura tatula, 257

Dicotyledons in cretaceous, II6

Dipnoi, 84

Direct and indirect development, I 35

Dispersal, means of, 184

Distinction between man and brute, 329

Distribution, and climate, 166 ; of families, 181 ; of orders, 182 ; of species, $\mathbf{1} 79$

Diversity of Silurian life, IO3

Dogs, 35, 38, 41, 302, 304, 312, 319

Duke of Argyle, 300, 320

\section{E}

Echinoderms of Silurian, Ioo

Edentates, I7I, I 88

Effort a modifying cause, 264

Elephants, breeding of, 42

Embryology, a repetition of past history, 122; an assistance in classification, 139; compared with hypothetical history, 126 ; history in general, 155

Emotions, 304

Eozoan Canadense, 94, 96

Evolution, not Darwinism, 9, 208 ; and theology, 13

Extraordinary births, 255

Eye in vertebrates and mollusks, 232

F

Falsification of embryological history, 134
Fertility of, hybrids, 37 ; varieties, 34

First appearance of life, 94

Food-yolk, effects of, 129

Fresh-water animals, distribution, 183,184

Frog of Guadaloupe, 132

Frogs on islands, 193

\section{G}

Galapagos islands, 194

Galaxias attenuatus, 187

Gastrula, I 56

Gemmules, 276, 278

General summary, 232

Glacial age, effect on distribution, 174

Greenland whale, 227

$\mathrm{H}$

Haeckel's, history of man, I49; theory of heredity, 275

Heredity, 213, 269

Homology and analogy, 70 ; explanation, $7 I$; between types, 62 ; in young stages, 62

Horse, 3I, 39, 49, I09, 167,173 , 23I ; history of, Io9

Human race, a possible case of sterility, 35

Huxley and comparative anatomy, 53

Hybrids, 38

Hypothetical stages, 148

Hyracoidea, 66

\section{I}

Imperfection of paleontology, 90

Importance of embryology, 120

Impossibility of a complete evolution theory, 6

Incompleteness of Darwinism, 213

Individual variation, 26

Indirect evidence of immutability, 45

Inherent tendency to vary, 29, 213 
Inheritance of acquired variations, 270,273

Insectivora, $18 \mathrm{I}$

Instinct and moral sense, 320 , 327

Intelligence, 294, 296, 299

Internal,factors in evolution, 252 ; laws of variation, 29, 252

Islands once connected with mainland, 198

Isolation, effect of, I90, 247

Isthmus of Panama, 183, I84

$$
\mathrm{J}
$$

Jager's theory of heredity, 276 Jay, I 79, 180

K

Knowledge of tools, fire, etc., 305

L

Lamarck, II, 262

Language, 306

Larval life, effect of, 145

Laws of distribution, 168

Life in Silurian, 94

Limits of variation, 31

Lingula, ro6

\section{M}

Magpie, 180

Mammals on islands, 193

Man as a fossil, 292

Man the highest animal, 33I

Man's influence on distribution,

Man's physical nature, 290

Marsh-tit, 179

Marsupials, 172, 178, 252

Meehan, 250

Migration theory of Wagner, 247

Mimicry, 235

Minute steps, 226

Missing link, 65

Mivart, 255, 320

Mole, 180

Monkeys, New and Old World, I $71,177,178$
Moral, nature, 314 ; sense, 317. 320 ; sense in animals, 318 ; sense as explained by Darwin, 320

Mutability of species, 22

\section{$\mathrm{N}$}

Nägeli, inherent tendency to vary theory, 253

Narrow straits as barriers, 199

Nascent organs, 82

Natural selection, 208; originates nothing, 213 ; still accepted as sufficient by some, 246

Negro, 310

Neo-Lamarckianism, 29, 262

Notochord, I33

Number of types, 60

\section{O}

Oceanic islands, 189

Odontornithes, Iro

Ontogenetic descent, 78

Origin of variations, 251

Ovum, division of, 272

\section{$\mathrm{P}$}

Paleobotany, II 5

Pangenesis, theory of, 276

Parallel between embryology and paleontology, 123

Peacock, $25^{8}$

Pigeon, 24, 26, 34, 46, 48, IgI, 247

Planorbis, 46

Potto, 230

Power to improve, 309

Presilurian times, 96

Prevalence of the evolution theory, 18

Primates, 292, 296

Proboscidea, 66

Prophetic organs, 82

Protista, 67

Pug-dog, 26 
R

Race-horses, $3 \mathrm{I}$

Rats on the island of Formosa, 25

Reciprocal crosses, 39

Relation of the present animals to the past, I7I

Religion, 314

Return to the original condition of domestic animals becoming feral, 43

Revelation, 17

Reversions, 47

Rhyncophora of St. Helena, I97

Ritta, I8o

Rodents, 66

Romanes, 302, 303, 320

Rudimentary organs, $78,267,29 \mathrm{~J}$

S

Schmankewitsch, experiments on artemia, 26

Scorpions, 95

Sea-urchins, fossils, I1 2

Separation of the sub-kingdoms from gastrula, 158

Serial homology, 72

Sexual selection, 2 10

Significance of the parallel between embryology and paleontology, 140

Silurian animals all marine, 107

Similarity of independently acquired organs, 23I

Sirenia, 66

Slowness of modification by natural selection, 2I 5

Specialized fauna of the Silurian, 100

Species not definable, 32

Spencer, 5, 15, 73, 315

Spontaneous generation, 4,7

Steinheim Lake deposit, 46

Sterile insects, 237
Sterility, a variable quantity, 39 ; explanation of, 40

St. Helena, I 66

Summary of all the evidence, 20 , 203,232

Supernatural, 315

Synthetic types few in number of individuals, 102

\section{$\mathrm{T}$}

Tapir, 188

Teeth of ungulates, 268

Theistic evolution, 17

Thrush-tit, I 80

Tortoises of the Galapagos islands, I95

Transitional varieties wanting in most cases, 217

Tree-like arrangement of relations, 58

Troch osphere stage of mollusks and worms, 62

Tsetze fly, I66

Tyndall and spontaneous generation, 7

Types, number of, 60

$\mathrm{U}$

Ungulates, 66,268

Unity of the organic world, 58

Unspecialized, doctrine of the, 330

Use and effort, 262, 263

Uselessness of many characteristics, 219

\section{W}

Wagner, theory of migration, 247 Weissmann, theory of heredity 269

\section{Z}

Zoölogical regions, I 76 




STAMPED BELOW.

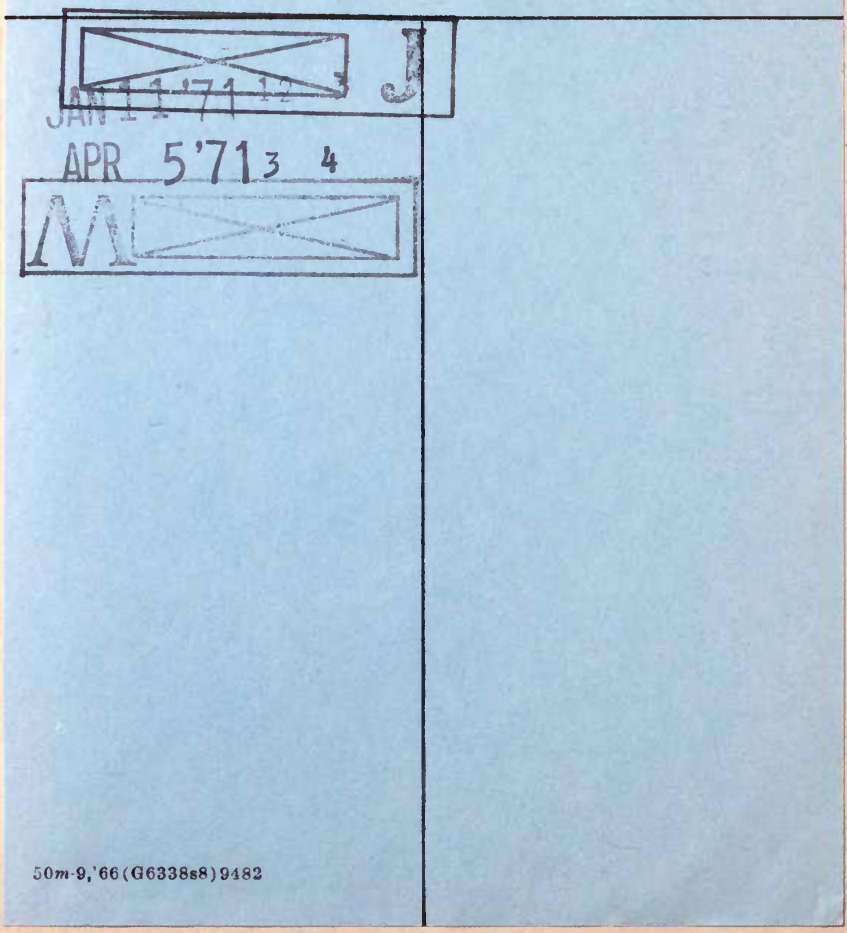


UC SOUTHERN REGIONAL. LIBRARY FACULTY 

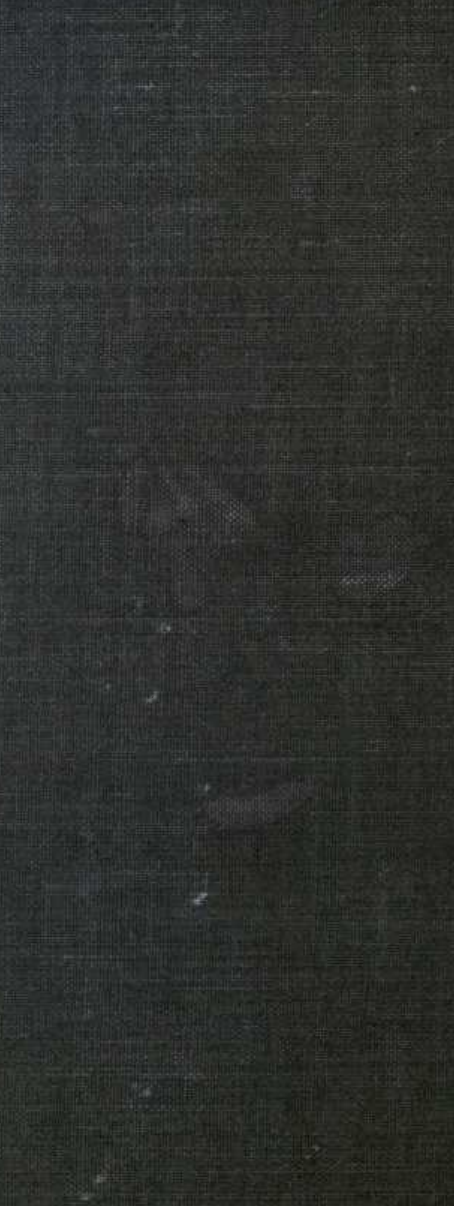